\title{
Recent developments in enantioselective cobalt-catalyzed transformations
}

\section{Hélène Pellissier}

Aix Marseille Univ, CNRS, Centrale Marseille, iSm2, Marseille, France

Transition metals

Asymmetric catalysis

Enantioselectivity

Chirality

Enantioselective transformations

\section{Contents}

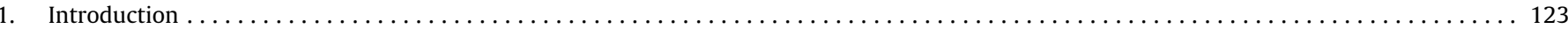

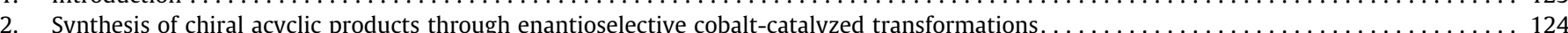

2.1. Ring-opening reactions . . . .

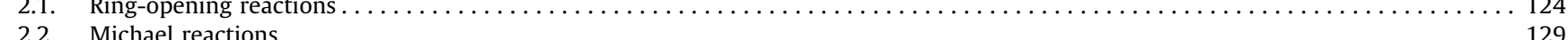

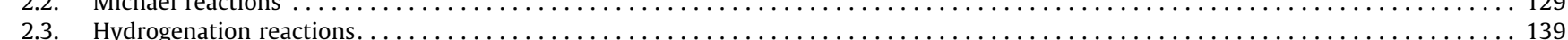

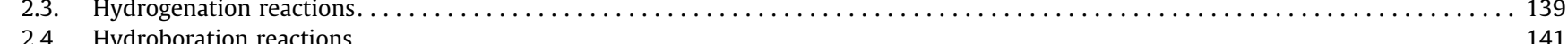

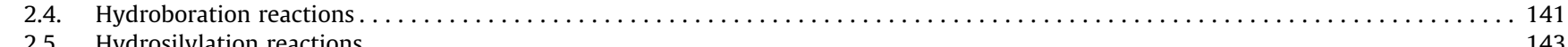

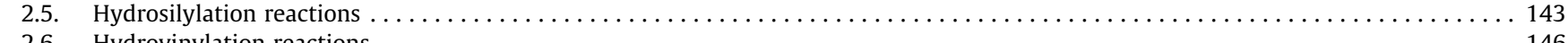

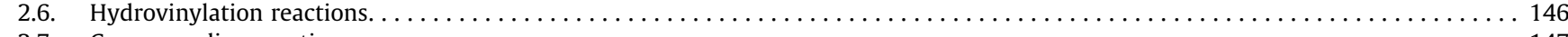

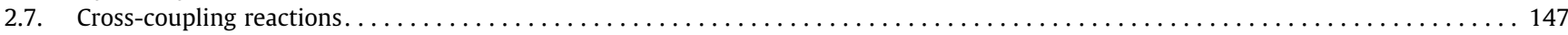

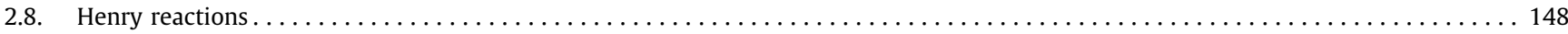

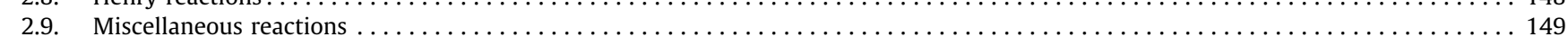

3. Enantioselective cobalt-catalyzed cyclization reactions

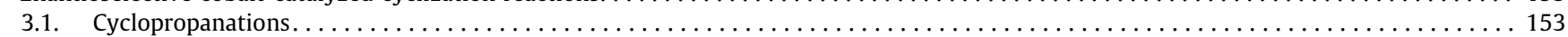

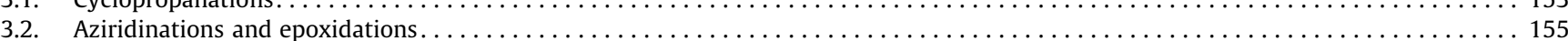

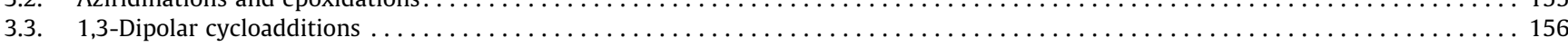

Abbreviations: Acac, acetylacetone; Ar, aryl; BDPP, 2,4-bis(diphenylphosphino)pentane; BINAP, 2,2'-bis(diphenylphosphino)-1,1'-binaphthyl; BINOL, 1,1'-bi-2-naphthol; Abbreviations: Acac, acetylacetone; Ar, aryl; BDPP, 2,4-bis(diphenylphosphino)pentane; BINAP, 2,2'-bis(diphenylphosphino)-1,1'-binaphthyl; BINOL, 1,1'-bi-2-naphthol;
Bn, benzyl; Boc, tert-butoxycarbonyl; Bz, benzoyl; Cbz, benzyloxycarbonyl; Cy, cyclohexyl; DCE, 1,2-dichloroethane; de, diastereomeric excess; DIOP, 2,3-O-isopropylidene2,3-dihydroxy-1,4-bis-(diphenylphosphino)butane; DIPEA, diisopropylethylamine; DMAP, 4-(N,N-dimethylamino)pyridine; DMF, dimethylformamide; DNP, 2,4-

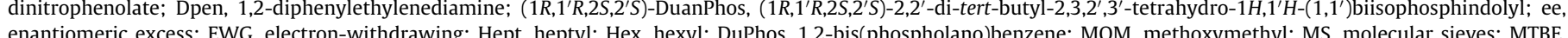
enantiomeric excess, EWG, electron-withdrawing; Hept, heptyl, Hex, hexyl; DuPhos, 1,2-bis(phospholano)benzene, MOM, methoxymethyl, MS, molecular sieves; MTBE, methyl ter-butl ether nyl]-N-[1-phes room to

E-mail address: h.pellissier@univ-amu.fr 
3.4. $[2+2+2]$ Cycloadditions .

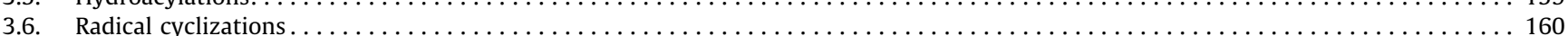

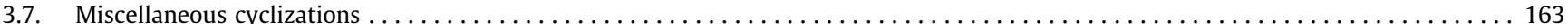

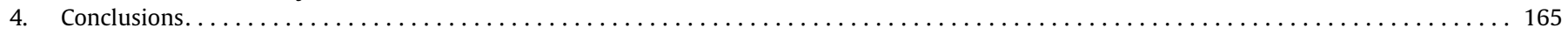

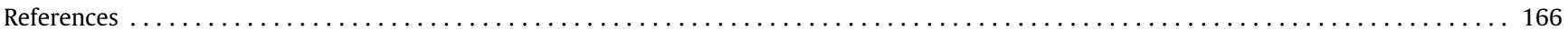

\section{Introduction}

The catalysis of organic reactions by metals still represents one of the most powerful tools in organic synthesis [1], with a special mention for asymmetric transition-metal catalysis allowing highly enantioselective reactions to be performed. Efforts to develop novel asymmetric transformations have focused for a long time on the use of metals, including palladium, rhodium, copper, irid-

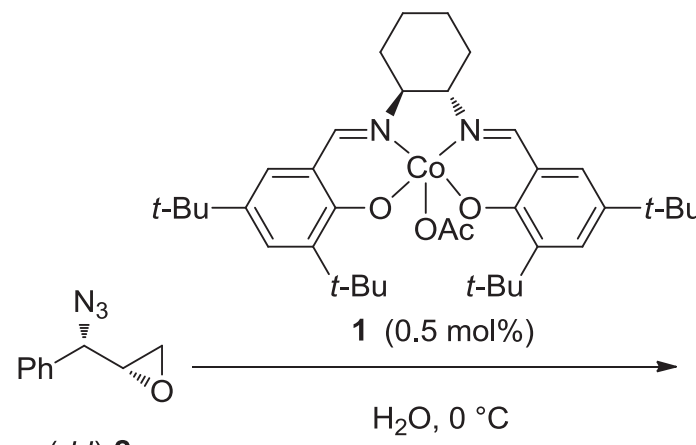

$(d, I)-2$<smiles>N[C@@H](c1ccccc1)[PH+]([NH3+])CO</smiles>

3
$(R, R)-2$

$48 \%$ yield, $98 \%$ ee $\quad 47 \%$ yield<smiles>FC(F)(F)c1cc(CO[C@H]2CCCN[C@H]2Pc2ccccc2)cc(C(F)(F)F)c1</smiles>

$(+)-L-733,060$<smiles>N[C@@H](COBr)C1CO1</smiles>

$(d, l)-4$

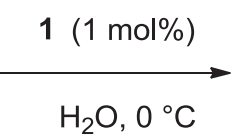

$\mathrm{H}_{2} \mathrm{O}, 0^{\circ} \mathrm{C}$<smiles>N[C@@H](CO)[C@@H](O)C[OH2+]</smiles>

5<smiles>N[C@@H](COc1ccccc1)C1CO1</smiles>

$(S, R)-4$

$50 \%$ yield, $99 \%$ ee $\quad 48 \%$ yield, $97 \%$ ee<smiles>OC[C@H]1NC[C@@H](O)[C@@H]1O</smiles>

DAB-1

Scheme 1. Hydrolytic kinetic resolutions of azido epoxides catalyzed with a salen cobalt complex and total syntheses of (+)-L-733,060 and DAB-1 [15,16]. 
ium and ruthenium. Nevertheless, by the very fact of the lower costs and toxicity of cobalt catalysts in comparison with other transition metals, more ecologic and economic cobalt-catalyzed transformations have received a growing attention in the last two decades. This interest might be related to the early successes of the Pauson-Khand reaction, $[2+2+2]$ cycloadditions, or the Nicholas reaction among other transformations. These works have translated in the development of many novel transformations, such as cyclopropanations through diazo transfer among other cycloadditions, and carbon-carbon bond-forming reactions including carbon-hydrogen bond activation methodologies. In the area of asymmetric cobalt-catalyzed reactions, a number of novel methodologies have been recently reported based on the impressive ability of cobalt catalysts to adopt unexpected reaction pathways to reach new chiral acyclic as well as cyclic products under relatively mild conditions. For example, enantioselective cobalt-mediated domino reactions, Michael additions, Henry reactions, hydrovinylations, ring-opening reactions of epoxides, hydrogenations of alkenes and ketones, hydroborations, hydrosilylations, cross-coupling reactions, various cycloadditions, hydroacylations, and miscellaneous reactions have been recently described. The goal of this review is to collect the major developments in all types of enantioselective cobalt-catalyzed transformations published since the beginning of 2014, since this field was most recently reviewed in 2014 [2]. Previous to 2014, this field has been reviewed by various authors [3-6]. It must be noted that a Synthesis special topic dedicated to cobalt in organic synthesis was recently published [7]. However, it includes only one example of enantioselective cobalt-catalyzed transformation along with a mini-review focussing on cross- couplings among which only one enantioselective example reported in 2014. Moreover, Gladysz and co-workers recently reported a specific review on hydrogen bonding motifs in structurally characterized salts of the tris(ethylenediamine)cobalt trication, but it included only structural informations and no catalytic applications [8]. The present review is divided into two parts, dealing successively with the synthesis of chiral acyclic products through enantioselective cobalt-catalyzed transformations, and enantioselective cobalt-catalyzed cyclization reactions.

\section{Synthesis of chiral acyclic products through enantioselective cobalt-catalyzed transformations}

\subsection{Ring-opening reactions}

Catalytic kinetic resolutions [9] constitute useful tools in asymmetric catalysis, complementing other approaches to chiral products, such as asymmetric synthesis and classical resolution [10]. A wide number of reactions evolving through kinetic resolution have been developed with high efficiency, such as nucleophilic ring-opening reactions of racemic epoxides [11]. For example, the hydrolytic kinetic resolution constitutes the simplest methodology for the synthesis of enantiopure epoxides and diols [12]. The process, early reported by Jacobsen and co-workers in 1997, was used to synthesize terminal epoxides along with the corresponding chiral diols [13]. This methodology employed water as the sole reagent, small amounts of solvent and often low loadings (0.2-2 mol\%) of recyclable chiral cobalt(III)-based complexes. This methodology has allowed many building blocks for the synthesis

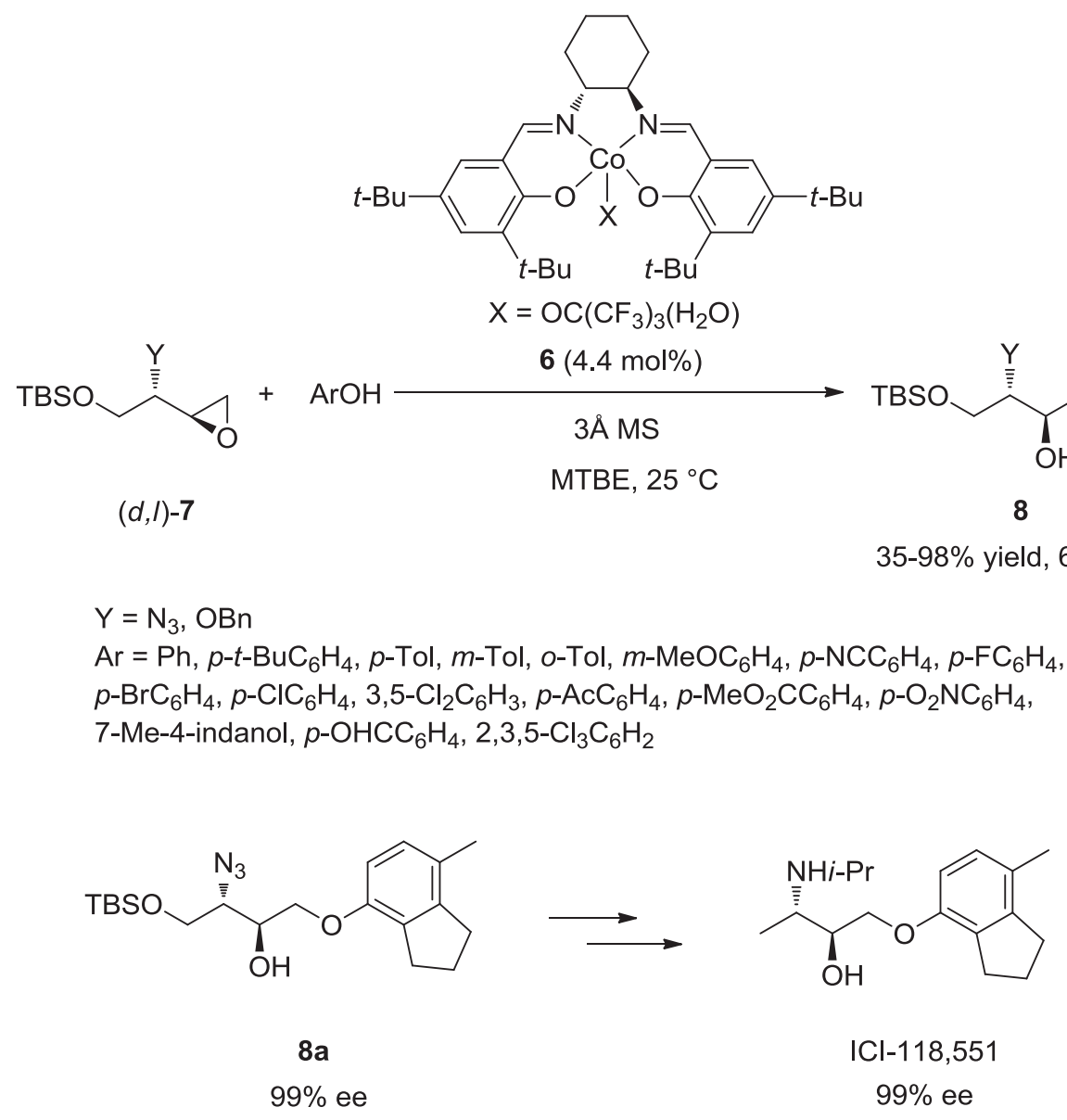

Scheme 2. Phenolic ring-opening of azido and benzyloxy epoxides catalyzed with a salen cobalt complex and total synthesis of ICI-118,551 [17]. 
of complex natural products and pharmaceuticals to be prepared [14]. For example, an hydrolytic kinetic resolution based on the use of Jacobsen's chiral salen $\mathrm{Co}$ (III) complexes, such as catalyst 1, was recently applied by Sudalai and co-workers to a concise enantioselective synthesis of (+)-L-733,060, a potent and selective nerokinin-1 substance $P$ receptor antagonist [15]. As shown in Scheme 1, this synthesis began with the hydrolytic kinetic resolution of racemic azido epoxide 2 with water performed in the pres- ence of only $0.5 \mathrm{~mol} \%$ of $(S, S)$-salen-cobalt(III) acetate complex $\mathbf{1}$, which afforded the corresponding diol 3 in 48\% yield and 98\% ee, along with recovered $(R, R)$-epoxide 2 in $47 \%$ yield. Subsequently, diol 3 was converted through eight supplementary steps into (+)L-733,060 in 19\% overall yield. Later in 2017, the same authors described a total synthesis of the naturally occurring and biologically active alkaloid DAB-1 the key step of which was the hydrolytic kinetic resolution of another racemic azido epoxide $\mathbf{4}$ promoted

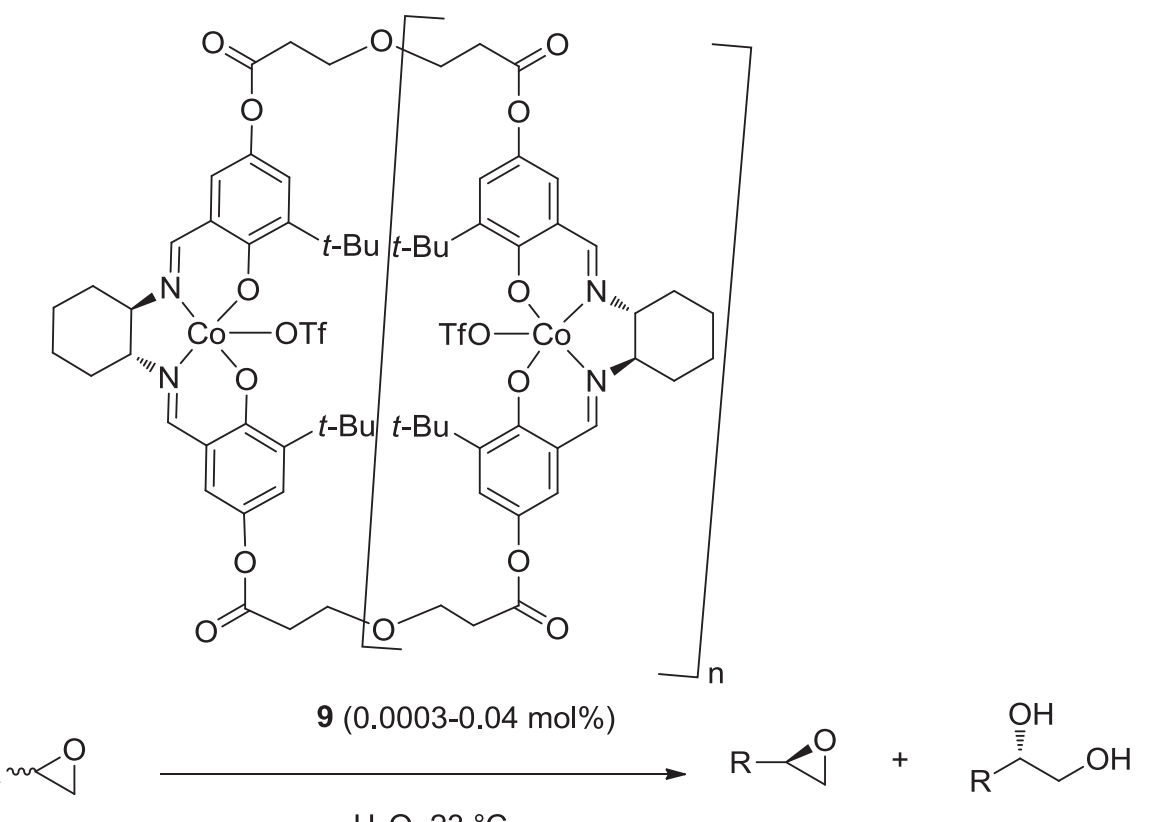

10

$\mathrm{H}_{2} \mathrm{O}, 23^{\circ} \mathrm{C}$

(S)-10

$35-44 \%$ yield, $>99 \%$ ee

$\mathrm{R}=\mathrm{Me}, \mathrm{CH}_{2} \mathrm{Cl}, \mathrm{CH}_{2} \mathrm{Oallyl}, \mathrm{CO}_{2} \mathrm{Me}, \mathrm{CH}=\mathrm{CH}_{2}, \mathrm{Ph}$

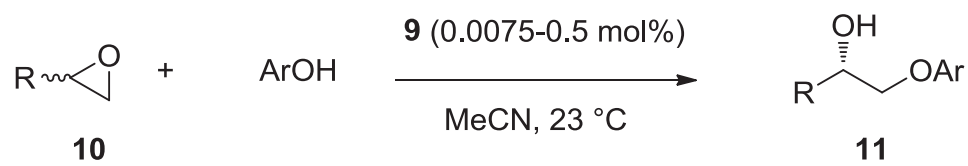

79->99\% yield, $97->99 \%$ ee

$\mathrm{R}=\mathrm{Me}, n-\mathrm{Bu}, \mathrm{CH}_{2} \mathrm{Cl}, \mathrm{CH}_{2} \mathrm{Oallyl}, \mathrm{Ph}, \mathrm{CO}_{2} \mathrm{Me}$

$\mathrm{Ar}=\mathrm{Ph}, o-\mathrm{ClC}_{6} \mathrm{H}_{4}, o-\mathrm{BrC}_{6} \mathrm{H}_{4}, o-\mathrm{Tol}, m-\mathrm{AcC}_{6} \mathrm{H}_{4}, m-\mathrm{Tol}, p-\mathrm{O}_{2} \mathrm{NC}_{6} \mathrm{H}_{4}, p-\mathrm{MeOC}_{6} \mathrm{H}_{4}$, $p-\mathrm{BrC}_{6} \mathrm{H}_{4}, p-\mathrm{Tol}, 2-\mathrm{Cl}-6-\mathrm{MeC}_{6} \mathrm{H}_{3}$,

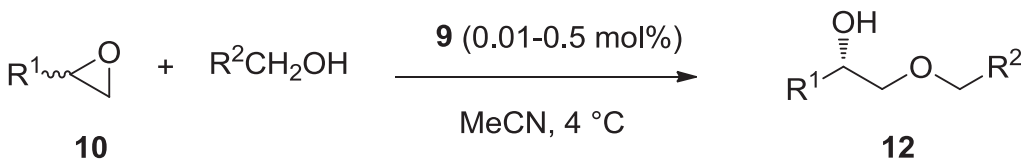

$80->99 \%$ yield, $97->99 \%$ ee

$$
\begin{aligned}
& \mathrm{R}^{1}=\mathrm{Me}, n-\mathrm{Bu}, \mathrm{CH}_{2} \mathrm{OBn}, \mathrm{CH}_{2} \mathrm{Cl}, \mathrm{CO}_{2} \mathrm{Me}, \mathrm{Ph} \\
& \mathrm{R}^{2}=\mathrm{Ph}, p-\mathrm{MeOC}_{6} \mathrm{H}_{4}, \mathrm{H}, o-\mathrm{BrC}_{6} \mathrm{H}_{4}, \mathrm{CH}=\mathrm{CH}_{2}, o-\mathrm{O}_{2} \mathrm{NC}_{6} \mathrm{H}_{4}, \mathrm{CH}_{2} \mathrm{TMS}
\end{aligned}
$$


by $1 \mathrm{~mol} \%$ of the same catalyst $\mathbf{1}$ [16]. This provided the corresponding almost enantiopure azido diol $\mathbf{5}$ in 50\% yield which was further converted into expected DAB-1 through five supplementary steps in $18 \%$ overall yield.

A related catalyst $\mathbf{6}$ was employed by the same authors to the phenolic ring-opening of racemic azido $\left(\mathrm{Y}=\mathrm{N}_{3}\right)$ and benzyloxy $(\mathrm{Y}=\mathrm{OBn}$ ) epoxides [17]. As depicted in Scheme 2, the reaction of a range of racemic anti-azido and -benzyloxy epoxides 7 with variously substituted phenols in the presence of $4.4 \mathrm{~mol} \%$ of catalyst 6 in MTBE as solvent led at $25^{\circ} \mathrm{C}$ to the corresponding chiral anti-1aryloxy-3-azido or benzyloxy-2-alcohols $\mathbf{8}$ in generally excellent yields of up to $98 \%$ and enantioselectivities of up to $99 \%$ ee. In the case of azido epoxides as substrates, a wide range of phenols bearing either electron-donating or electron-withdrawing groups reacted efficiently, delivering the corresponding products in good to high yields and enantioselectivities, whereas benzyloxy epoxides underwent the reaction only with electron-deficient phenols. The utility of this methodology was demonstrated in its application to a total synthesis of the $\beta$-blocker ICI-118,551 by using enantiopure anti-1-aryloxy-3-azido product 8a (99\% ee) as intermediate (Scheme 2).

The recognition that the hydrolytic kinetic resolution and related epoxide ring-opening reactions proceed via cooperative bimetallic mechanisms, in which both the epoxide and the nucleophile are activated through separate salen cobalt complexes in the rate-limiting step [18], has prompted the development of a

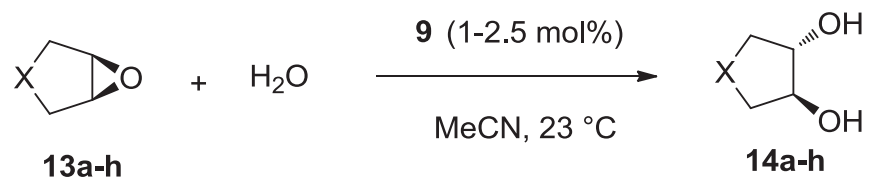

$76->99 \%$ yield, $72-99 \%$ ee

$\mathrm{X}=\mathrm{CH}_{2},\left(\mathrm{CH}_{2}\right)_{2},\left(\mathrm{CH}_{2}\right)_{3}, \mathrm{CH}_{2} \mathrm{CH}=\mathrm{CHCH}_{2}, \mathrm{O}, \mathrm{NBoc}, \mathrm{CH}\left(\mathrm{CO}_{2} \mathrm{Et}\right), \mathrm{CH}=\mathrm{CH}$

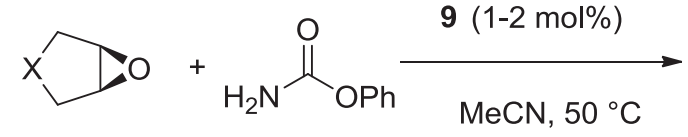

$13 a-b$

$84-94 \%$ yield, $96 \%$ ee

$$
\mathrm{X}=\left(\mathrm{CH}_{2}\right)_{2}, \mathrm{CH}=\mathrm{CH}
$$

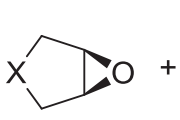

$13 c-d$

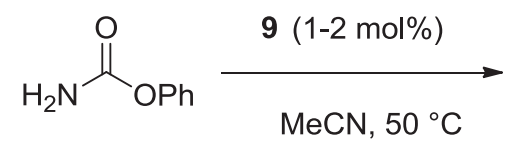

$49-66 \%$ yield, $>99 \%$ ee

$\mathrm{X}=\mathrm{CH}_{2}, \mathrm{O}$<smiles>O=C1N[C@H]2CC[C@H]2O1</smiles>

15a-b<smiles>[X]C[C@H](O)[C@H]1CC[C@H]1NC(=O)Oc1ccccc1</smiles>

16c-d

Scheme 4. Hydrolytic and carbamolytic desymmetrizations of meso-epoxides catalyzed with an oligomeric salen cobalt complex [19].<smiles></smiles><smiles>O[CH+]1CC1CBr</smiles>

17

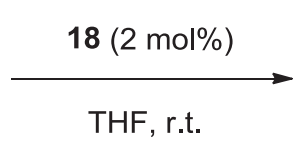

THF, r.t.<smiles>OC[C@@H](O)CBr</smiles>

19

$>99 \%$ conversion, $92 \%$ ee

Scheme 5. Hydrolytic ring-opening of epibromohydrin catalyzed with a tetrameric calix-salen cobalt complex [20]. 
wide variety of linked multi-salen cobalt catalysts. For example, Jacobsen and co-workers have reported the synthesis of novel cyclic oligomeric salen cobalt catalysts to be applied to promote the hydrolytic kinetic resolution of terminal epoxides [19]. Among them, oligomeric chiral complex $\mathbf{9}$ employed at remarkably low catalyst loadings $(0.0003-0.04 \mathrm{~mol} \%)$ was selected as optimal catalyst to prepare at $23^{\circ} \mathrm{C}$ a series of enantiopure terminal epoxides (S)-10 in moderate yields (35-44\%) starting from the corresponding racemic ones (Scheme 3). The efficiency of this catalyst was also applied to the regioselective phenolytic ring-opening of terminal epoxides performed at the same temperature in acetonitrile (Scheme 3). Indeed, the ring-opening of epoxides $\mathbf{1 0}$ with phenols bearing a broad range of electron-withdrawing and electrondonating substituents at the ortho, meta, and para positions was accomplished with catalyst loadings lower than $0.1 \mathrm{~mol} \%$ in nearly all cases. The corresponding chiral alcohols $\mathbf{1 1}$ were formed in uniformly excellent yields (79-99\%) and enantioselectivities (97->99\% ee). Moreover, the regioselective ring-opening of

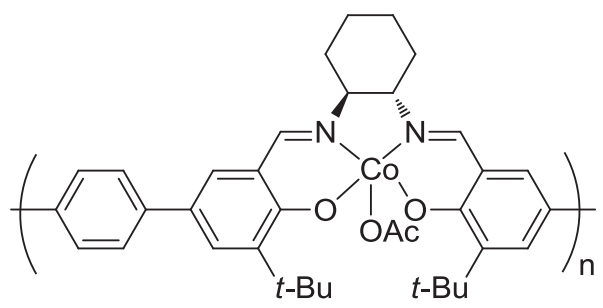

$20(1 \mathrm{~mol} \%)$

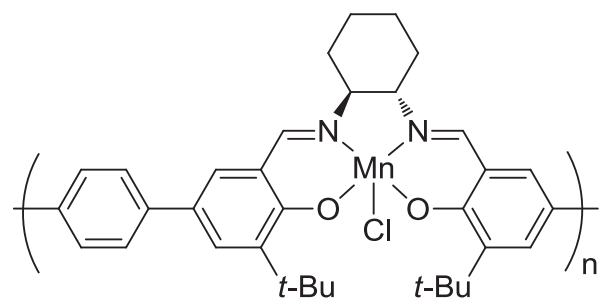<smiles>O[C+]1CC1CBr</smiles>

17

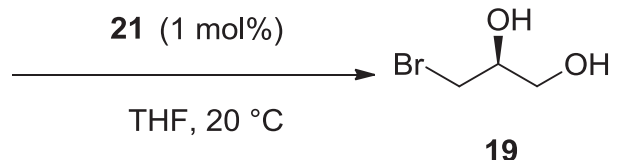

$97 \%$ yield, $92 \%$ ee

Scheme 6. Hydrolytic ring-opening of epibromohydrin catalyzed with a combination of oligomeric calix-salen cobalt and manganese catalysts [21].

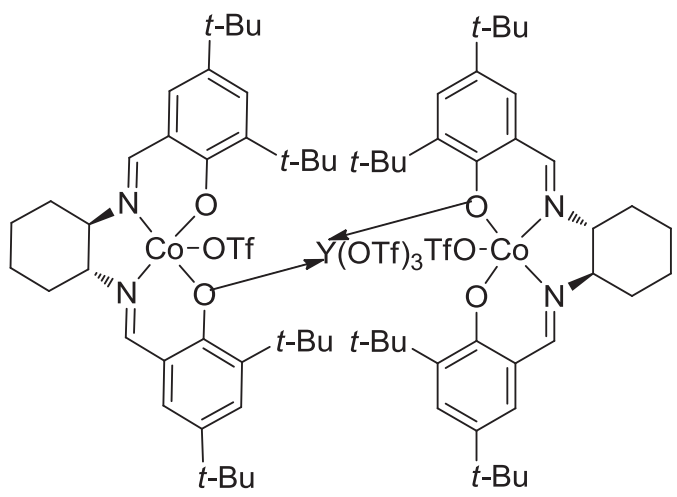

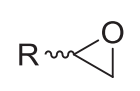

10

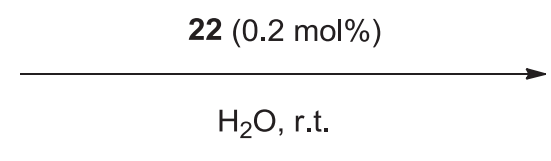

$\mathrm{H}_{2} \mathrm{O}$, r.t.<smiles>[R]C(O)CO</smiles>

$(S)-10$

$42-46 \%$ yield, $97->99 \%$ ee

\author{
$\mathrm{R}=\mathrm{CH}_{2} \mathrm{Cl}, \mathrm{Me}, n-\mathrm{Bu}, \mathrm{CH}_{2} \mathrm{OMe}, \mathrm{CH}_{2} \mathrm{O}$ i-Pr, $\mathrm{CH}_{2} \mathrm{OCO}$ - $\mathrm{Pr}$, \\ $\mathrm{CH}_{2} \mathrm{O}\left(p-\mathrm{CHOC}_{6} \mathrm{H}_{4}\right), \mathrm{CH}_{2} \mathrm{O}(2-\mathrm{Naph})$
}

Scheme 7. Hydrolytic kinetic resolution of terminal epoxides catalyzed with a dinuclear salen cobalt complex incorporating $\mathrm{Y}(\mathrm{OTf})_{3}[22]$. 
terminal epoxides $\mathbf{1 0}$ with aliphatic alcohols could be performed under comparable reaction conditions, providing a range of chiral monoprotected 1,2-diols 12 in high to quantitative yields (80$>99 \%$ ) and remarkable enantioselectivities (97->99\% ee), as shown in Scheme 3.

The hydrolysis of meso-epoxides derived from cyclic alkenes represents an attractive approach to chiral diols that are not accessible via asymmetric alkene dihydroxylation. In this context, the same authors showed that oligomeric salen cobalt complex 9 employed at 1 or $2.5 \mathrm{~mol} \%$ of catalyst loading was a highly efficient catalyst in the hydrolytic desymmetrization of a variety of cyclic meso-epoxides 13a-h (Scheme 4) [19]. Indeed, the corresponding chiral trans-1,2-diols 14a-h were obtained in good to quantitative yields (76->99\%) and generally excellent enantioselectivities (96$99 \%$ ee). A lower enantioselectivity of $72 \%$ ee was observed in the case of a seven-membered substrate $\left(\mathrm{X}=\left(\mathrm{CH}_{2}\right)_{3}\right)$. In addition, the carbamolytic desymmetrization of several cyclic meso-epoxides 13a-b through ring-opening reaction with phenyl carbamate could be achieved at $50^{\circ} \mathrm{C}$ by using $1-2 \mathrm{~mol} \%$ of the same oligomeric catalyst (Scheme 4). Starting from six-membered substrates 13a-b, the reaction led to the corresponding trans-4,5-disubstituted oxazolidinones 15a-b in high yields (84-94\%) and excellent enantioselectivity $(96 \%$ ee) through successive ring-opening and intramolecular cyclization, while five-membered substrates 13cd $\left(\mathrm{X}=\mathrm{O}, \mathrm{CH}_{2}\right)$ provided the corresponding ring-opened products 16c-d in moderate yields (49-66\%) albeit with remarkable enantioselectivity ( $>99 \%$ ee). Even if the reaction of six-membered substrates 13a-b led to cyclic products, it was decided to situate these results in this section since they belong to a study mainly dedicated to acyclic products.

The synthesis of another type of oligomeric salen cobalt complexes was reported by Schulz and co-workers, in 2014 [20]. These chiral calix-salen cobalt complexes were investigated as catalysts to promote the asymmetric hydrolytic ring-opening of epibromohydrin 17. As illustrated in Scheme 5, the use of optimal cyclic tetramer complex 18 at $2 \mathrm{~mol} \%$ of catalyst loading in THF at room temperature allowed through dynamic kinetic resolution the corresponding diol 19 to be obtained with complete conversion $(>99 \%)$ and high enantioselectivity (92\% ee). Importantly, the catalyst could be easily recovered from the reaction mixture by simple filtration and reused in other runs to produce the diol with steady enantioselectivity (89-95\% ee) albeit with decreased conversions (63-95\%).

Later in 2016, the same authors reinvestigated this reaction by using a combination of chiral oligomeric cobalt- and manganesebased calix-salen complexes as catalysts [21]. As shown in Scheme 6 , when the asymmetric ring-opening of epibromohydrin 17 was performed at room temperature in THF as solvent in the presence of $1 \mathrm{~mol} \%$ of cobalt catalyst $\mathbf{2 0}$ and the same quantity of manganese catalyst 21, it afforded the corresponding chiral diol 19 in both excellent yield (97\%) and enantioselectivity (92\% ee). In this study, the authors showed that using an equimolar combination of these chiral catalysts proved to be more enantioselective than using the sole cobalt system. Furthermore, as heterogeneous complexes, the catalytic mixture could be easily recovered by simple filtration and reused in up to eight runs with reasonable stability in terms of activity (82-97\% conversion) and enantioselectivity (82-90\% ee).

In 2015, Thakur and co-workers reported the synthesis of dinuclear salen cobalt complex 22 incorporating $\mathrm{Y}(\mathrm{OTf})_{3}$ which was further investigated as chiral catalyst in the hydrolytic kinetic resolution of terminal epoxides 10 [22]. Employed at only 0.2 mol\% of catalyst loading, it provided higher reactivity and enantioselectivity than its monomer analogue since a range of terminal epoxides $(S)-\mathbf{1 0}$ could be recovered with uniformly excellent enantioselectivities (97->99\% ee) and moderate yields (42-46\%), as shown in Scheme 7. One advantage of this catalyst was related to its water tolerance related to the moisture stability of $\mathrm{Y}(\mathrm{OTf})_{3}$.

In 2015, Sun and co-workers described the synthesis of novel macroporous helical silica-supported salen cobalt complexes to be investigated in water as chiral catalysts in the same reactions [23]. Among them, catalyst $\mathbf{2 3}$ prepared from an (S)-amino alcohol-doped silica and a Co- $(R, R)$-salen complex was found optimal catalyst when used at $2 \mathrm{~mol} \%$ of catalyst loading in the presence of $n-\mathrm{Bu}_{4} \mathrm{NBr}$ as an additive. These conditions allowed the recovering of chiral 1,2-epoxybutane $(R)-\mathbf{1 0 a}(\mathrm{R}=\mathrm{Et})$ in moderate yield (46\%) and high enantioselectivity (91\% ee) along with the formation of the corresponding chiral diol 24a in comparable yield

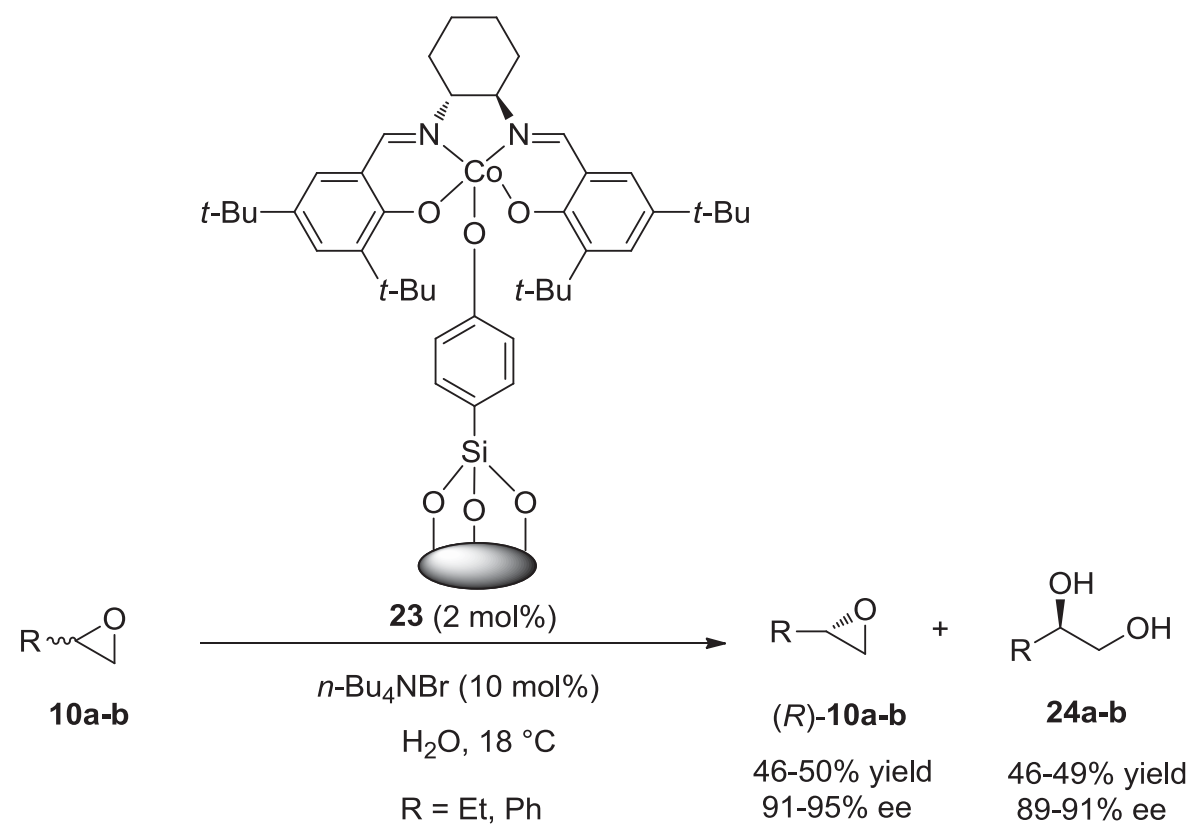

Scheme 8. Hydrolytic kinetic resolution of terminal epoxides catalyzed with a macroporous helical silica-supported salen cobalt complex [23]. 
(49\%) and enantioselectivity (91\% ee), as shown in Scheme 8. Moreover, styrene oxide $10 \mathrm{~b}(\mathrm{R}=\mathrm{Ph})$ was also compatible with the catalyst system, providing the recovered chiral epoxide $(R)-\mathbf{1 0 b}$ in $50 \%$ yield and $95 \%$ ee along with the corresponding diol $\mathbf{2 4 b}$ in $46 \%$ yield and $89 \%$ ee.

In 2016, mesoporous silica-supported salen cobalt complex 25 was designed by Islam and Bhaumik [24]. This material showed an excellent catalytic activity for the regio- and enantioselective asymmetric ring-opening of terminal epoxides $\mathbf{1 0}$ using aromatic as well as cyclic aliphatic amines to produce the corresponding chiral $\beta$-amino alcohols $\mathbf{2 6}$ at ambient temperature under solvent-free conditions. As shown in Scheme 9, these products were achieved in uniformly excellent yields (92-98\%) and enantioselectivities (87$>99 \%$ ee). The scope of the process was extended to meso-epoxides such as 13a, which led to the corresponding chiral products 27 with high yields (87-97\%) and good to excellent enantioselectivities (77->99\% ee). The advantages of this novel heterogeneous catalyst are its easy separation, recyclability and reusability for up to five times without loss in both activity ( $\geq 85 \%$ yield) and enantioselectivity ( $\geq 88 \%$ ee).

The desymmetrization of meso-epoxides through copolymerization with $\mathrm{CO}_{2}$ using chiral catalysts constitutes a valuable strategy for the synthesis of chiral polycarbonates with main-chain chirality. In this context, Lu and co-workers have investigated the asymmetric cobalt-catalyzed copolymerization of meso-epoxide 13a with $\mathrm{CO}_{2}$ to give the corresponding chiral polycarbonates $\mathbf{2 8}$ exhibiting a complete alternating structure (Scheme 10) [25]. The latter were obtained with enantioselectivities of up to $98 \%$ ee when the reaction was catalyzed by $10 \mathrm{~mol} \%$ of dinuclear salen cobalt complex 29 in toluene at $0{ }^{\circ} \mathrm{C}$ in the presence of $20 \mathrm{~mol} \%$ of bistriphenylphosphine iminium 2,4-dinitrophenolate (PPN-DNP) as ionic additive. The presence of this additive bearing a bulky cation was found to significantly improve both the catalytic activity and enantioselectivity of the reaction.

\subsection{Michael reactions}

The conjugate additions of nucleophiles to electron-poor alkenes constitute a powerful tool in organic synthesis, allowing carbon-carbon and carbon-heteroatom bond-forming reactions to be easily achieved [26]. Consequently, many different versions of these transformations including asymmetric ones have been developed, using a wide variety of conjugate acceptors, nucleophiles, and catalysts [27]. Among the latter, chiral cobalt catalysts have
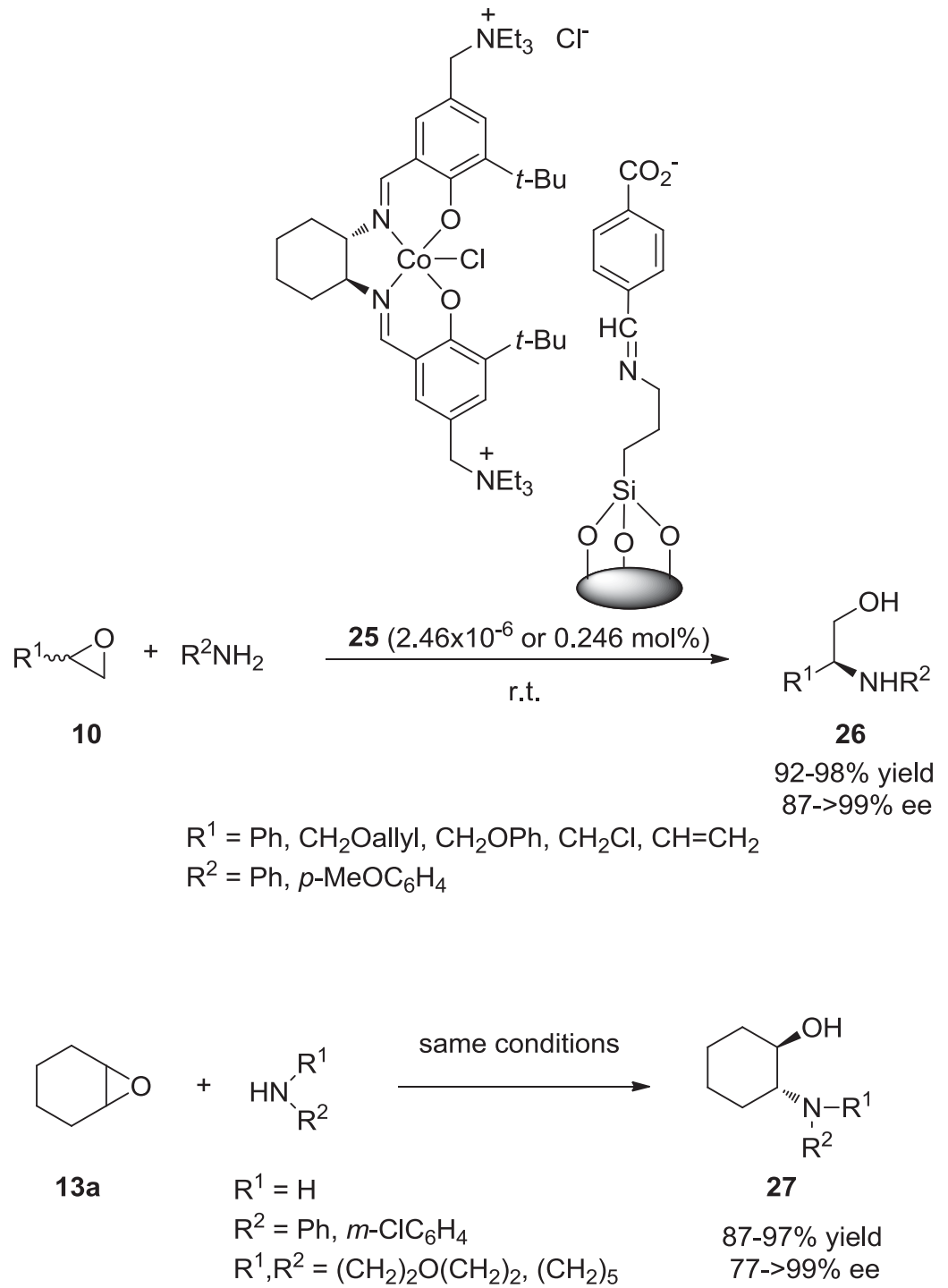

Scheme 9. Aminolysis of epoxides catalyzed with a macroporous silica-supported salen cobalt complex [24]. 


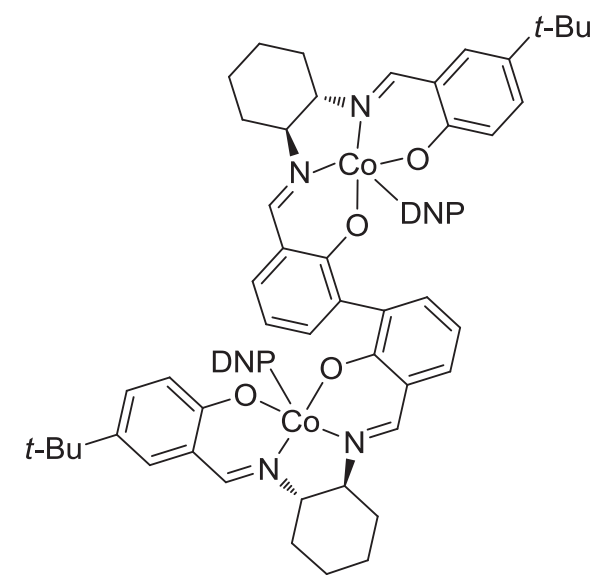

$29(10 \mathrm{~mol} \%)$

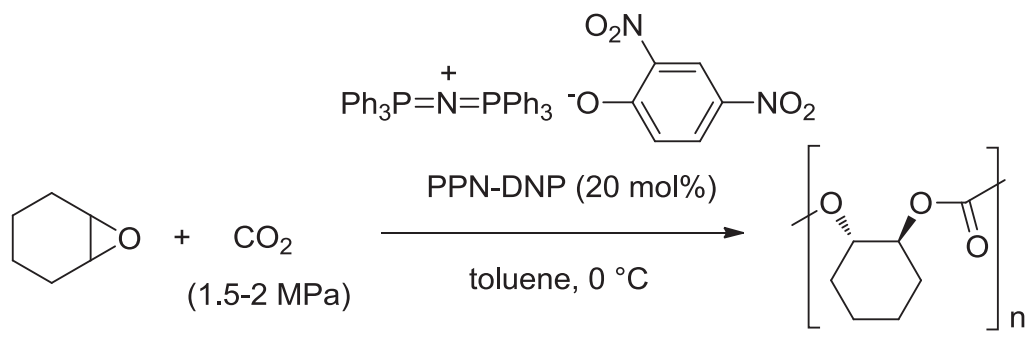

$13 a$

28

$>99 \%$ carbonate linkages, $98 \%$ ee

Scheme 10. Copolymerization of meso-cyclohexene with $\mathrm{CO}_{2}$ catalyzed with a dinuclear salen cobalt catalyst [25].
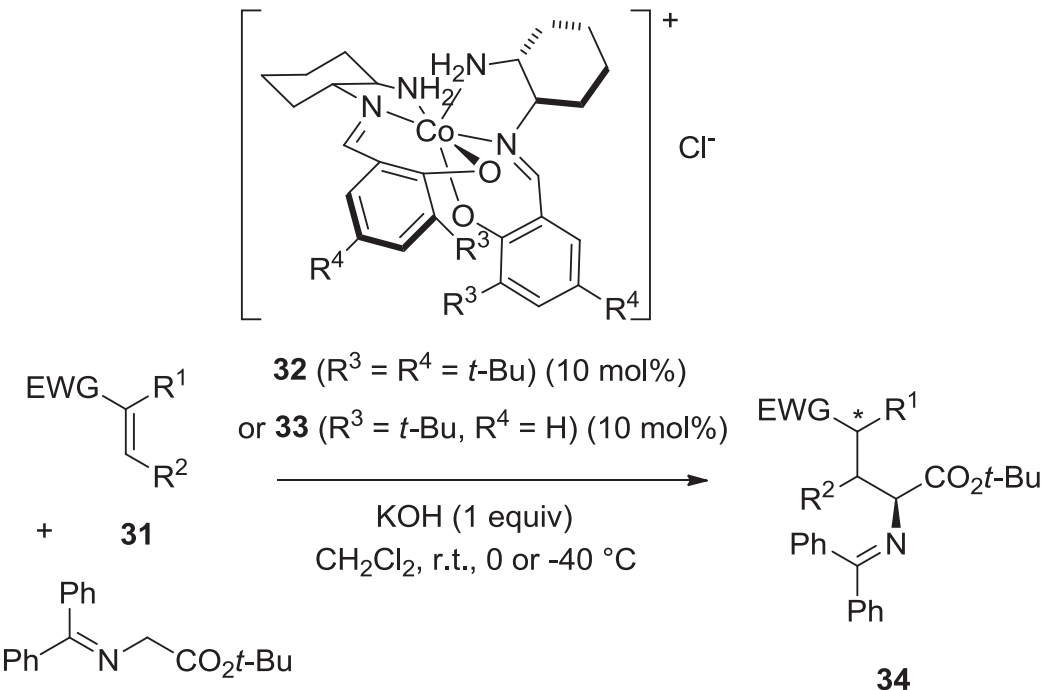

30

$70-97 \%$ yield, $34->99 \%$ de, $60-96 \%$ ee

$\mathrm{EWG}=\mathrm{CO}_{2} \mathrm{Me}, \mathrm{CO}_{2} t-\mathrm{Bu}, \mathrm{CO}_{2} \mathrm{Et}, \mathrm{CN}, \mathrm{Ac}, \mathrm{Bz}$

$\mathrm{R}^{1}=\mathrm{H}, \mathrm{Me}$

$\mathrm{R}^{2}=\mathrm{H}, \mathrm{CF}_{3}, \mathrm{Ph}$

$\mathrm{R}^{1}, \mathrm{R}^{2}=\left(\mathrm{CH}_{2}\right)_{4}$

$\mathrm{R}^{2}, \mathrm{EWG}=\left(\mathrm{CH}_{2}\right)_{3} \mathrm{CO}$

Scheme 11. Michael addition of a glycine Schiff base to activated olefins [32]. 
provided excellent results since the pioneering works reported by Brunner et al. in which a catalytic system, in situ generated from $\mathrm{Co}(\mathrm{acac})_{2}$ and (+)-1,2-diphenylethylenediamine as chiral ligand, was found to promote the addition of methyl 1-oxo-2indanecarboxylate to methylvinylketone with enantioselectivity of up to $66 \%$ ee [28]. However, attempts to improve the enantioselectivity of the Michael addition of 1,3-dicarbonyl compounds by involving other chiral ligands, such as alkaloid or salicylaldimine derivatives [28b,c], proline-based ligands [29], or spirobiindane-containing ligands [30] were unsuccessful for many

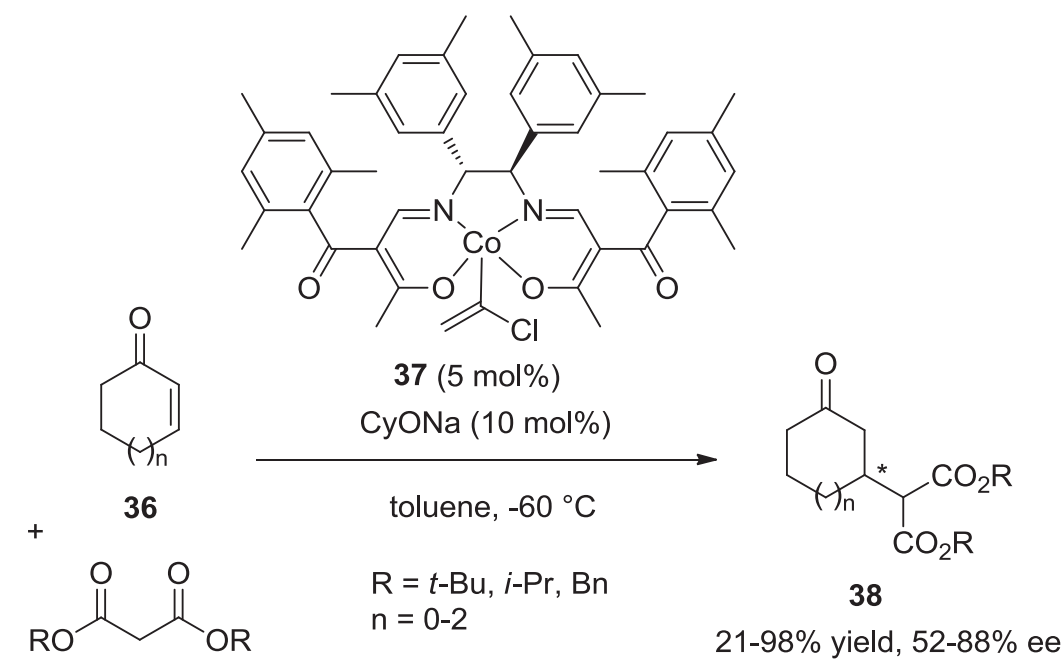

35

Scheme 12. Michael addition of malonates to cyclic $\alpha, \beta$-unsaturated ketones [33].<smiles>[R11]CNC(=O)C1Cc2cc[R11](C)cc2C1=O</smiles>

41<smiles></smiles>

42<smiles>[R][R3]NC(=O)[C@H]1CCCC[N+]1([O-])CCC[N+]1([O-])CCCCC1C(N)=O</smiles>

$39\left(\mathrm{R}^{3}=2,6-\mathrm{Et}_{2} \mathrm{C}_{6} \mathrm{H}_{3}\right)(12 \mathrm{~mol} \%)$ or $\mathbf{4 0}\left(\mathrm{R}^{3}=2,6-i-\mathrm{Pr}_{2} \mathrm{C}_{6} \mathrm{H}_{3}\right)(12 \mathrm{~mol} \%)$ $\mathrm{Co}\left(\mathrm{BF}_{4}\right)_{2}\left(6 \mathrm{H}_{2} \mathrm{O}\right)(10 \mathrm{~mol} \%)$

4Å MS

$\mathrm{CH}_{2} \mathrm{Cl}_{2}, 0^{\circ} \mathrm{C}$<smiles>[R][R]1ccc2c(c1)C(=O)[C@@](/C=C/C(=O)c1ccccc1)(C(N)=O)C2</smiles>

43

with 39:

$92-99 \%$ yield, $Z / E=65: 35$ to $78: 22$

$84-93 \%$ ee $(Z), 69-85 \%$ ee $(E)$

with 40:

$80-98 \%$ yield, $Z / E=52: 48$ to $68: 32$

$93-97 \%$ ee $(Z), 92-97 \%$ ee $(E)$

$\mathrm{R}^{1}=\mathrm{H}, 5-\mathrm{F}, 5-\mathrm{Br}, 6-\mathrm{Me}, 6-\mathrm{Cl}, 6-\mathrm{F}$

$\mathrm{R}^{2}=\mathrm{H}, 4-\mathrm{Me}, 3-\mathrm{CF}_{3}, 4-\mathrm{CF}_{3}$, 4-OMe

Scheme 13. Michael addition of $\beta$-ketoamides to alkynones [34]. 
years. It is only in 1998 that enantioselectivities of up to $89 \%$ ee were reported by Pfaltz and co-workers by using tert-butylsubstituted chiral bisoxazoline oxalamide ligands to promote the Michael addition of malonates to chalcone [31]. Ever since, various types of chiral cobalt catalysts have been applied to promote enantioselective additions of different types of nucleophiles to $\alpha, \beta$-unsaturated carbonyl compounds as well as nitroolefins. Concerning Michael additions to $\alpha, \beta$-unsaturated carbonyl compounds, Belokon and co-workers have recently reported enantioselectivities of up to $96 \%$ ee in the enantioselective Michael addition of glycine Schiff base $\mathbf{3 0}$ to activated olefins $\mathbf{3 1}$ promoted by positively charged chiral cobalt(III) complexes, such as $\mathbf{3 2}$ or $\mathbf{3 3}$, prepared from Schiff bases derived from chiral diamines and salicylaldehydes [32]. As shown in Scheme 11, the process performed in the presence of $\mathrm{KOH}$ as base led to the corresponding chiral Michael products 34 in good to quantitative yields (70-97\%), low to complete diastereoselectivities ( $34->99 \%$ de), and moderate to high enantioselectivities (60-96\% ee). In addition to $\alpha, \beta$-unsaturated esters, $\alpha, \beta$-unsaturated nitriles and $\alpha, \beta$-unsaturated ketones were compatible with the reaction conditions.

Later in 2015, Yamada and Tsubo described the enantioselective Michael addition of various dialkyl malonates $\mathbf{3 5}$ to cyclic

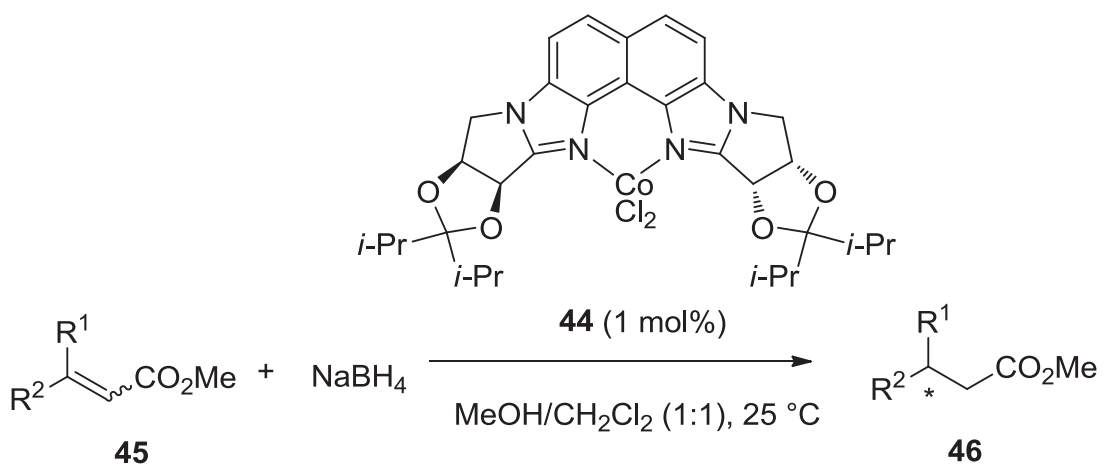

$72-98 \%$ yield, $84->98 \%$ ee

$\mathrm{R}^{1}=\mathrm{Me}, \mathrm{Et}, i-\mathrm{Pr}, c-\mathrm{Pr}, \mathrm{Ph}, \mathrm{BnCH}_{2}, \mathrm{NHAc}$, TBSO

$\mathrm{R}^{2}=\mathrm{Ph}, p-\mathrm{MeOC}_{6} \mathrm{H}_{4}, p-\mathrm{F}_{3} \mathrm{CC}_{6} \mathrm{H}_{4}, \mathrm{BnCH}_{2}, \mathrm{Cy}, t-\mathrm{Bu}, \mathrm{Me}$

Scheme 14. Conjugate reduction of C3-disubstituted 2-propenoates with $\mathrm{NaBH}_{4}$ [35].<smiles>CC(C)NC(=O)C1Cc2cc[R1]cc2C1=O</smiles>

41

$+$<smiles>[R]C=C[N+](=O)[O-]</smiles>

47<smiles>CC(C)(C)[14C](=O)[14CH]c1ccccc1</smiles>

$48(12 \mathrm{~mol} \%)$

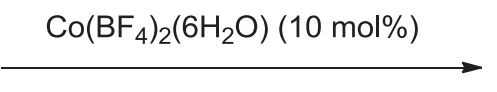

$\mathrm{CH}_{2} \mathrm{Cl}_{2}, 0-30^{\circ} \mathrm{C}$<smiles>[R15][R1]1ccc2c(c1)C(=O)[C@](C(N)=O)(C([R])C[N+](=O)[O-])C2</smiles>

49

$51-98 \%$ yield, $8-44 \%$ de

$93-97 \%$ ee (major diastereomer)

$55-90 \%$ ee (minor diastereomer)

$\mathrm{R}^{1}=\mathrm{H}, 5-\mathrm{Cl}, 5-\mathrm{F}, 5-\mathrm{Br}, 5,6-(\mathrm{OMe})_{2}, 6-\mathrm{F}, 6-\mathrm{Cl}, 6-\mathrm{Me}$

$\mathrm{R}^{2}=\mathrm{Ph}, p-\mathrm{FC}_{6} \mathrm{H}_{4}, p-\mathrm{ClC}_{6} \mathrm{H}_{4}, p-\mathrm{BrC}_{6} \mathrm{H}_{4}, p-\mathrm{PhC}_{6} \mathrm{H}_{4}$,

$m-\mathrm{BrC}_{6} \mathrm{H}_{4}, m-\mathrm{ClC}_{6} \mathrm{H}_{4}, 3,4-\mathrm{Cl}_{2} \mathrm{C}_{6} \mathrm{H}_{3}, o-\mathrm{BrC}_{6} \mathrm{H}_{4}, 2$-furyl

Scheme 15. Michael addition of cyclic $\beta$-ketoamides to nitroolefins [34]. 
$\alpha, \beta$-unsaturated ketones $\mathbf{3 6}$ promoted by $5 \mathrm{~mol} \%$ of chiral cobalt catalyst 37 in the presence of a base such as CyONa [33]. The corresponding products $\mathbf{3 8}$ were obtained in low to quantitative yields (21-98\%) and moderate to good enantioselectivities (52-88\% ee), as shown in Scheme 12 . The catalytic system tolerated five-membered, six-membered, as well as seven-membered $\alpha, \beta$-unsaturated ketones. Although the mechanism of the process was not detailed, the combination of the 1-chlorovinyl axial ligand with the sodium cation of the additive was confirmed as a crucial condition to achieve high reactivity and enantioselectivity. With the aim of extending the scope of the reaction, the same reaction conditions were applied to acyclic $\alpha, \beta$-unsaturated ketones, which led to the corresponding Michael products albeit in lower enantioselectivities (32-38\% ee) combined with low yields (26-30\%).
Another type of chiral cobalt catalysts, in situ generated from Co $\left(\mathrm{BF}_{4}\right)_{2}\left(6 \mathrm{H}_{2} \mathrm{O}\right)$ and chiral $N, N^{\prime}$-dioxide ligands, such as $\mathbf{3 9}$ and $\mathbf{4 0}$, was applied by Feng and co-workers to promote the enantioselective addition of cyclic $\beta$-ketoamides 41 to alkynones 42 [34]. The corresponding chiral Michael products 43 were obtained as mixtures of $Z$ - and E-diastereomers in high yields (80-99\%) and moderate to high enantioselectivities $(69-97 \%$ ee) for both diastereomers when using ligand $\mathbf{3 9}$ or $\mathbf{4 0}$ (Scheme 13). The Z/E ratios ranged from 52:48 to 78:22. The best enantioselectivities (92-97\% ee) were obtained by using ligand $\mathbf{4 0}$.

In another context, novel cobalt complex $\mathbf{4 4}$ derived from a chiral diamidine ligand was demonstrated by Kitamura and co-workers to catalyze the asymmetric $\mathrm{NaBH}_{4}$ conjugate reduction of C3-disubstituted 2-propenoates $\mathbf{4 5}$ to give the corresponding

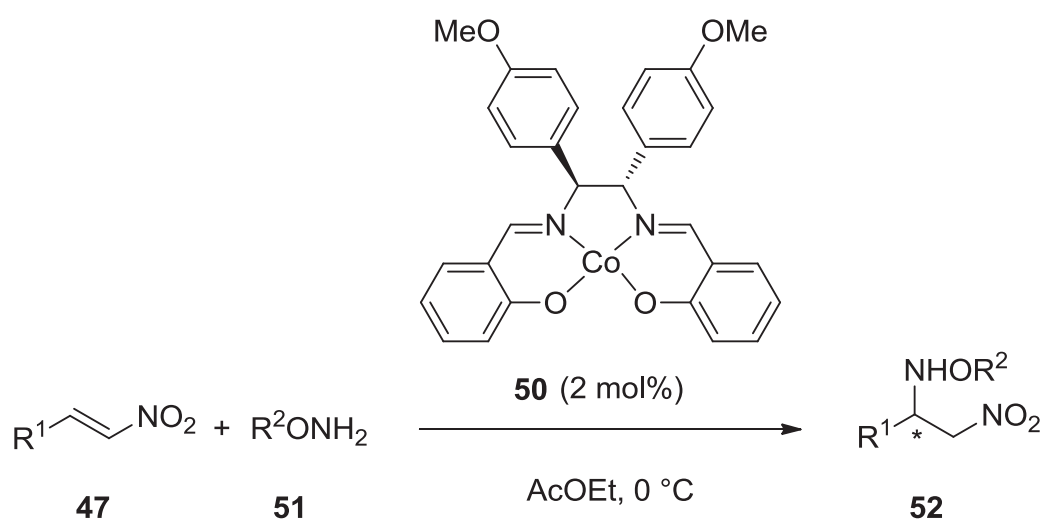

$58-99 \%$ yield, $56-91 \%$ ee

$\mathrm{R}^{1}=\mathrm{Ph}, p$-Tol, $p-\mathrm{FC}_{6} \mathrm{H}_{4}, p-\mathrm{MeOC}_{6} \mathrm{H}_{4}, o-\mathrm{MeOC}_{6} \mathrm{H}_{4}, m-\mathrm{MeOC}_{6} \mathrm{H}_{4}$, 2-Naph, 2-furyl, 2-thienyl, $\mathrm{Cy}, \mathrm{BnO}\left(\mathrm{CH}_{2}\right)_{2}, n$-Hept, $\mathrm{BnCH}_{2}$ $\mathrm{R}^{2}=\mathrm{Me}, \mathrm{Et}, \mathrm{Bn}$

Scheme 16. Michael addition of amines to nitroolefins [36].<smiles>[R]C=C[N+](=O)[O-]</smiles>

acetone, $0{ }^{\circ} \mathrm{C}$<smiles>[R]C(C[N+](=O)[O-])C(C(=O)OC)C(=O)OC</smiles>

54<smiles>COC(=O)CC(=O)OC</smiles>

$\mathrm{R}=\mathrm{Ph}, 2-\mathrm{Naph}, 1-\mathrm{Naph}, \mathrm{p}-\mathrm{MeOC}_{6} \mathrm{H}_{4}, 3,4-\mathrm{Cl}_{2} \mathrm{C}_{6} \mathrm{H}_{3}$, 3-pyridyl, $o-\mathrm{F}_{3} \mathrm{CC}_{6} \mathrm{H}_{4}, \mathrm{o}-\mathrm{AcC}_{6} \mathrm{H}_{4}, \mathrm{o}-\mathrm{BzC}_{6} \mathrm{H}_{4}, \mathrm{o}-\mathrm{BnC}_{6} \mathrm{H}_{4}$

Scheme 17. Michael addition of dimethyl malonate to nitroolefins [37]. 
chiral esters 46 with both high yields (72-98\%) and enantioselectivities (84->98\% ee) [35]. Notably, the process employed, under mild reaction conditions $\left(25^{\circ} \mathrm{C}\right)$, a low catalyst loading of only $1 \mathrm{~mol} \%$ of complex 44 (Scheme 14). In all cases of substrates, the reaction provided excellent enantioselectivities (94->98\% ee) excepted for C3-diaryl substituted ones $\left(\mathrm{R}^{1}=\mathrm{Ph}, \mathrm{R}^{2}=p-\mathrm{MeOC}_{6} \mathrm{H}_{4}\right.$ or $\left.p-\mathrm{F}_{3} \mathrm{CC}_{6} \mathrm{H}_{4}\right)$ which led to the corresponding products in slightly lower enantioselectivities ( $84-88 \%$ ee). Generally, the substrates

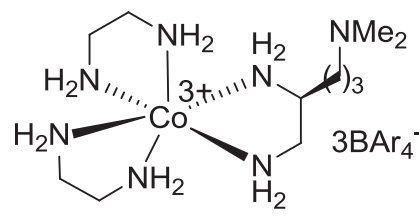

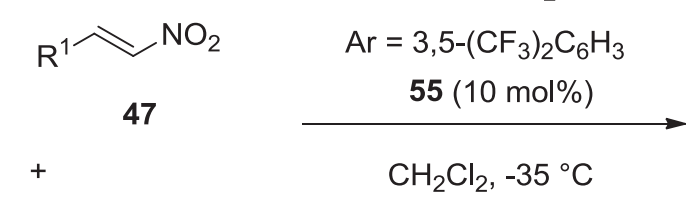

$\mathrm{R}_{\mathrm{OR}^{2}}$

$\mathrm{CH}_{2} \mathrm{Cl}_{2},-35^{\circ} \mathrm{C}$<smiles>[R]OC(=O)C(C([R])=O)C([R2])C[N+](=O)[O-]</smiles>

54

$72-98 \%$ yield, $90-99 \%$ ee

35

$\mathrm{R}^{1}=\mathrm{Ph}, p-\mathrm{MeOC}_{6} \mathrm{H}_{4}, 3,4-\mathrm{Cl}_{2} \mathrm{C}_{6} \mathrm{H}_{3}, 1-\mathrm{Naph}, 2$ furyl, $n-\mathrm{Pr}, \mathrm{Cy}$
$\mathrm{R}^{2}=\mathrm{Me}, \mathrm{Et}, \mathrm{Bn}$

Scheme 18. Michael addition of dialkyl malonates to nitroolefins [38].<smiles>[R]/C(=C/[N+](=O)[O-])C(F)(F)F</smiles><smiles>[X]c1cccnc1C(C)=O</smiles><smiles>CC(C)(C1=N[C@@H](c2ccccc2)CO1)C1=NC(c2ccccc2)CN1[O]</smiles>

58 (12 mol\%)

$\mathrm{Co}(\mathrm{acac})_{2}(10 \mathrm{~mol} \%)$

MTBE, $20^{\circ} \mathrm{C}$

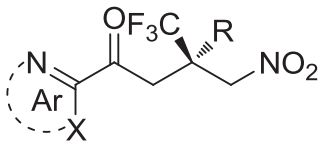

59

$24-98 \%$ yield, $60-98 \%$ ee

$\mathrm{R}=\mathrm{Ph}, p$-Tol, $m$-Tol, $p-\mathrm{MeOC}_{6} \mathrm{H}_{4}, p-\mathrm{FC}_{6} \mathrm{H}_{4}, p-\mathrm{ClC}_{6} \mathrm{H}_{4}, p-\mathrm{BrC}_{6} \mathrm{H}_{4}$, $p-\mathrm{F}_{3} \mathrm{CC}_{6} \mathrm{H}_{4}$, 3-thienyl, $\mathrm{Bn}$
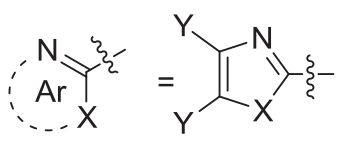

$\mathrm{X}=\mathrm{O}, \mathrm{S}, \mathrm{NH}, \mathrm{NMe}$

$\mathrm{Y}=\mathrm{H},(\mathrm{CH}=\mathrm{CH})_{2}$<smiles>[Y]c1cnc([Y])c([Y])n1</smiles>

$\mathrm{Y}=\mathrm{H},(\mathrm{CH}=\mathrm{CH})_{2}$<smiles>[Y]c1cnc([AlH2])nc1[Y]</smiles>

$\mathrm{Y}=\mathrm{H},(\mathrm{CH}=\mathrm{CH})_{2}$

Scheme 19. Michael addition of 2-acetyl azaarenes to $\beta-\mathrm{CF}_{3}-\beta$-disubstituted nitroolefins [39]. 
exhibiting an E-configuration led to the corresponding $(R)$ enantiomers while the $Z$-diastereomeric substrates provided the opposite enantioselectivity.

Along with $\alpha, \beta$-unsaturated carbonyl compounds, nitroolefins have also been used as Michael acceptors in various enantioselective cobalt-catalyzed conjugate additions. For example, Feng and co-workers developed the enantioselective conjugate addition of cyclic $\beta$-ketoamides $\mathbf{4 1}$ to nitroolefins $\mathbf{4 7}$ promoted by cobalt catalysts in situ generated from $\mathrm{Co}\left(\mathrm{BF}_{4}\right)_{2}\left(6 \mathrm{H}_{2} \mathrm{O}\right)$ and chiral $N, N^{\prime}$-dioxide ligands such as 48 [34]. The reaction afforded the corresponding densely functionalized chiral Michael products 49 bearing a quaternary carbon center as mixtures of two diastereomers in moderate to quantitative yields (51-98\%) combined with low to moderate diastereoselectivities (8-44\% de). The major diastere-<smiles></smiles>

60

(4 atm)

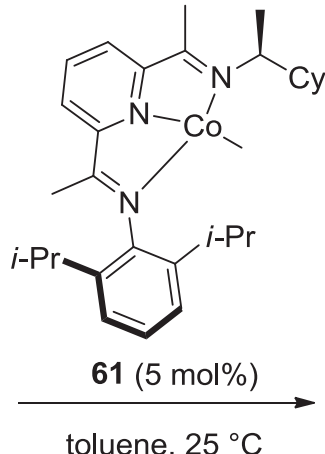

toluene, $25^{\circ} \mathrm{C}$<smiles>[R]c1ccc2c(c1)CCC2[R]</smiles>

62

$41-98 \%$ yield, $91-99 \%$ ee

$\mathrm{R}^{1}=\mathrm{H}, \mathrm{Br}, \mathrm{Ac}$

$\mathrm{R}^{2}=\mathrm{Ph}, p-\mathrm{MeOC}_{6} \mathrm{H}_{4}, p-\left(\mathrm{NMe}_{2}\right) \mathrm{C}_{6} \mathrm{H}_{4}, p-\mathrm{ClC}_{6} \mathrm{H}_{4}, p-\mathrm{FC}_{6} \mathrm{H}_{4}, i-\mathrm{Pr}$

$\mathrm{n}=1-2$<smiles>C=C1CC=C2C=CC=C12</smiles>

63
$\mathrm{H}_{2}$

(4 atm)

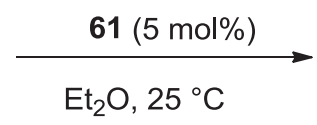

$n=1-3$<smiles>CC1CCCC1</smiles>

64

$84-97 \%$ yield, $53-85 \%$ ee

Scheme 20. Hydrogenations of exo- and endocyclic alkenes [41].

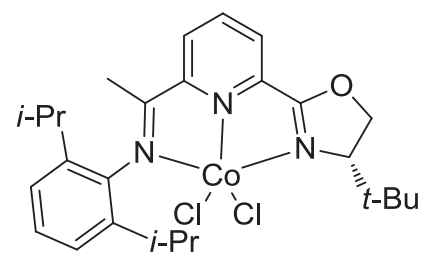

$66(5 \mathrm{~mol} \%)$<smiles>C=C([Mg])[Al]</smiles>

65

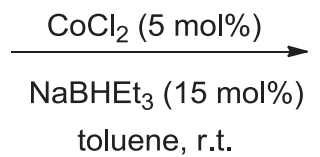

(balloon)

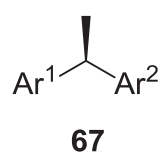

67

77->99\% yield, $58->99 \%$ ee

$\mathrm{Ar}^{1}=0-\mathrm{ClC}_{6} \mathrm{H}_{4}, 2,4-\mathrm{Cl}_{2} \mathrm{C}_{6} \mathrm{H}_{3}, 2,3-\mathrm{Cl}_{2} \mathrm{C}_{6} \mathrm{H}_{3}, 2,5-\mathrm{Cl}_{2} \mathrm{C}_{6} \mathrm{H}_{3}, 2-\mathrm{Cl}-4-\mathrm{FC}_{6} \mathrm{H}_{3}$, 2-Cl-4- $\mathrm{MeC}_{6} \mathrm{H}_{3}, 2-\mathrm{Cl}-4-\mathrm{MeOC}_{6} \mathrm{H}_{3}, 2-\mathrm{Cl}-3,4-(\mathrm{MeO})_{2} \mathrm{C}_{6} \mathrm{H}_{2}, 0-\mathrm{FC}_{6} \mathrm{H}_{4}$, o- $\mathrm{MeOC}_{6} \mathrm{H}_{4}$, o-Tol, o- $\mathrm{EtC}_{6} \mathrm{H}_{4}, 1-\mathrm{Naph}$ $\mathrm{Ar}^{2}=\mathrm{Ph}, p$-Tol, $p$ - $\mathrm{MeOC}_{6} \mathrm{H}_{4}, o-\mathrm{MeOC}_{6} \mathrm{H}_{4}, m-\mathrm{MeOC}_{6} \mathrm{H}_{4}, m$-Tol, $p$-Tol, $m$-TBSOC $6 \mathrm{H}_{4}, m-\left(\mathrm{TBSOCH}_{2}\right) \mathrm{C}_{6} \mathrm{H}_{4}, m-\mathrm{F}_{3} \mathrm{CC}_{6} \mathrm{H}_{4}, m-\mathrm{PhC}_{6} \mathrm{H}_{4}, p-\mathrm{PhC}_{6} \mathrm{H}_{4}$, p- $\left(\mathrm{NMe}_{2}\right) \mathrm{C}_{6} \mathrm{H}_{4}, 3,4-\mathrm{MeO}_{2} \mathrm{C}_{6} \mathrm{H}_{3}, 3,4-\left(\mathrm{OCH}_{2} \mathrm{O}\right) \mathrm{C}_{6} \mathrm{H}_{3}, 3,5-\mathrm{Me}_{2} \mathrm{C}_{6} \mathrm{H}_{3}$, Phth

Scheme 21. Hydrogenation of 1,1-diarylethenes[42]. 
omers were achieved in uniformly excellent enantioselectivities (93-97\% ee) while the minor ones in lower enantioselectivities (55-90\% ee), as shown in Scheme 15. It was found that the electronic nature of the substituents $\left(\mathrm{R}^{1}\right)$ on the aromatic ring of the indenone scaffold had no effects on the enantioselectivity and reactivity of the reaction.

In 2014, Kezuka and co-workers reported that chiral salen cobalt(II) complex $\mathbf{5 0}$ was an effective catalyst for the enantiose- lective Michael addition of $O$-alkylhydroxylamines $\mathbf{5 1}$ to nitroolefins 47 to afford the corresponding chiral $\mathrm{N}$-alkylhydroxyl-1,2nitroamines 52 [36]. As shown in Scheme 16, these products were achieved in moderate to quantitative yields (58-99\%) and moderate to high enantioselectivities (56-91\% ee) starting from either alkyl- or (hetero)aryl-substituted nitroalkenes. In most cases, the best enantioselectivities (82-91\% ee) were achieved in the reaction of $O$-benzylhydroxylamine $\left(\mathrm{R}^{2}=\mathrm{Bn}\right)$ with alkyl-substituted<smiles>[R]c1ccc(/C(=C/C(=O)OCC)N[Ga])cc1</smiles>

$\mathrm{Co}_{2}(\mathrm{CO})_{8}(1 \mathrm{~mol} \%)$

(R)-BINAP (2 mol\%)

$+\mathrm{H}_{2} / \mathrm{CO}$

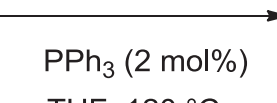<smiles>[R]c1ccc([C@@H](N)CC(=O)OCC)cc1</smiles>

(450 psi)

THF, $120^{\circ} \mathrm{C}$

$82-93 \%$ yield, $4-43 \%$ ee

$\mathrm{R}=\mathrm{H}, \mathrm{OMe}, \mathrm{Me}$

$\mathrm{Ar}=\mathrm{Ph}, p-\mathrm{MeOC}_{6} \mathrm{H}_{4}, p-\mathrm{Tol}, p-\mathrm{ClC}_{6} \mathrm{H}_{4}, p-\mathrm{FC}_{6} \mathrm{H}_{4}, m-\mathrm{Tol}, m-\mathrm{ClC}_{6} \mathrm{H}_{4}$,

$o-\mathrm{MeOC}_{6} \mathrm{H}_{4}, o-\mathrm{EtC}_{6} \mathrm{H}_{4}, o-\mathrm{BrC}_{6} \mathrm{H}_{4}, \mathrm{o}-\mathrm{HOC}_{6} \mathrm{H}_{4}, o-\mathrm{Tol}$

Scheme 22. Hydrogenation of $\beta$-enamino esters [43].
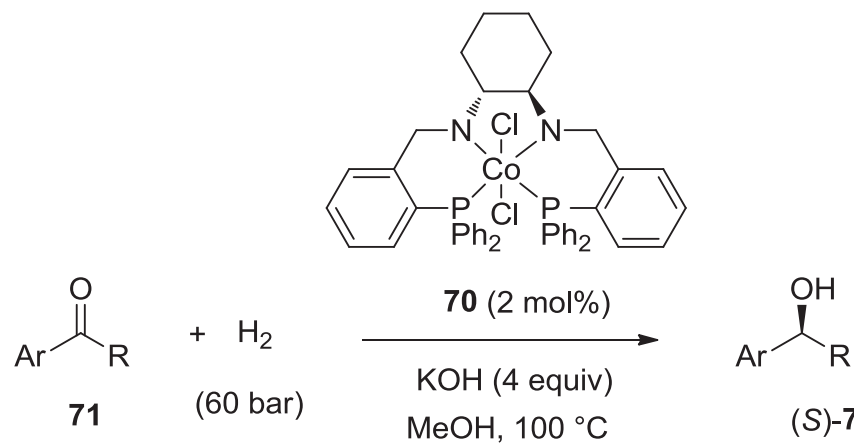

$\mathrm{MeOH}, 100^{\circ} \mathrm{C}$

(S)-72

$31-99 \%$ yield, $35-92 \%$ ee

$\mathrm{R}=\mathrm{Me}, \mathrm{Et}, i-\mathrm{Pr}, \mathrm{Ph}$

$\mathrm{Ar}=\mathrm{Ph}, o-\mathrm{Tol}, m$-Tol, $p$-Tol, o- $\mathrm{MeOC}_{6} \mathrm{H}_{4}, m-\mathrm{MeOC}_{6} \mathrm{H}_{4}$,

$p-\mathrm{MeOC}_{6} \mathrm{H}_{4}, o-\mathrm{ClC}_{6} \mathrm{H}_{4}, m-\mathrm{ClC}_{6} \mathrm{H}_{4}, m-\mathrm{BrC}_{6} \mathrm{H}_{4}, p-\mathrm{BrC}_{6} \mathrm{H}_{4}, p-\mathrm{EtC}_{6} \mathrm{H}_{4}$
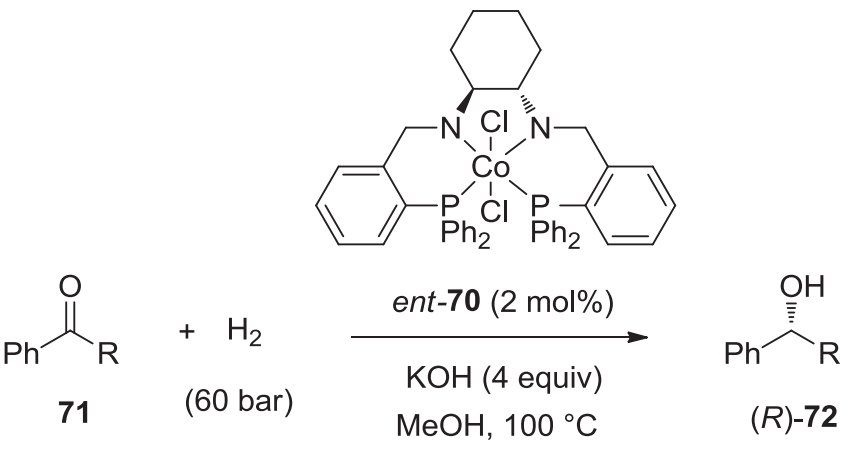

$(R)-72$

$$
\begin{gathered}
35-98 \% \text { yield, } 54-95 \% \text { ee } \\
\text { R = Cy, } n-\mathrm{Pr}, n-\mathrm{Bu}, \mathrm{Ph}
\end{gathered}
$$

Scheme 23. Hydrogenations of aromatic ketones [44] 
nitroalkenes $\left(\mathrm{R}^{1}=\mathrm{CH}_{2} \mathrm{Bn}\right.$, $n$-Hept, $\left.\left(\mathrm{CH}_{2}\right)_{2} \mathrm{OBn}\right)$. This study represented the first example of a transition-metal-catalyzed asymmetric Michael addition of amines to nitroalkenes.

Werner complexes of cobalt(III) and 1,2-diamines represent examples of substitution inert low-spin $\mathrm{d}^{6}$ complexes, and consequently are incapable of traditional-metal-based substrate activation. However, the coordinated $\mathrm{NH}$ groups of their chiral 1,2-diamine ligands constitute powerful hydrogen-bond donors. Therefore, in the presence of this type of catalysts, the substrates are not activated by classical metal coordination, but rather by second coordination sphere hydrogen bonding involving the ligating $\mathrm{NH}_{2}$ groups. In this context, Gladysz and co-workers have

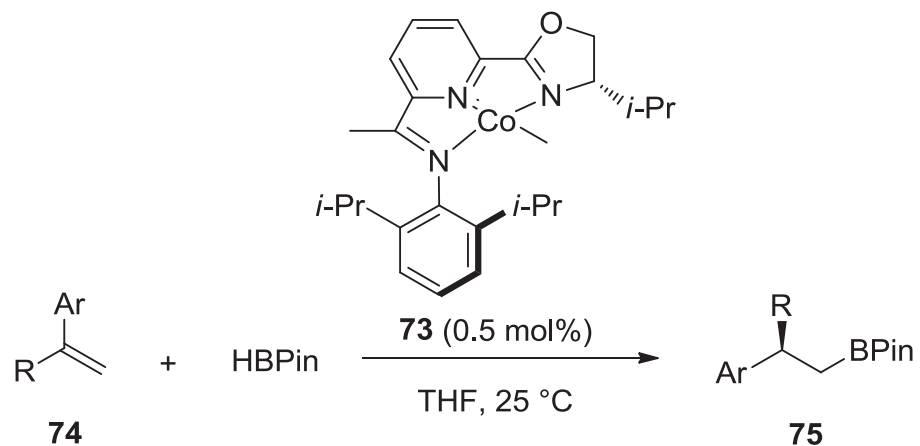

$69-98 \%$ yield, $92-99 \%$ ee

$\mathrm{Ar}=\mathrm{Ph}, p-\mathrm{Tol}, p-\mathrm{FC}_{6} \mathrm{H}_{4}, m-\mathrm{FC}_{6} \mathrm{H}_{4}, p-\mathrm{F}_{3} \mathrm{CC}_{6} \mathrm{H}_{4}, p-\mathrm{ClC}_{6} \mathrm{H}_{4}, p-\mathrm{BrC}_{6} \mathrm{H}_{4}, p-\mathrm{IC}_{6} \mathrm{H}_{4}$,

$p-\mathrm{AcOC}_{6} \mathrm{H}_{4}, p-\left(\mathrm{NMe}_{2}\right) \mathrm{C}_{6} \mathrm{H}_{4}, 2-\mathrm{Naph}, 7-\mathrm{MeO}-2-\mathrm{Naph}$,
$\mathrm{R}=\mathrm{Me}, \mathrm{Et}, n-\mathrm{Pr}, \mathrm{Bn},\left(\mathrm{CH}_{2}\right)_{3} \mathrm{CO}_{2} \mathrm{Me},\left(\mathrm{CH}_{2}\right)_{3} \mathrm{Cl}$

Scheme 24. Hydroboration of 1,1-disubstituted aryl alkyl alkenes [46].

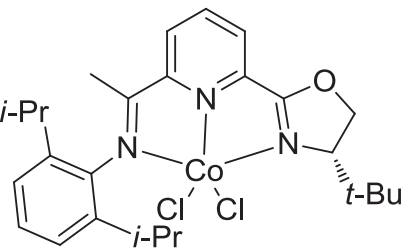

$66(0.5$ or $5 \mathrm{~mol} \%)$

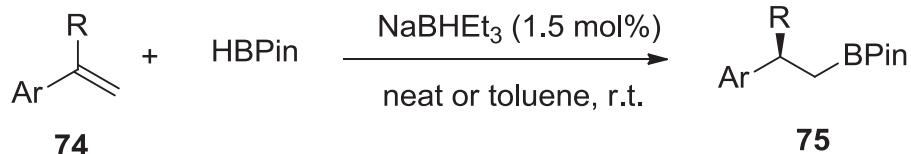

$45-96 \%$ yield, $53->99 \%$ ee

$\mathrm{Ar}=\mathrm{Ph}, p-\mathrm{Tol}, p-i-\mathrm{BuC}_{6} \mathrm{H}_{4}, p-\mathrm{MeOC}_{6} \mathrm{H}_{4}, p-\mathrm{TIPSOC}_{6} \mathrm{H}_{4}, p-\left(\mathrm{NMe}_{2}\right) \mathrm{C}_{6} \mathrm{H}_{4}$, $p$ - $\mathrm{MeSC}_{6} \mathrm{H}_{4}, p-\mathrm{TBSOCH}_{2} \mathrm{C}_{6} \mathrm{H}_{4}, p-\mathrm{FC}_{6} \mathrm{H}_{4}, p-\mathrm{ClC}_{6} \mathrm{H}_{4}, p-\mathrm{BrC}_{6} \mathrm{H}_{4}, m$-Tol, $m-\mathrm{MeOC}_{6} \mathrm{H}_{4}, m-\mathrm{FC}_{6} \mathrm{H}_{4}, m-\mathrm{ClC}_{6} \mathrm{H}_{4}, m-\mathrm{BrC}_{6} \mathrm{H}_{4}, m-\mathrm{F}_{3} \mathrm{CC}_{6} \mathrm{H}_{4}, o-\mathrm{Tol}, o-\mathrm{FC}_{6} \mathrm{H}_{4}$, 3-Br-4-MeOC ${ }_{6} \mathrm{H}_{3}$, 1-Naph, 2-Naph, 7-MeO-2-Naph,

$\mathrm{R}=\mathrm{Me}, \mathrm{Et}, n-\mathrm{Pr},\left(\mathrm{CH}_{2}\right)_{3} \mathrm{OTBS}$

Scheme 25. Hydroboration of 1,1-disubstituted aryl alkyl alkenes [47].

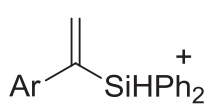

76

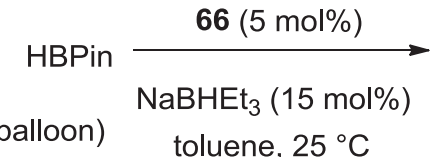

toluene, $25^{\circ} \mathrm{C}$

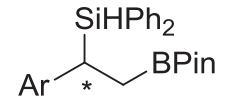

77

$76-82 \%$ yield, $80-85 \%$ ee

$$
\mathrm{Ar}=\mathrm{Ph}, \mathrm{p}-\mathrm{Tol}, 2-\mathrm{Naph}
$$

Scheme 26. Hydroboration of $\alpha$-silyl alkenes [48]. 
investigated the use of inexpensive and readily available Werner complexes based on the $D_{3}$-symmetric chiral trication $[\mathrm{Co}((S, S)$ dpen $\left.)_{3}\right]^{3+}$ (dpen $=1,2$-diphenylethylenediamine) in the enantioselective Michael addition of dimethyl malonate 35a to nitroolefins 47 [37]. Indeed, when this reaction was promoted by $10 \mathrm{~mol} \%$ of catalyst $\mathbf{5 3}$ in acetone at $0{ }^{\circ} \mathrm{C}$ in the presence of TEA as base, it led to the corresponding chiral nitroalkanes $\mathbf{5 4}$ in uniformly excellent yields (93-98\%) and high enantioselectivities (85-98\% ee), as shown in Scheme 17. This study illustrated the possibility associated with enantioselective second coordination sphere-promoted catalysis.

These reactions were also performed by the same authors in the presence of another Werner cobalt complex $\mathbf{5 5}$ incorporating an additional functionality, such as a dimethylamino group [38].
Performed at $-35^{\circ} \mathrm{C}$ in dichloromethane as solvent, the reactions of dialkyl malonates $\mathbf{3 5}$ with aryl- as well as alkyl-substituted nitroalkenes 47 catalyzed with $10 \mathrm{~mol} \%$ of complex 55 provided the corresponding chiral nitroalkanes $\mathbf{5 4}$ in good to quantitative yields (72-98\%) and excellent enantioselectivities (90-99\% ee), as shown in Scheme 18. Very high enantioselectivities (93-99\% ee) were obtained in the reaction of aryl-substituted nitroalkenes bearing electron-donating or electron-withdrawing substituents. Particularly noteworthy were analogous additions to alkylsubstituted nitroalkenes which also provided uniformly excellent enantioselectivities (90-94\% ee).

Recently, Song and co-workers described the synthesis of novel imidazoline/oxazoline $N, N^{\prime}$-didentate chiral ligands derived from 2,2-dimethylmalonic acid which were further used to develop<smiles>[R]c1cc(C([R])Cc2ccccc2)c([R])c([R])c1[R]</smiles>

$47-86 \%$ yield, $57-95 \%$ ee

$\mathrm{R}^{1}=\mathrm{H}, \mathrm{Me}, \mathrm{Et}, n-\mathrm{Bu}, i-\mathrm{Pr}, \mathrm{Ph}, \mathrm{OMe}, \mathrm{OBn}, \mathrm{CF}_{3}$

$\mathrm{R}^{2}=\mathrm{H}, \mathrm{Me}, \mathrm{OMe}$, OTBS, $\mathrm{NMe}_{2}, \mathrm{Cl}, \mathrm{Br}$

$\mathrm{R}^{3}=\mathrm{H}, \mathrm{Me}$

$\mathrm{R}^{4}=\mathrm{H}$

$\mathrm{R}^{1}, \mathrm{R}^{4}=(\mathrm{CH}=\mathrm{CH})_{2}$

$\mathrm{R}^{5}=\mathrm{Me}, \mathrm{Et}, n-\mathrm{Bu}$<smiles></smiles>

$35-81 \%$ yield, $65-95 \%$ ee

$\mathrm{R}^{1}=\mathrm{H}, \mathrm{Me}, \mathrm{Et}, n-\mathrm{Bu}, i-\mathrm{Pr}, \mathrm{Ph}, \mathrm{OMe}, \mathrm{OBn}, \mathrm{CF}_{3}$

$\mathrm{R}^{2}=\mathrm{H}, \mathrm{Me}, \mathrm{OMe}$, OTBS, $\mathrm{NMe}_{2}, \mathrm{Cl}, \mathrm{Br}$

$\mathrm{R}^{3}=\mathrm{H}, \mathrm{Me}$

$\mathrm{R}^{4}=\mathrm{H}$

$\mathrm{R}^{1}, \mathrm{R}^{4}=(\mathrm{CH}=\mathrm{CH})_{2}$

$\mathrm{R}^{5}=\mathrm{Me}, \mathrm{Et}, n-\mathrm{Bu}$

Scheme 27. Hydroborations of sterically hindered styrenes [49]. 
the first enantioselective cobalt-catalyzed Michael addition of 2acetyl azaarenes 56 to $\beta-\mathrm{CF}_{3}-\beta$-disubstituted nitroolefins 57 [39]. When using $12 \mathrm{~mol} \%$ of optimal chiral ligand $\mathbf{5 8}$ in combination with $10 \mathrm{~mol} \%$ of $\mathrm{Co}(\mathrm{acac})_{2}$ in MTBE at $20^{\circ} \mathrm{C}$, the process afforded the corresponding chiral products $\mathbf{5 9}$ bearing a trifluoromethylated all-carbon quaternary center in low to quantitative yields (24-98\%) and moderate to excellent enantioselectivities (60-98\% ee). As shown in Scheme 19, the reaction tolerated a wide variety of $\beta$ $\mathrm{CF}_{3}-\beta$-(hetero)aryl-disubstituted nitroalkenes and a range of 2acetyl azaarenes containing thiazole, $N$-methylimidazole, pyrazine, benzothiazole, quinoxaline, benzoxazole, pyrimidine and quinolone groups. For a nitroalkene containing a $\beta$-alkyl group $(R=B n)$, the reactivity was found still good (47-84\% yield) but the stereocontrol was only moderate (66-78\% ee).

\subsection{Hydrogenation reactions}

The asymmetric hydrogenation of alkenes has found numerous applications in pharmaceutical and agrochemical industries. In most cases, it is catalyzed by metals such as ruthenium, rhodium or iridium [40]. Replacing these expensive and toxic elements with more abundant and environmentally compatible transition metals, such as cobalt, is attractive. However, examples of enantioselective cobalt-catalyzed hydrogenation of alkenes are still rare. In this context, Chirik et al. described the asymmetric hydrogenation of cyclic alkenes 60 with $5 \mathrm{~mol} \%$ of $C_{1}$-symmetric bis(imino)pyridine cobalt (II) catalyst $\mathbf{6 1}$ in toluene at $25^{\circ} \mathrm{C}$ [41]. As shown in Scheme 20, high yields and enantioselectivities of up to $98 \%$ and $99 \%$ ee, respectively, were achieved in the reaction of substituted benzofused five- and six-membered alkenes to give the corresponding products 62. The stereochemical outcome of the reaction was dependent on both the ring size and exo/endo disposition of the $\mathrm{C}=\mathrm{C}$ bond to be hydrogenated. For example, while endocyclic alkenes 60 led to enantiomers 62, exocyclic alkenes 63 generally yielded the opposite enantiomers $\mathbf{6 4}$. Moreover, better enantiose- lectivities were obtained in the hydrogenation of endocyclic alkenes ( $91-99 \%$ ee vs $53-85 \%$ ee).

In 2016, Lu and co-workers reported the first highly enantioselective hydrogenation of 1,1-diarylalkenes 65 promoted by a combination of a metal and a chiral base ligand [42]. As shown in Scheme 21, this reaction was catalyzed in toluene at room temperature with $5 \mathrm{~mol} \%$ of chiral cobalt complex 66 exhibiting a chiral oxazoline iminopyridine ligand in the presence of $\mathrm{NaBHEt}_{3}$ as reductant. It led to the corresponding chiral 1,1-diarylethanes 67 in high to quantitative yields (77->99\%) and moderate to excellent enantioselectivities (58->99\% ee). A unique 0 -chloride effect was observed to achieve high enantioselectivity. Indeed, 1-(2'-chloro phenyl)-1-arylethenes provided the best enantioselectivities (85$>99 \%$ ee). However, a wide range of other substituents could also be present along with this chloride atom on the phenyl ring as well as on the second aryl group. The utility of this protocol was related to the easy dechlorination of the products by treatment with $\mathrm{HCO}_{2} \mathrm{NH}_{4}$ on $\mathrm{Pd} / \mathrm{C}$.

In another area, there have been only few reports on the asymmetric hydrogenation of $\beta$-enamino esters especially using chiral cobalt catalysts. Among them, Amezquita-Valencia and Cabrera recently investigated these reactions in the presence of different ligands including $(R)$-BINAP and derivatives, $(R, R)$-DIOP, $(R, R)$-MeDuPhos, and $(R)$-PROPHOS [43]. The authors demonstrated that a combination of $\mathrm{Co}_{2}(\mathrm{CO})_{8}$ with $(R)$-BINAP was the best catalytic system for the asymmetric hydrogenation of a range of $\beta$-enamino esters 68 since the corresponding chiral amino esters 69 were obtained in high yields (82-93\%) albeit with low enantioselectivities (4-43\% ee), as shown in Scheme 22.

In another area, the enantioselective metal-catalyzed hydrogenation of ketones is a powerful method to prepare optically active alcohols which constitute important intermediates in organic synthesis. Along with expensive and toxic metal complexes based on ruthenium, rhodium and iridium, chiral cobalt complexes have been rarely applied to the hydrogenation of ketones and moreover with only moderate enantioselectivities. In this context,

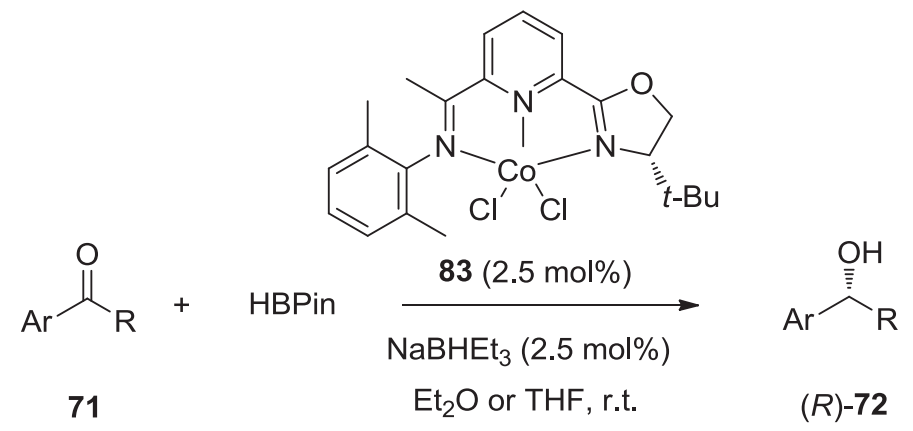

$71-99 \%$ yield, 63->99\% ee

$\mathrm{Ar}=\mathrm{Ph}, p$-Tol, $m$-Tol, $p-\mathrm{FC}_{6} \mathrm{H}_{4}, o-\mathrm{FC}_{6} \mathrm{H}_{4}, o-T o l$, ferrocenyl, 2-Naph,

6-MeO-2-Naph, $p-\mathrm{MeOC}_{6} \mathrm{H}_{4}, m-\mathrm{MeOC}_{6} \mathrm{H}_{4}, o-\mathrm{MeOC}_{6} \mathrm{H}_{4}, p-i-\mathrm{BuC}_{6} \mathrm{H}_{4}$, $m-\mathrm{FC}_{6} \mathrm{H}_{4}$, "

$\mathrm{R}=\mathrm{Me}$, Et, $n-\mathrm{Pr},\left(\mathrm{CH}_{2}\right)_{2} \mathrm{Cl},\left(\mathrm{CH}_{2}\right)_{3} \mathrm{Cl},\left(\mathrm{CH}_{2}\right)_{2} \mathrm{CONEt}_{2},\left(\mathrm{CH}_{2}\right)_{2} \mathrm{CO}_{2} \mathrm{Et}, \mathrm{Bn}, \mathrm{Ph}$<smiles></smiles>

Scheme 28. Hydroboration of aryl ketones [53]. 


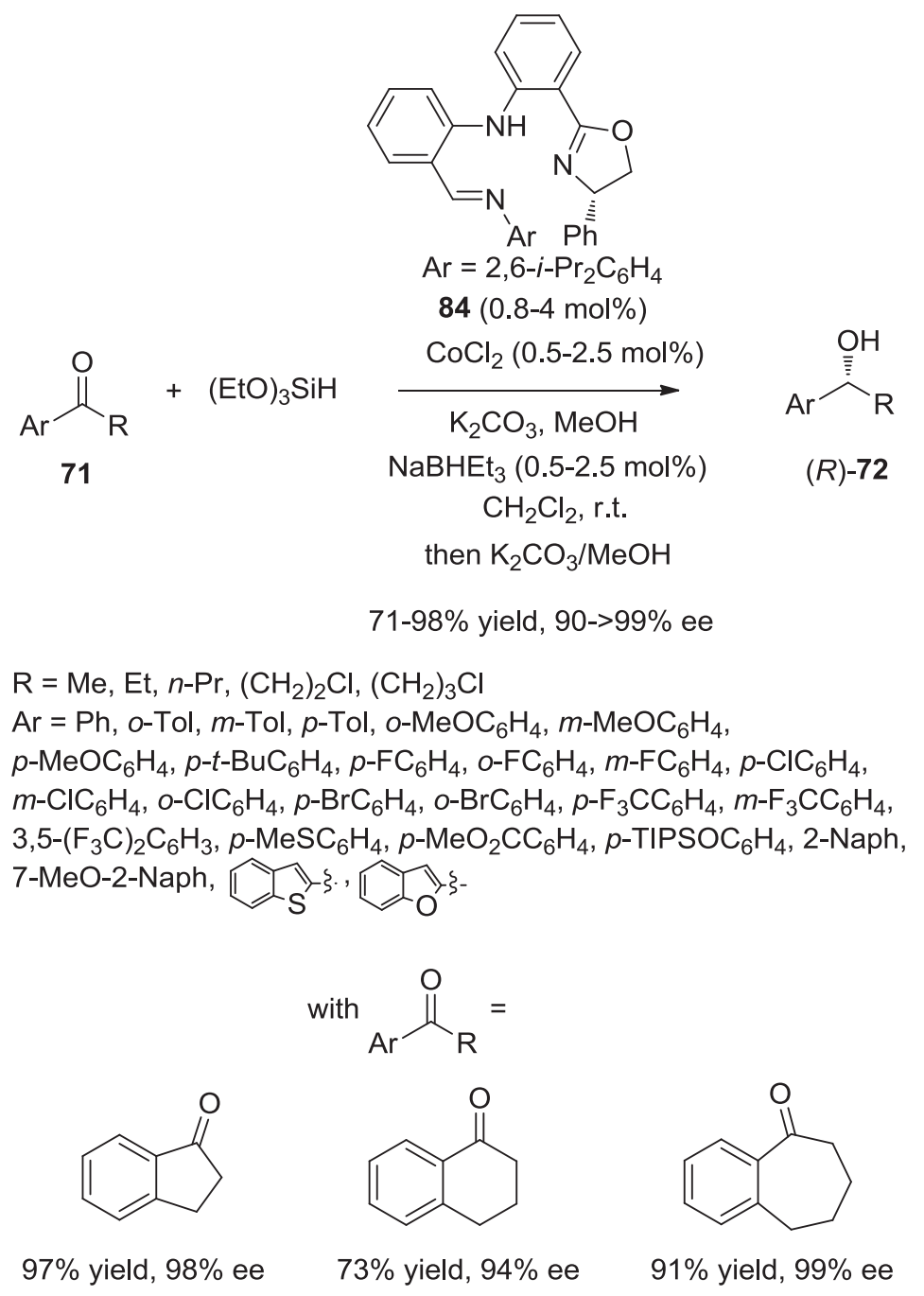

Scheme 29. Hydrosilylation of aryl ketones [56].

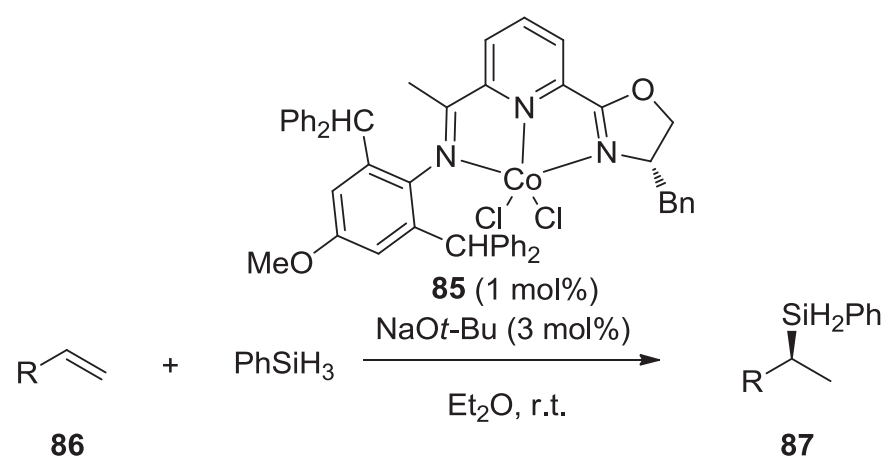

$53-97 \%$ yield, $81->99 \%$ ee

$\mathrm{R}=p-\mathrm{Tol}, p-t-\mathrm{BuC}_{6} \mathrm{H}_{4}, p-\mathrm{PhC}_{6} \mathrm{H}_{4}, p-\mathrm{MeOC}_{6} \mathrm{H}_{4}, p-\mathrm{MeSC}_{6} \mathrm{H}_{4}$,

$p-\mathrm{FC}_{6} \mathrm{H}_{4}, p-\mathrm{ClC}_{6} \mathrm{H}_{4}, p-\mathrm{BrC}_{6} \mathrm{H}_{4}, p-\mathrm{F}_{3} \mathrm{CC}_{6} \mathrm{H}_{4}, p-\mathrm{MeO}_{2} \mathrm{CC}_{6} \mathrm{H}_{4}, p-\left(\mathrm{AcOCH}_{2}\right) \mathrm{C}_{6} \mathrm{H}_{4}$, $m-\mathrm{F}_{3} \mathrm{CC}_{6} \mathrm{H}_{4}, m-\mathrm{ClC}_{6} \mathrm{H}_{4}, m-\mathrm{Tol}$, o-Tol, 3-MeO-4-F- $\mathrm{C}_{6} \mathrm{H}_{3}$,

1-Naph, 2-Naph, 2-thienyl, $n$-Hex, $\left(\mathrm{CH}_{2}\right)_{3} \mathrm{Br}, \mathrm{CH}_{2} \mathrm{TMS},\left(\mathrm{CH}_{2}\right)_{2} \mathrm{Ac},\left(\mathrm{CH}_{2}\right)_{4} \mathrm{OH}$,

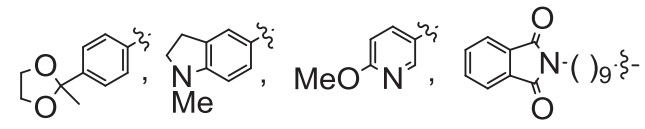

Scheme 30. Hydrosilylation of alkenes [57]. 

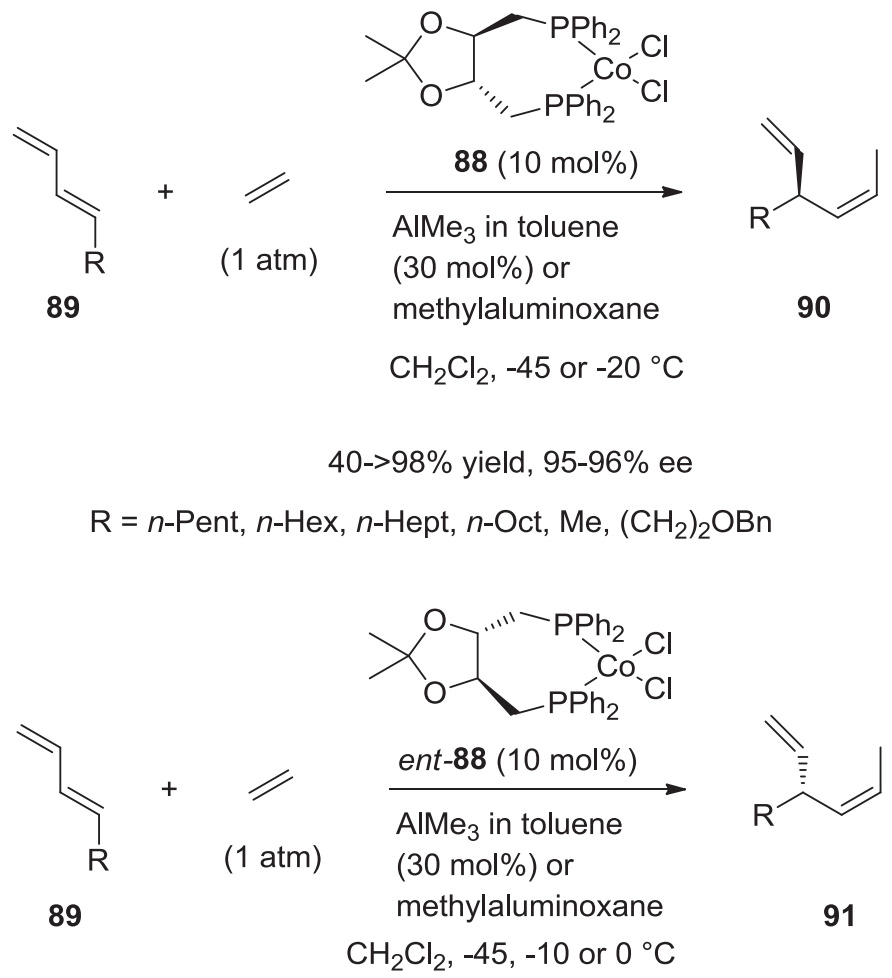

$46-99 \%$ yield, $74-94 \%$ ee

$$
\mathrm{R}=n \text {-Oct, } \mathrm{Cy},\left(\mathrm{CH}_{2}\right)_{2} \mathrm{OBn}, \mathrm{Ph}
$$

Scheme 31. Hydrovinylations of acyclic 1,3-dienes [63].
$\mathrm{Li}$ and co-workers recently reported the synthesis of novel chiral cobalt complex 70 containing a chiral PNNP-type ligand which was further investigated to promote the hydrogenation of various aromatic ketones 71 [44]. Employed at only $2 \mathrm{~mol} \%$ of catalyst loading in methanol at $100{ }^{\circ} \mathrm{C}$ in the presence of $\mathrm{KOH}$ as base, the reaction afforded a range of chiral aromatic alcohols $(S)-72$ in low to quantitative yields (31-99\%) and low to excellent enantioselectivities (35-92\% ee), as shown in Scheme 23. When the reaction was promoted by ent-70, it led to the opposite enantiomeric products $(R)-72$ in comparable yields (35-98\%) combined with slightly higher enantioselectivities (54-95\% ee). This study represented the first example of a cobalt-catalyzed enantioselective hydrogenation of ketones with molecular hydrogen.

\subsection{Hydroboration reactions}

The catalytic asymmetric hydroboration of alkenes constitutes an efficient atom-economical method for the synthesis of chiral alkylboronic acid derivatives which are important intermediates in synthesis as being convertible into various functional groups via consecutive carbon-carbon and carbon-heteroatom bond formation reactions [45]. Due to the difficulty in differentiating two enantiotopic faces in prochiral substrates, the asymmetric hydroboration of 1,1-disubstituted alkenes is still challenging. Along with rhodium, iridium, copper and iron catalysts, chiral cobalt complexes have been found to be even more active promotors for asymmetric hydroborations of 1,1-disubstituted alkenes. For example, Huang and co-workers have reported excellent enantioselectivities of $92-99 \%$ ee when these reactions were catalyzed in THF at $25{ }^{\circ} \mathrm{C}$ with only $0.5 \mathrm{~mol} \%$ of novel cobalt(II) complex 73 derived from a chiral iminopyridine-oxazoline ligand (Scheme 24) [46]. Indeed, the asymmetric hydroboration of a wide range of 1,1-disubstituted aryl alkyl alkenes $\mathbf{7 4}$ with HBPin afforded the

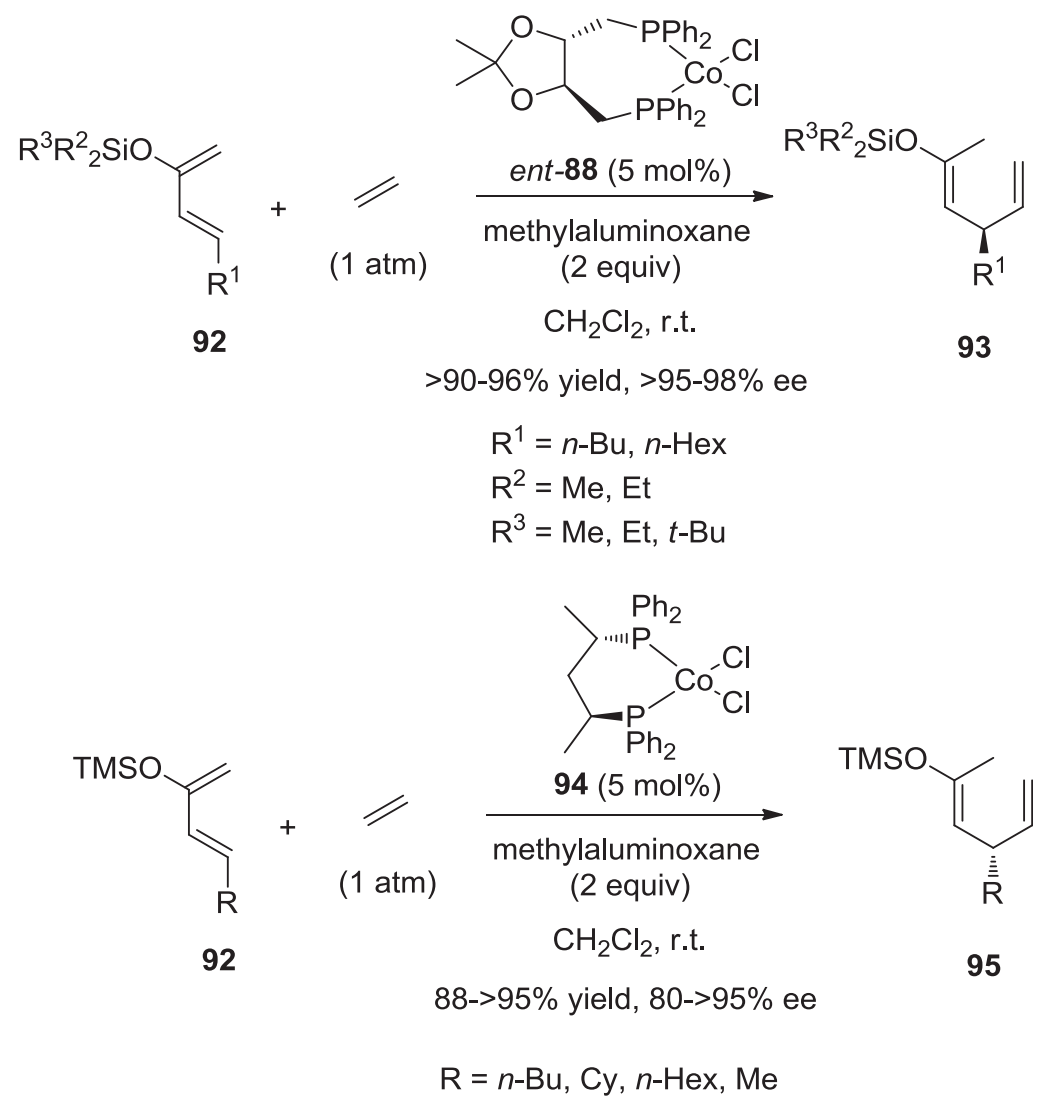

Scheme 32. Hydrovinylations of 1,3-siloxydienes [64]. 
corresponding chiral $\alpha$-alkyl- $\beta$-pinacolatoboranes 75 with exclusive anti-Markovnikov regioselectivity in high yields (69-98\%) and uniformly excellent enantioselectivities (92-99\% ee). When the reaction conditions were applied to the asymmetric hydroboration of 1,1-diarylethenes, much lower enantioselectivities were observed (8-54\% ee) in combination with low to good yields (19-84\%).

Comparable reactions were also performed by the same authors in the presence of cobalt complex $\mathbf{6 6}$ derived from another chiral iminopyridine-oxazoline ligand [47]. In this case, the process employed $\mathrm{NaBHEt}_{3}$ as activating agent at room temperature in toluene or under solvent-free conditions. A range of 1,1disubstituted aryl alkyl alkenes $\mathbf{7 4}$ reacted with HBPin to provide the corresponding chiral $\alpha$-alkyl- $\beta$-pinacolatoboranes 75 with exclusive anti-Markovnikov regioselectivity in moderate to excellent yields (45-96\%) and enantioselectivities (53->99\% ee), as shown in Scheme 25. Uniformly very high enantioselectivities (95->99\% ee) were obtained in the reaction of almost all the substrates excepted for ortho-substituted styrenes $(\mathrm{Ar}=0$-Tol or $o-\mathrm{FC}_{6} \mathrm{H}_{4}, \mathrm{R}=\mathrm{Me}, 66-84 \%$ ee) and naphthyl-substituted alkene ( $\mathrm{Ar}=1-\mathrm{Naph}, \mathrm{R}=\mathrm{Me}, 53 \%$ ee $)$.

Since no example of enantioselective hydroboration of vinylsilanes was previously reported, the same authors successfully applied catalyst $\mathbf{6 6}$ to develop the first asymmetric hydroboration of $\boldsymbol{\alpha}$-silyl alkenes $\mathbf{7 6}$ [48]. As shown in Scheme 26, the reaction of the latter with HBPin in the presence of $5 \mathrm{~mol} \%$ of catalyst $\mathbf{6 6}$ and $\mathrm{NaBHEt}_{3}$ as reductant in toluene at $25^{\circ} \mathrm{C}$ led regioselectively to the corresponding chiral anti-Markovnikov products $\mathbf{7 7}$ in good yields (76-82\%) and enantioselectivities (80-85\% ee).In Scheme 26, we can remove the structure of 66 since it is already drawn in previous Scheme 25, just keep 66 (5 mol\%)

Another closely related cobalt catalyst $\mathbf{7 8}$ was used by these authors to the asymmetric anti-Markovnikov hydroboration of challenging sterically hindered styrenes 79 [49]. When $5 \mathrm{~mol} \%$ of this catalyst was employed in the presence of $\mathrm{NaBH}(s-\mathrm{Bu})_{3}$ in THF at $25^{\circ} \mathrm{C}$, the hydroboration with HBPin led to the corresponding products 80 in moderate to high yields (47-86\%) and enantioselectivities (57-95\% ee), as shown in Scheme 27. Furthermore, the authors discovered that by using another cobalt catalyst in situ generated from $\mathrm{CoCl}_{2}$ and chiral oxazoline aminopyridine ligand $\mathbf{8 1}$ under the same reaction conditions, the process led to products 82 exhibiting the opposite absolute configuration. As shown in Scheme 27, these products were obtained in slightly lower yields (35-81\%) and moderate to high enantioselectivities (65-95\% ee).

The reduction of carbonyl compounds is one of the most direct approaches to optically active alcohols [50]. In this context, sodium borohydride is the most conventional reducing agent due to its stability, high selectivity and ease of handling. While optically active semi-corrin cobalt(II) complexes were proved by Pfaltz

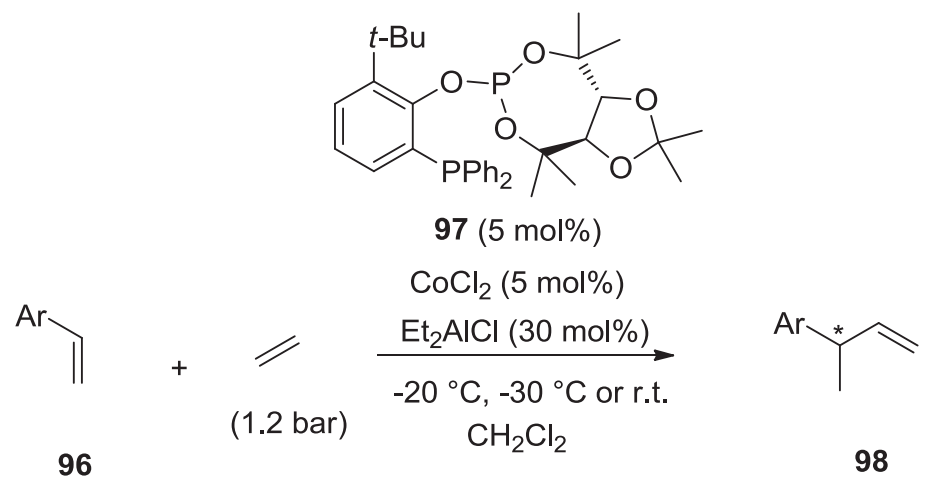

$76-99 \%$ yield, $44-99 \%$ ee

$\mathrm{Ar}=$ 2-Naph, $p-(i-\mathrm{Bu}) \mathrm{C}_{6} \mathrm{H}_{4}, 3,4-(\mathrm{MeO})_{2} \mathrm{C}_{6} \mathrm{H}_{3}, 7-\mathrm{MeO}-2-\mathrm{Naph}$, $p-\mathrm{MeO}_{2} \mathrm{CC}_{6} \mathrm{H}_{4}, p-\mathrm{HO}_{2} \mathrm{CC}_{6} \mathrm{H}_{4}, p-\mathrm{HOC}_{6} \mathrm{H}_{4}, m-\mathrm{HOC}_{6} \mathrm{H}_{4}, o-\mathrm{HOC}_{6} \mathrm{H}_{4}$, $p-\left(\mathrm{NH}_{2}\right) \mathrm{C}_{6} \mathrm{H}_{4}, p-\mathrm{NCC}_{6} \mathrm{H}_{4}, p-\mathrm{FC}_{6} \mathrm{H}_{4}, p-\mathrm{BrC}_{6} \mathrm{H}_{4}$, ferrocenyl,<smiles>[Y]c1cc2ccccc2o1</smiles>

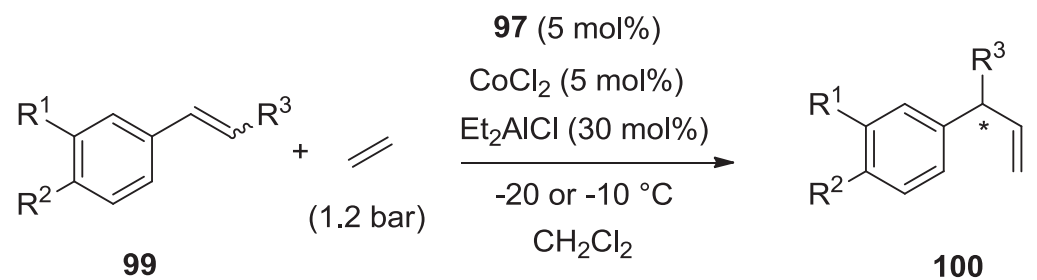

$74-96 \%$ yield, $16-84 \%$ ee

$$
\begin{aligned}
& \mathrm{R}^{1}=\mathrm{H}, \mathrm{OMe} \\
& \mathrm{R}^{2}=\mathrm{OMe}, n-\mathrm{Bu} \\
& \mathrm{R}^{3}=\mathrm{Me}, i-\mathrm{Pr}
\end{aligned}
$$

Scheme 33. Hydrovinylations of vinylarenes and $\beta$-alkyl-styrenes [65]. 
and co-workers in 1989 to promote the highly enantioselective 1,4-reduction with this reductant [51], no application to the 1,2reduction version was reported until 1995, when the group of Mukaiyama reported the first enantioselective borohydride 1,2reduction of ketones catalyzed by chiral cobalt complexes [52]. Although aryl ketones and sterically hindered aliphatic ketones were successfully reduced to afford the corresponding alcohols with enantioselectivities of up to $99 \%$ ee, the chiral ligands were limited in the semi-corrin structure for a long time. However in 2015, Lu and co-workers demonstrated that cobalt complex 83 derived from a chiral iminopyridine oxazoline ligand could promote highly enantioselective hydroboration of aryl ketones with HBPin under mild conditions [53]. As shown in Scheme 28, the reaction of a range of aryl ketones $\mathbf{7 1}$ in the presence of $2.5 \mathrm{~mol} \%$ of catalyst $\mathbf{8 3}$ and $\mathrm{NaBHEt}_{3}$ as reductant in diethylether at room temperature led to the corresponding alcohols $(R)-72$ in good to quantitative yields (71->99\%) and moderate to excellent enantioselectivities (63->99\% ee). In addition to aryl alkyl ketones, diaryl ones could also be hydroborated with up to $90 \%$ ee while dialkyl ketones provided the corresponding products in lower enantioselectivities (17-64\% ee).

\subsection{Hydrosilylation reactions}

The asymmetric 1,2-hydrosilylation of carbon-heteroatom bonds catalyzed by chiral transition metal complexes constitutes an alternative to the asymmetric hydrogenation owing to the mild conditions and practicability [54]. In the past two decades, a variety of chiral transition metal catalysts based on titanium, zinc, tin, copper and iron have been widely applied to promote asymmetric 1,2-hydrosilylation reactions with moderate to excellent enantioselectivities. However, the enantioselective cobalt-catalyzed

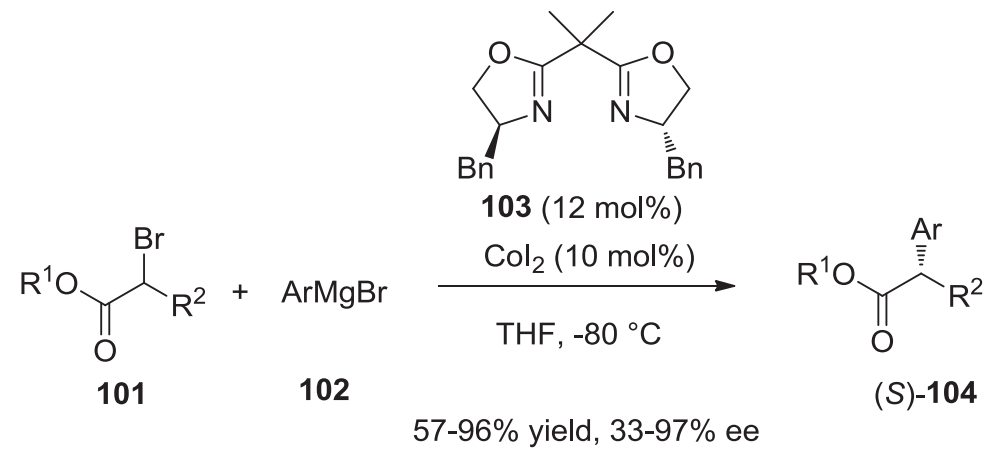

$\mathrm{Ar}=\mathrm{Ph}, p-\mathrm{MeOC}_{6} \mathrm{H}_{4}, p-\mathrm{Tol}, p-\mathrm{FC}_{6} \mathrm{H}_{4}, p-\mathrm{ClC}_{6} \mathrm{H}_{4}, p-\mathrm{PhC}_{6} \mathrm{H}_{4}, p-\mathrm{EtO}_{2} \mathrm{CC}_{6} \mathrm{H}_{4}, m-\mathrm{MeOC}_{6} \mathrm{H}_{4}$, $m-\mathrm{ClC}_{6} \mathrm{H}_{4}, m-\mathrm{F}_{3} \mathrm{CC}_{6} \mathrm{H}_{4}, 3,4-\mathrm{F}_{2} \mathrm{C}_{6} \mathrm{H}_{3}, m-\mathrm{BnOC}_{6} \mathrm{H}_{4}$, 2-Naph, 7-MeO-2-Naph,

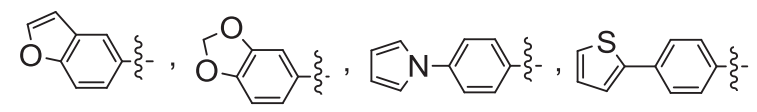

$\mathrm{R}^{1}=\mathrm{Bn}$, Et, Me, $i-\mathrm{Pr}, t-\mathrm{Bu}, \mathrm{Ph}, c-\mathrm{Pent}, \mathrm{Cy}, \mathrm{CyCH}_{2}, \mathrm{Br}\left(\mathrm{CH}_{2}\right)_{2},(\mathrm{Me})_{2} \mathrm{C}=\mathrm{CHCH}_{2}$

$\mathrm{R}^{2}=\mathrm{Me}, \mathrm{Et}, i-\mathrm{Pr}, n-\mathrm{Bu}, i-\mathrm{Bu}, c-\mathrm{Pent}, \mathrm{Br}\left(\mathrm{CH}_{2}\right)_{2}, \mathrm{Cl}\left(\mathrm{CH}_{2}\right)_{2}$, allyl, $\mathrm{Bn}, \mathrm{BnO} \mathrm{C}_{2} \mathrm{C}\left(\mathrm{CH}_{2}\right)_{2}$,

2-furyl- $\left(\mathrm{CH}_{2}\right)_{3}$, 2-thienyl- $\left(\mathrm{CH}_{2}\right)_{3},\left(\mathrm{Et}_{2} \mathrm{~N}\right) \mathrm{OC}\left(\mathrm{CH}_{2}\right)_{4}, \mathrm{Ph}_{2}(t-\mathrm{Bu}) \mathrm{OSi}\left(\mathrm{CH}_{2}\right)_{3}$

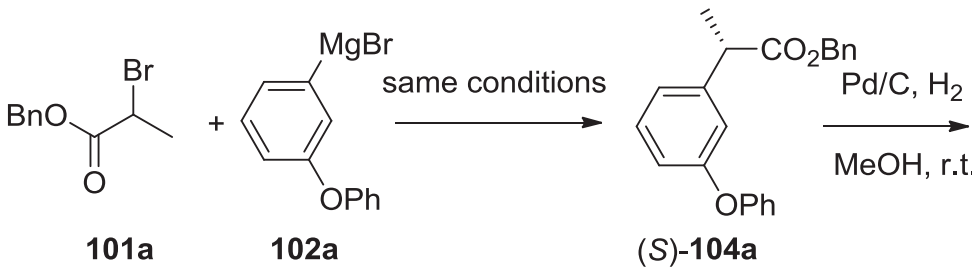

$87 \%$ yield, $93 \%$ ee<smiles>C[C@H](C(=O)O)c1cccc(Oc2ccccc2)c1</smiles>

(S)-fenoprofen

$81 \%$ yield, $92 \%$ ee

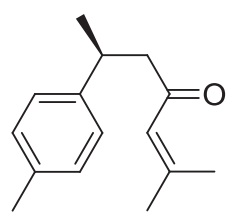

(S)-ar-turmerone<smiles>C[C+]([O+][Na])C(=O)OCc1ccccc1</smiles>

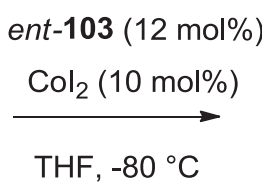

$(R)-104 \mathrm{~b}$

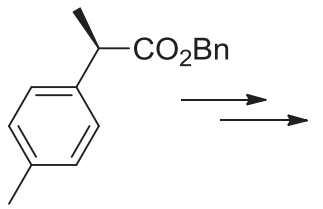

$88 \%$ yield, $93 \%$ ee 

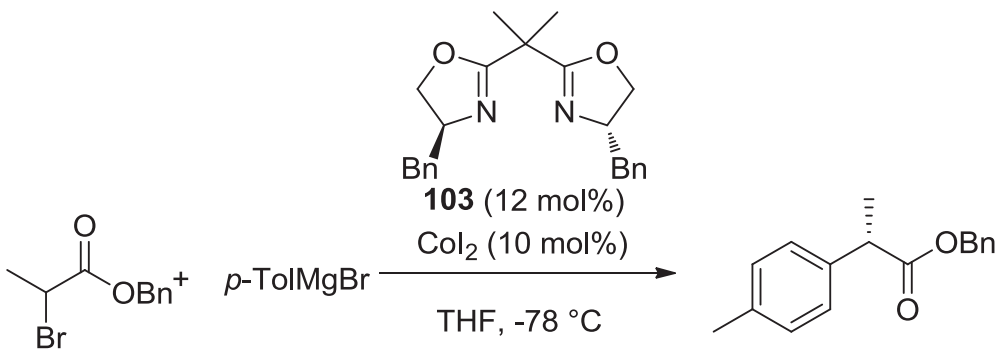

$101 \mathrm{a}$

$102 b$

$(S)-104 b$

$88 \%$ yield, $92 \%$ ee<smiles>C=CC=Cc1ccc([C@@H](C)CCC=C(C)C)cc1</smiles>

(R)-ar-curcumene

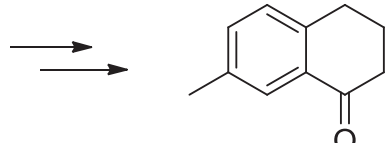

(R)-4,7-dimethyl-1-tetralone

Scheme 35. Synthesis of (R)-ar-curcumene and (R)-4,7-dimethyl-1-tetralone [68].

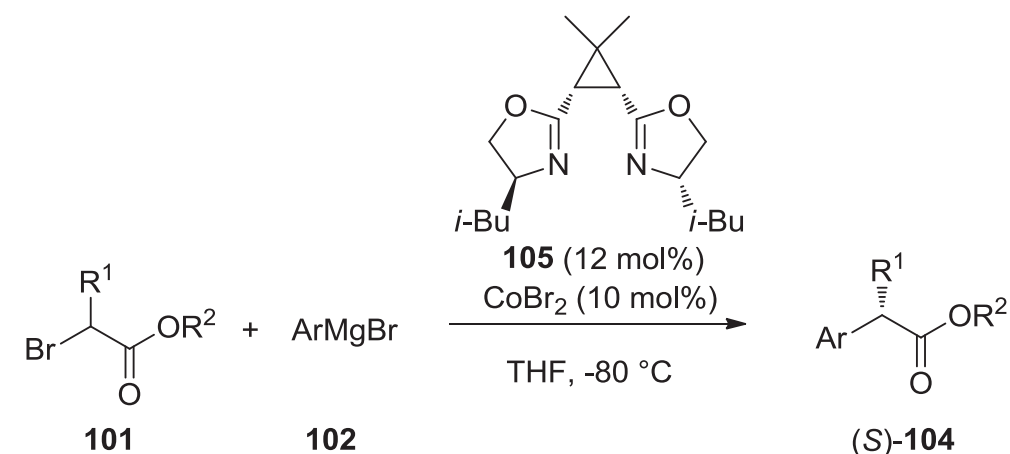

$79-93 \%$ yield, $56-84 \%$ ee

$\mathrm{Ar}=\mathrm{Ph}, p-i-\mathrm{BuC}_{6} \mathrm{H}_{4}, p-\mathrm{Tol}, p-\mathrm{FC}_{6} \mathrm{H}_{4}, p-\mathrm{ClC}_{6} \mathrm{H}_{4}, m-\mathrm{MeOC}_{6} \mathrm{H}_{4}$

$\mathrm{R}^{1}=\mathrm{Me}, \mathrm{Et}, n-\mathrm{Bu}, \mathrm{Bn}, \mathrm{Cl}\left(\mathrm{CH}_{2}\right)_{2}$

$\mathrm{R}^{2}=\mathrm{Bn}, \mathrm{Me}, \mathrm{Et}, i-\mathrm{Pr}, t-\mathrm{Bu}, c-\mathrm{Pent}, \mathrm{Cy}, \mathrm{CyCH}_{2}$, isopentenyl,

$\mathrm{Ph}, p$-Tol, $p-\mathrm{ClC}_{6} \mathrm{H}_{4}, m-\mathrm{FC}_{6} \mathrm{H}_{4}$<smiles>CC(Br)C(=O)OCc1ccccc1</smiles>

$101 \mathrm{a}$<smiles></smiles>

same conditions

(S)-104c<smiles>C[C@H](C(=O)O)c1ccc(C(C)(C)C)cc1</smiles>

(S)-ibuprofen

$98 \%$ ee

Scheme 36. Kumada cross-coupling reactions of $\alpha$-bromo esters with aryl Grignard reagents and synthesis of (S)-ibuprofen [69]. 
hydrosilylation of ketones has received relatively moderate attention, since the pioneering works reported in 1991 by Brunner and Amberger [55]. In 2016, Lu and Chen reported enantioselectivities of up to $>99 \%$ ee in the enantioselective hydrosilylation of simple aryl alkyl ketones $\mathbf{7 1}$ promoted by a chiral cobalt catalyst in situ generated from $\mathrm{CoCl}_{2}$ and novel chiral iminophenyl oxazolinylphenylamine ligand $\mathbf{8 4}$ in dichloromethane at room temperature (Scheme 29) [56]. The reaction involved (EtO) ${ }_{3} \mathrm{SiH}$ as a reductant and $\mathrm{NaBHEt}_{3}$ as an activating agent of the precatalyst. It led to a range of optically active aromatic alcohols $(R)-72$ in high to quantitative yields (71-98\%) and uniformly excellent enantioselectivities (90->99\% ee). Notably, in most cases, very low catalyst loadings were employed since only $0.5 \mathrm{~mol} \%$ of $\mathrm{CoCl}_{2}$ combined with $0.8 \mathrm{~mol} \%$ of ligand $\mathbf{8 4}$ were sufficient to achieve excellent results.

Recently, the same authors developed an enantioselective Markovnikov-type hydrosilylation of alkenes with $\mathrm{PhSiH}_{3}$ to provide the corresponding chiral dihydrosilanes [57]. The process was promoted at room temperature by $1 \mathrm{~mol} \%$ of cobalt complex 85 derived from a chiral iminopyridine oxazoline ligand in the presence of $\mathrm{NaOt}$ - $\mathrm{Bu}$ in diethylether as solvent. It was suitable to a wide range of both aryl and aliphatic alkenes $\mathbf{8 6}$ with excellent functional group tolerability, allowing a variety of chiral dihydrosilanes 87 to be synthesized with moderate to high yields (53-97\%)

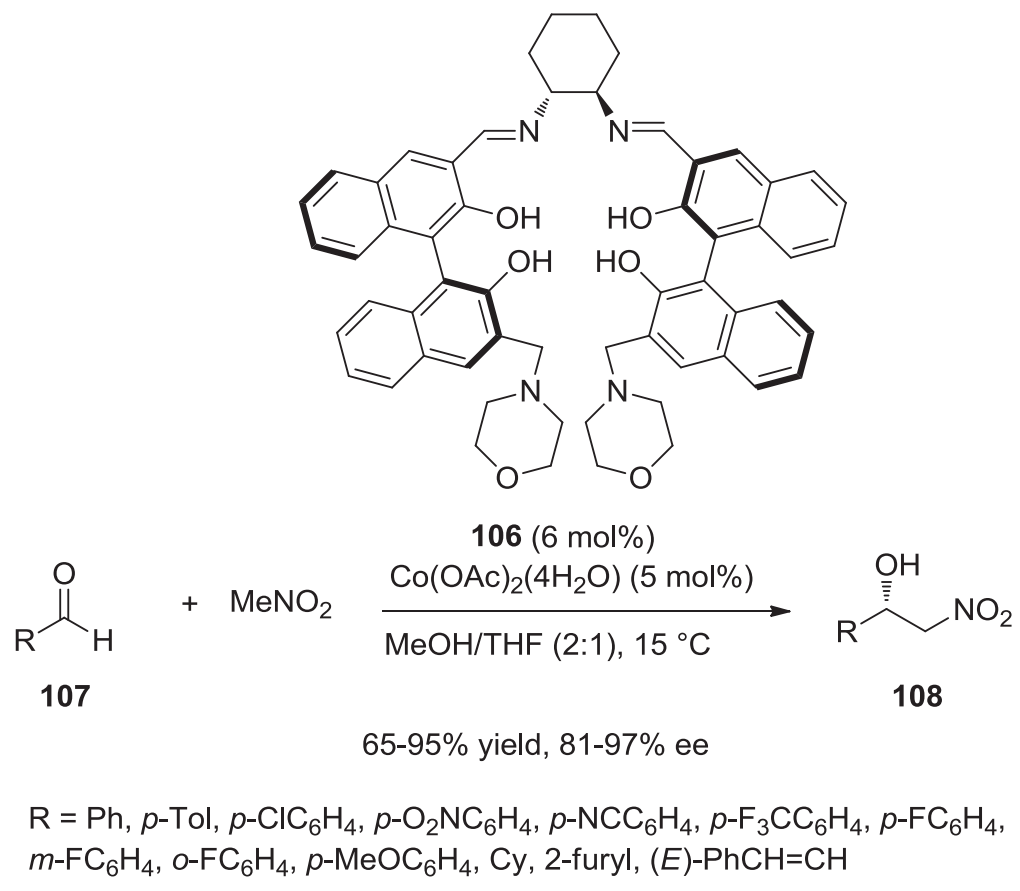

Scheme 37. Henry reaction of aldehydes with nitromethane [71].

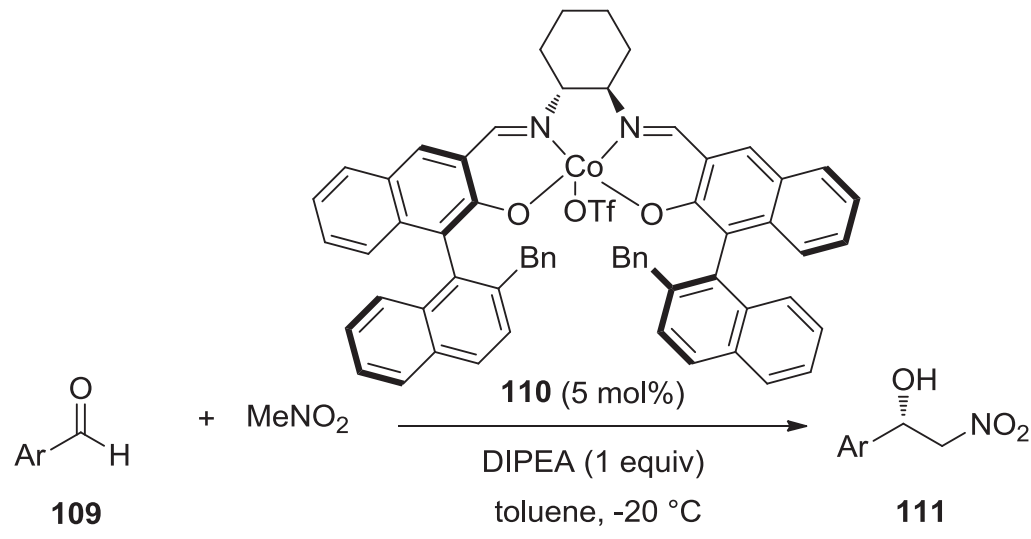

$48-99 \%$ yield, $70-98 \%$ ee

$\mathrm{Ar}=\mathrm{Ph}, o-\mathrm{MeOC}_{6} \mathrm{H}_{4}, m-\mathrm{MeOC}_{6} \mathrm{H}_{4}, o-\mathrm{FC}_{6} \mathrm{H}_{4}, m-\mathrm{FC}_{6} \mathrm{H}_{4}, p-\mathrm{FC}_{6} \mathrm{H}_{4}, o-\mathrm{BrC}_{6} \mathrm{H}_{4}$, $m-\mathrm{BrC}_{6} \mathrm{H}_{4}, p-\mathrm{BrC}_{6} \mathrm{H}_{4}, o-\mathrm{ClC}_{6} \mathrm{H}_{4}, p-\mathrm{ClC}_{6} \mathrm{H}_{4}, o-\mathrm{O}_{2} \mathrm{NC}_{6} \mathrm{H}_{4}, m-\mathrm{O}_{2} \mathrm{NC}_{6} \mathrm{H}_{4}, p-\mathrm{O}_{2} \mathrm{NC}_{6} \mathrm{H}_{4}$, $p-\mathrm{NCC}_{6} \mathrm{H}_{4}, p-\mathrm{PhC}_{6} \mathrm{H}_{4}$, 2-Naph, 2,6- $\mathrm{Cl}_{2} \mathrm{C}_{6} \mathrm{H}_{3}, 2,4-\mathrm{Cl}_{2} \mathrm{C}_{6} \mathrm{H}_{3}$ 
and high enantioselectivities (81->99\% ee), as illustrated in Scheme 30. Especially, uniformly remarkable enantioselectivities (98->99\% ee) were achieved in the reaction of vinylarenes while aliphatic alkenes led to the corresponding products in lower enantioselectivities (81-87\% ee) and yields (53-91\% vs 62-94\%). Moreover, using the opposite enantiomeric ligand, the authors obtained the opposite enantiomers of silanes.

\subsection{Hydrovinylation reactions}

The transition-metal-catalyzed codimerization of ethylene with alkenes, called hydrovinylation reaction, is the addition of the elements of ethylene across the double bond of a second alkene [58]. In most cases, this process is catalyzed by nickel or palladium complexes of monodentate ligands [59] while only moderate success has been generally reported in the first cobalt-catalyzed hydrovinylation reactions [60]. However in 2001, Hilt et al. reported a highly efficient cobalt-catalyzed hydroalkenylation reaction between 1,3-dienes and terminal alkenes [61]. Inspired by this work, Vogt and co-workers further explored the asymmetric cobalt-catalyzed hydrovinylation of styrene with ethylene, providing the corresponding chiral 3-phenyl-1-butene [62]. The activation of [ $\mathrm{CoX}_{2}$ (phosphine)] complexes by alkylating agents, especially $\mathrm{Et}_{2} \mathrm{AlCl}$, afforded very active catalysts with unprecedented high selectivity for the formation of the expected codimer. Indeed, this product was obtained with more than $99 \%$ selectivity without trace of double bond isomerization. Following this lead, RajanBabu and co-workers recently developed a highly enantioselective hydrovinylation of acyclic 1,3-dienes promoted by $10 \mathrm{~mol} \%$ of cobalt catalyst $\mathbf{8 8}$ derived from $(R, R)$-DIOP ligand [63]. The reaction of various acyclic $(E)-1,3$-dienes $\mathbf{8 9}$ with ethylene (1 atm) was performed in the presence of $\mathrm{AlMe}_{3}$ or methylaluminoxane as additive in dichloromethane at -45 or $-20^{\circ} \mathrm{C}$, providing regioselectively the corresponding chiral 1,4-hydrovinylation products 90 bearing a $Z$-internal alkene (Scheme 31 ). These products were obtained in moderate to quantitative yields (40->98\%) combined with uniformly very high enantioselectivities (95-96\% ee). The opposite enantiomers $\mathbf{9 1}$ could be synthesized under comparable reaction conditions by using $(S, S)$-DIOP as cobalt ligand in good to high enantioselectivities (74-94\% ee) and with comparable yields (46-99\%), as illustrated in Scheme 31.

Chiral trialkylsilyl enol ethers constitute versatile intermediates for the synthesis of optically active carbonyl compounds. Nevertheless, there are still few reports of broadly applicable catalytic methods for their synthesis. In 2015, RajanBabu and co-workers developed a general catalytic procedure for highly chemo-, regioand enantioselective synthesis of trialkylsilyl enol ethers exhibiting a vinyl-bearing chiral center at the $\beta$-position [64]. The reactions were performed at room temperature in dichloromethane in the presence of $5 \mathrm{~mol} \%$ of cobalt catalyst ent-88 derived from $(S, S)$-DIOP ligand and two equivalents of methylaluminoxane. As shown in Scheme 32, the reaction of various 1,3-siloxydienes 92

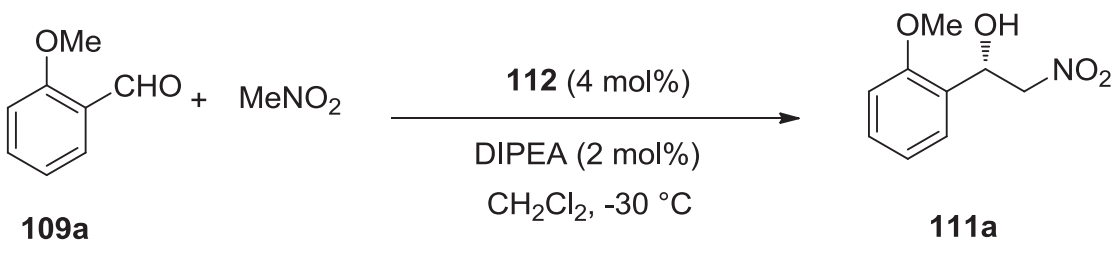

$91 \%$ yield, $89 \%$ ee

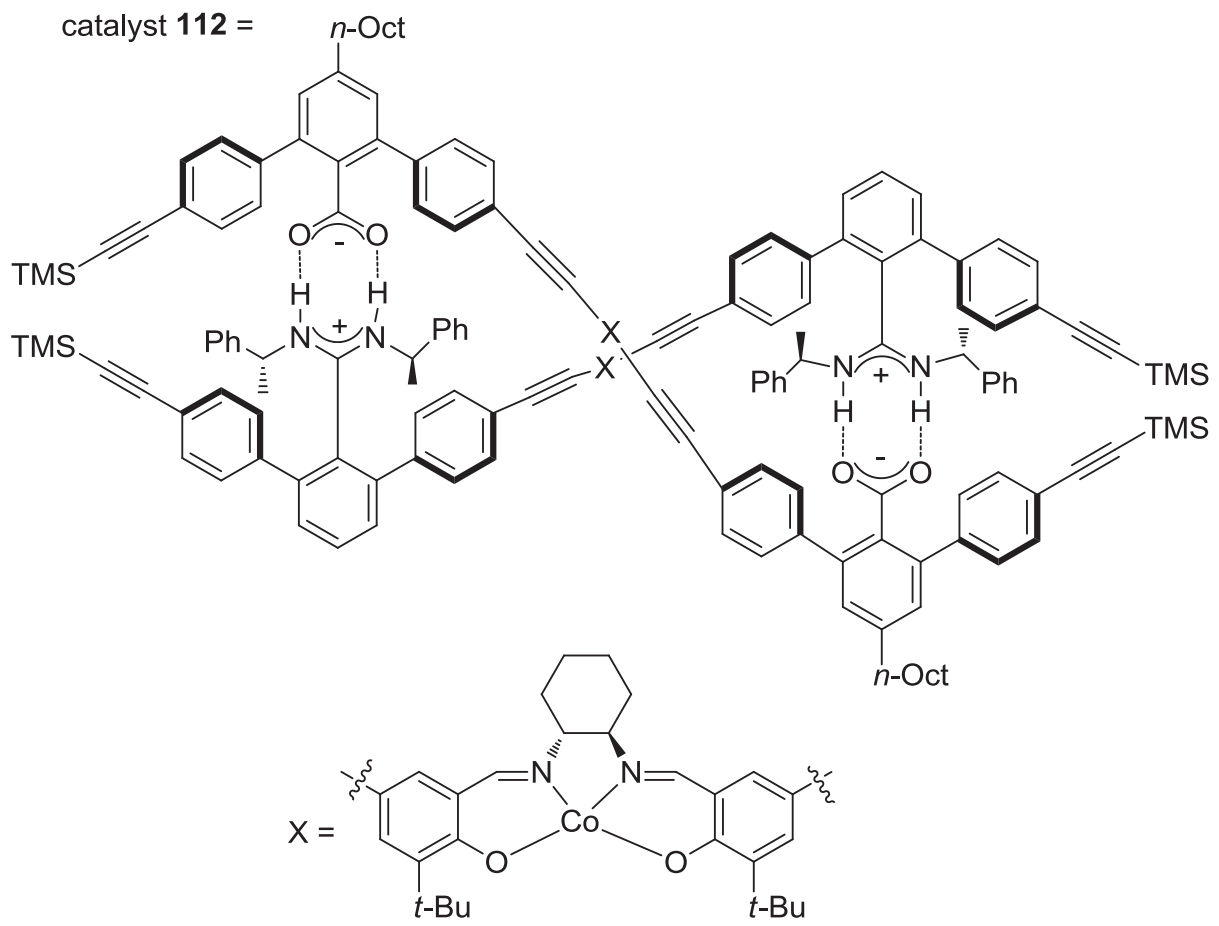

Scheme 39. Henry reaction of o-methoxybenzaldehyde with nitromethane [73]. 
with ethylene (1 atm) led regioselectively to the corresponding branched 1,4-hydrovinylation chiral products 93 in both remarkable yields ( $>90-96 \%$ ) and enantioselectivities ( $>95-98 \%$ ee). These reactions were also promoted by cobalt catalyst 94 derived from another chiral bisphosphine such as $(S, S)$-BDPP, providing the opposite enantiomers 95 in comparable yields (88->95\%) and good to excellent enantioselectivities ( $80->95 \%$ ee), as shown in Scheme 32.

In 2016, Schmalz and co-workers reported an efficient and practical protocol for the enantioselective cobalt-catalyzed hydrovinylation of vinylarenes 96 with ethylene at low pressure (1.2 bar) [65]. The reactions were performed in dichloromethane by using $5 \mathrm{~mol} \%$ of a chiral cobalt catalyst in situ generated from $\mathrm{CoCl}_{2}$ and a TADDOL-derived phosphine-phosphite ligand $\mathbf{9 7}$ in the presence of $30 \mathrm{~mol} \%$ of $\mathrm{Et}_{2} \mathrm{AlCl}$ as activating agent. It led regioselectively to a wide range of chiral branched products 98 in high yields (76-99\%) and moderate to excellent enantioselectivities (44-99\% ee), as shown in Scheme 33. Related reaction conditions were applied to the asymmetric hydrovinylation of $\beta$-alkylstyrenes 99 which regioselectively provided the corresponding 1,4-hydrovinylation chiral products $\mathbf{1 0 0}$ in good to high yields (74-96\%) and low to good enantioselectivities (16-84\% ee), as shown in Scheme 33. In both types of substrates, vinylarenes and $\beta$-alkyl-styrenes, an almost complete regioselectivity was observed $(\geq 98: 2)$.

\subsection{Cross-coupling reactions}

Metal-catalyzed coupling reactions are very efficient transformations for the elaboration of carbon-carbon bonds [66]. Among them, is the catalytic cross-coupling reaction of Grignard reagents with organic electrophiles also called the Kumada coupling [45b]. In spite of recent improvements in this methodology based on the use of more active catalyst systems based on nickel, palladium, cobalt, copper and iron, very few enantioselective versions allowed chiral products to be achieved in useful levels of enantioselectivity. The first highly enantioselective cobaltcatalyzed Kumada cross-coupling reaction was reported by Zhong and co-workers, in 2014 [67]. It occurred between $\alpha$-bromo esters 101 and aryl Grignard reagents 102 in THF at $-80{ }^{\circ} \mathrm{C}$ in the presence of a combination of $10 \mathrm{~mol} \%$ of $\mathrm{CoI}_{2}$ and $12 \mathrm{~mol} \%$ of bisoxazoline 103 as chiral ligand. It afforded a wide variety of chiral $\alpha$-arylalkanoic esters $(S)$-104 in moderate to excellent yields (57-96\%) and enantioselectivities (33-97\% ee), as illustrated in Scheme 34. The synthetic utility of this novel procedure was shown by its application to the total synthesis of nonsteroidal anti-inflammatory drugs, such as (S)-fenoprofen and (S)-arturmerone, the latter by using ent-103 as ligand.

Later, this methodology was also applied by Bian and coworkers to an efficient and concise synthesis of two naturally occurring and biologically active products, such as $(R)$-arcurcumene and (R)-4,7-dimethyl-1-tetralone (Scheme 35) [68]. Indeed, the key step of the synthesis was the cobalt-catalyzed Kumada cross-coupling of $\alpha$-bromo ester 101a with $p$ tolylmagnesium bromide $\mathbf{1 0 2 b}$ performed in the presence of chiral ligand $\mathbf{1 0 3}$ under the same reaction conditions as those described in Scheme 34, leading to the corresponding chiral benzyl ester $(S)-104 b$ in both high yield (88\%) and enantioselectivity (92\% ee). This product was subsequently converted into $(R)$-ar-curcumene through seven supplementary steps and (R)-4,7-dimethyl-1tetralone through eight supplementary steps.

Later, Zhong and co-workers described the synthesis of novel chiral cyclopropane-based bisoxazolines to be investigated in enantioselective Kumada cross-couplings of $\alpha$-bromo esters 101 with aryl Grignard reagents 102 [69]. Among them, ligand 105 was selected as optimal ligand, providing when combined at<smiles>[R]c1c([R])c([R])c2c(c1[R])C1C=CC2O1</smiles><smiles>[B-]CC=C</smiles>

114<smiles>[R]c1c([R])c([R])c2c(c1[R])C=C[C@@H](CC=C)[C@H]2O</smiles>

$66-90 \%$ yield, $94->98 \%$ ee

$$
\begin{aligned}
& \mathrm{R}^{1}=\mathrm{H}, \mathrm{Me}, \mathrm{Br}, \mathrm{F}, \mathrm{CN} \\
& \mathrm{R}^{2}=\mathrm{H}, \text { OMe, OBn, Oallyl }
\end{aligned}
$$<smiles>CCOC(=O)C1=C(C(=O)OCC)[C@H]2C=C[C@H]1O2</smiles>
116<smiles>C=CC[Bi]</smiles><smiles>C=CC[C@@H]1C=CC(C(=O)OCC)=C(COCC)[C@H]1O</smiles>

117

$74 \%, 98 \%$ ee 
$12 \mathrm{~mol} \%$ of catalyst loading with $10 \mathrm{~mol} \%$ of $\mathrm{CoBr}_{2}$ in THF at $-80{ }^{\circ} \mathrm{C}$ the corresponding chiral esters $(S)-\mathbf{1 0 4}$ in moderate to high yields (79-93\%) and moderate to good enantioselectivities (56-84\% ee), as shown in Scheme 36. To demonstrate the utility of this methodology, the anti-inflammatory drug (S)-ibuprofen was prepared with $98 \%$ ee starting from substrates 101a and 102c (Scheme 36).

\subsection{Henry reactions}

The Henry reaction or nitro-aldol reaction is one of the most convenient reactions for direct carbon-carbon bond formation to prepare $\beta$-hydroxy-nitroalkanes from aldehydes and nitroalkanes. Since the first catalytic enantioselective version of this reaction reported by Shibasaki and co-workers in 1992 based on the use of heterobimetallic lanthanide BINOL catalyst systems [70], various other catalytic systems have been successfully developed. For example, Wang and co-workers have reported the synthesis of novel $C_{2}$-symmetric salen ligands bearing morpholine functional group based on a BINOL framework to be investigated in enantioselective cobalt-catalyzed Henry reaction of aldehydes with nitromethane [71]. Among them, ligand 106 was selected as optimal one when used at $6 \mathrm{~mol} \%$ of catalyst loading in a $2: 1$ mixture of methanol/THF at $15{ }^{\circ} \mathrm{C}$ in combination with $5 \mathrm{~mol} \%$ of $\mathrm{Co}(\mathrm{OAc})_{2}(4-$ $\mathrm{H}_{2} \mathrm{O}$ ). Under these conditions, nitromethane reacted with a range of aromatic as well as aliphatic aldehydes $\mathbf{1 0 7}$ to give the corresponding chiral Henry products $\mathbf{1 0 8}$ in moderate to excellent yields (65-95\%) and high enantioselectivities (81-97\% ee), as shown in Scheme 37. Changing the Lewis acid from cobalt to ytterbium resulted in decreasing the enantioselectivities (10-87\% ee).

The Henry reaction of aromatic aldehydes 109 with nitromethane was also investigated by $\mathrm{Xu}$ and co-workers by using a novel type of chiral salen cobalt catalysts such as $\mathbf{1 1 0}$ [72]. As shown in Scheme 38, the reaction was performed in toluene at $-20{ }^{\circ} \mathrm{C}$ in the presence of DIPEA as base and $5 \mathrm{~mol} \%$ of catalyst<smiles>[R]C(=O)C=C([R])[R20]</smiles>

119

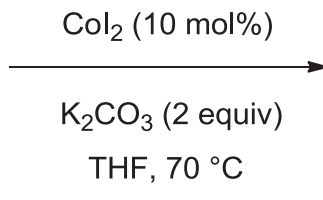

$30-75 \%$ yield, $78-92 \%$ ee<smiles>[R]C([R])=CC([R])(O)C([R20])[R]</smiles>

120

$\mathrm{R}^{1}=\mathrm{Et}, \mathrm{Bn}, \mathrm{Me}$

$\mathrm{R}^{2}=\mathrm{Me}, \mathrm{CH}_{2} \mathrm{Bn}, \mathrm{H},(E)-\mathrm{PhCH}=\mathrm{CH}$

$\mathrm{R}^{3}=\mathrm{Ph}, p-\mathrm{FC}_{6} \mathrm{H}_{4}, p-\mathrm{MeOC}_{6} \mathrm{H}_{4}, \mathrm{Me}$

$\mathrm{R}^{4}=\mathrm{H}, \mathrm{Me}$<smiles>[R]C(=O)C([R20])=O</smiles>

118<smiles>[R]C=C[Hg]</smiles>

$119 a-e$<smiles>CC(C)(C)P1Cc2ccccc2[C@H]1[C@H]1c2ccccc2CP1C(C)(C)C</smiles>

$\left(R, R^{\prime}, S, S^{\prime}\right)$-DuanPhos (12 mol\%)

$$
\mathrm{Col}_{2}(10 \mathrm{~mol} \%)
$$

$\mathrm{K}_{2} \mathrm{CO}_{3}$ (2 equiv)

$\mathrm{THF}, 70^{\circ} \mathrm{C}$

$40-75 \%$ yield, $84-95 \%$ ee<smiles>[R]C=CC([R])(O)C([R20])[R]</smiles>

121

$\mathrm{R}^{1}=\mathrm{Me}, \mathrm{Et}$

$\mathrm{R}^{2}=(E)-\mathrm{PhCH}=\mathrm{CH},(E)-\left(m-\mathrm{ClC}_{6} \mathrm{H}_{4}\right) \mathrm{CH}=\mathrm{CH},(E)-\left(p-\mathrm{NCC}_{6} \mathrm{H}_{4}\right) \mathrm{CH}=\mathrm{CH}$,

$(E)-(p-\mathrm{Tol}) \mathrm{CH}=\mathrm{CH},(E)-\left(p-\mathrm{F}_{3} \mathrm{CC}_{6} \mathrm{H}_{4}\right) \mathrm{CH}=\mathrm{CH},(E)-\left(p-\mathrm{BrC}_{6} \mathrm{H}_{4}\right) \mathrm{CH}=\mathrm{CH}$,

$(E)-\left(p-\mathrm{FC}_{6} \mathrm{H}_{4}\right) \mathrm{CH}=\mathrm{CH},(E)-\left(p-\mathrm{ClC}_{6} \mathrm{H}_{4}\right) \mathrm{CH}=\mathrm{CH},(E, E)-\mathrm{PhCH}=\mathrm{CH}-\mathrm{CH}=\mathrm{CH}$,<smiles></smiles>

$\mathrm{R}^{3}=\mathrm{Ph}, p-\mathrm{MeOC}_{6} \mathrm{H}_{4}, p-\mathrm{ClC}_{6} \mathrm{H}_{4}, \mathrm{Me}, p-\mathrm{FC}_{6} \mathrm{H}_{4}$

Scheme 41. Vinylations of $\alpha$-ketoesters [75]. 
110. Under these conditions, a wide variety of chiral aromatic alcohols 111 were obtained in moderate to quantitative yields (4899\%) and moderate to excellent enantioselectivities (70-98\% ee). Better yields and enantioselectivities were achieved for aromatic aldehydes functionalized in the ortho-position of the phenyl ring. This result could suggest that the selective recognition to orthosubstituted benzaldehydes was ascribed to the difference in the molecular size of aromatic aldehydes and possible aromatic-aromatic interaction between the phenyl rings of the ligand and the aromatic ring of aldehydes.

In 2016, Yashima and co-workers reported the synthesis of a novel double-helical bimetallic cobalt salen complex 112 stabilized by chiral amidinium-carboxylate salt bridges to catalyze the asymmetric Henry reaction of o-methoxybenzaldehyde 109a and nitromethane [73]. As shown in Scheme 39, the corresponding Henry product 111a was obtained in both high yield (91\%) and enantios- electivity ( $89 \%$ ee) when the reaction was performed with 4 mol\% of this catalyst in dichloromethane at $-30^{\circ} \mathrm{C}$ in the presence of DIPEA as base. The reactivity and enantioselectivity of the reaction were higher than those catalyzed by the corresponding single strands, showing the key role of the chiral double-helical framework for the supramolecular bimetallic catalysis.

\subsection{Miscellaneous reactions}

In 2015, Zhao and co-workers reported the first enantioselective cobalt-catalyzed allylation of heterobicyclic alkenes, which used potassium allyltrifluoroborate as the allylating agent [74]. Among a series of chiral bisphosphines investigated as cobalt ligands, $(S$, $S$ )-BDPP was found optimal ligand in combination with $\mathrm{CoCl}_{2}$. As shown in Scheme 40, the reaction of various heterobicyclic alkenes $\mathbf{1 1 3}$ with potassium allyltrifluoroborate $\mathbf{1 1 4}$ performed in a 1:1<smiles>[R]c1cc([R2])c2c(c1)C(=O)C(=O)N2</smiles>

122

$+$<smiles>[R]C([R])=C[Hg]O</smiles>

$\left(R, R^{\prime}, S, S^{\prime}\right)$-DuanPhos (12 mol\%)

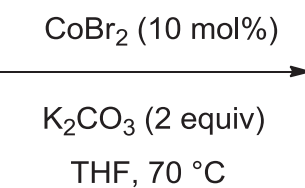<smiles>[R]C([R])=C[C@]1(O)C(=O)Nc2c([R])cc([R1])cc21</smiles>

119

$50-90 \%$ yield, $84-94 \%$ ee

$\mathrm{R}^{1}=\mathrm{H}, \mathrm{Me}, \mathrm{OMe}, \mathrm{I}, \mathrm{Cl}, \mathrm{OCF}_{3}$

$\mathrm{R}^{2}=\mathrm{H}, \mathrm{C}$

$\mathrm{R}^{3}=\mathrm{Ph}, p-\mathrm{ClC}_{6} \mathrm{H}_{4}, p-\mathrm{FC}_{6} \mathrm{H}_{4}, p-\mathrm{Tol}, \mathrm{Me}$

$\mathrm{R}^{4}=\mathrm{H}, \mathrm{Me}$

Scheme 42. Vinylation of isatins [75].<smiles>[R]c1cc2c(cc1[R])OS(=O)(=O)N=C2</smiles>

124<smiles>[R]C([R])=C[Hg]O</smiles>

119
$\left(R, R^{\prime}, S, S^{\prime}\right)$-DuanPhos (10 mol\%)

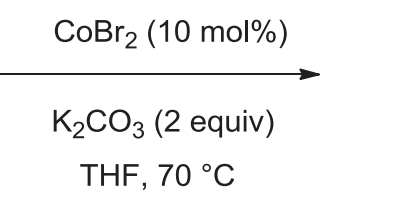<smiles>[R]C([R])=C[C@H]1NS(=O)(=O)Oc2cc([R2])c([R16])cc21</smiles>

$52-85 \%$ yield, $98->99 \%$ ee

$$
\begin{aligned}
& \mathrm{R}^{1}=\mathrm{H}, \mathrm{OMe}, \mathrm{Br}, \mathrm{Cl} \\
& \mathrm{R}^{2}=\mathrm{H}, \mathrm{Me} \\
& \mathrm{R}^{3}=\mathrm{Ph}, p-\mathrm{MeOC}_{6} \mathrm{H}_{4}, p-\mathrm{ClC}_{6} \mathrm{H}_{4}, p-\mathrm{Tol}, p-\mathrm{FC}_{6} \mathrm{H}_{4}, \mathrm{Me}, n-\mathrm{Pr} \\
& \mathrm{R}^{4}=\mathrm{H}, \mathrm{Me}
\end{aligned}
$$


mixture of THF and DCE at $70^{\circ} \mathrm{C}$ led to the corresponding ringopened chiral products $\mathbf{1 1 5}$ in moderate to quantitative yields (66-90\%) and uniformly excellent enantioselectivities (94->98\% ee). The extension of the scope of the reaction to less reactive non-benzofused substrates, such as $\mathbf{1 1 6}$, proved to be successful since product $\mathbf{1 1 7}$ was obtained in 74\% yield and 98\% ee (Scheme 40).

The same ligand was later applied by these authors to promote the first cobalt-catalyzed enantioselective vinylation of activated carbonyl compounds such as $\alpha$-ketoesters [75]. Indeed, when the

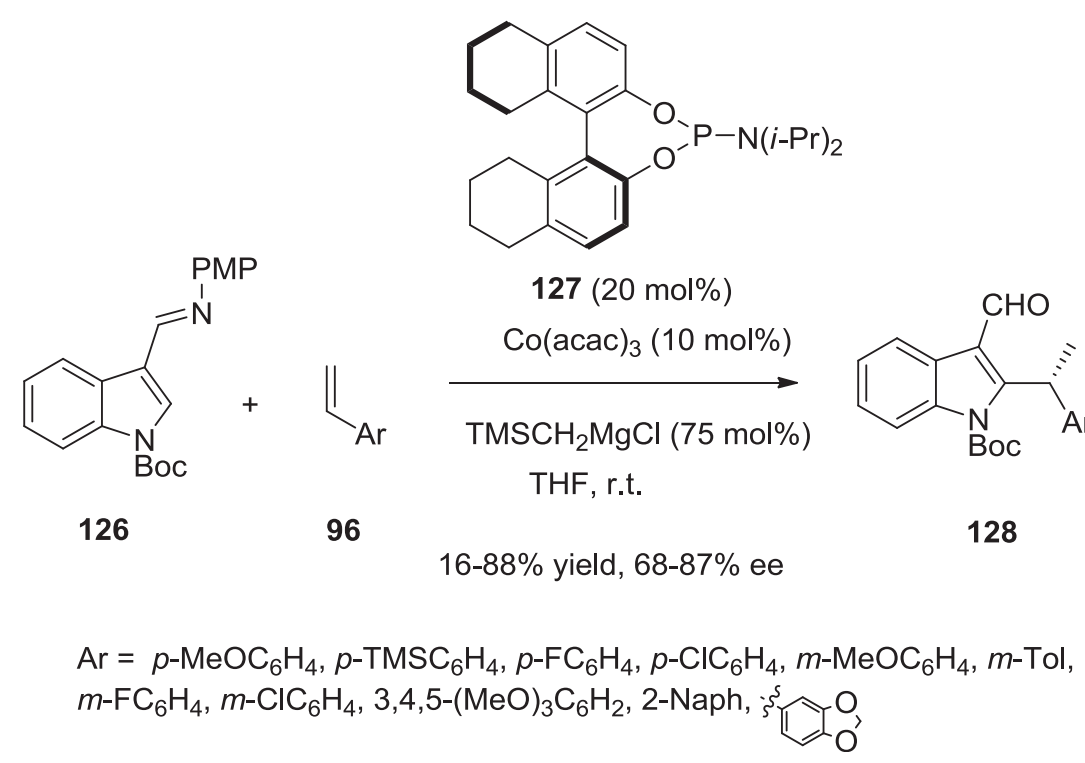

Scheme 44. C2-alkylation of indoles with aryl alkenes [76].
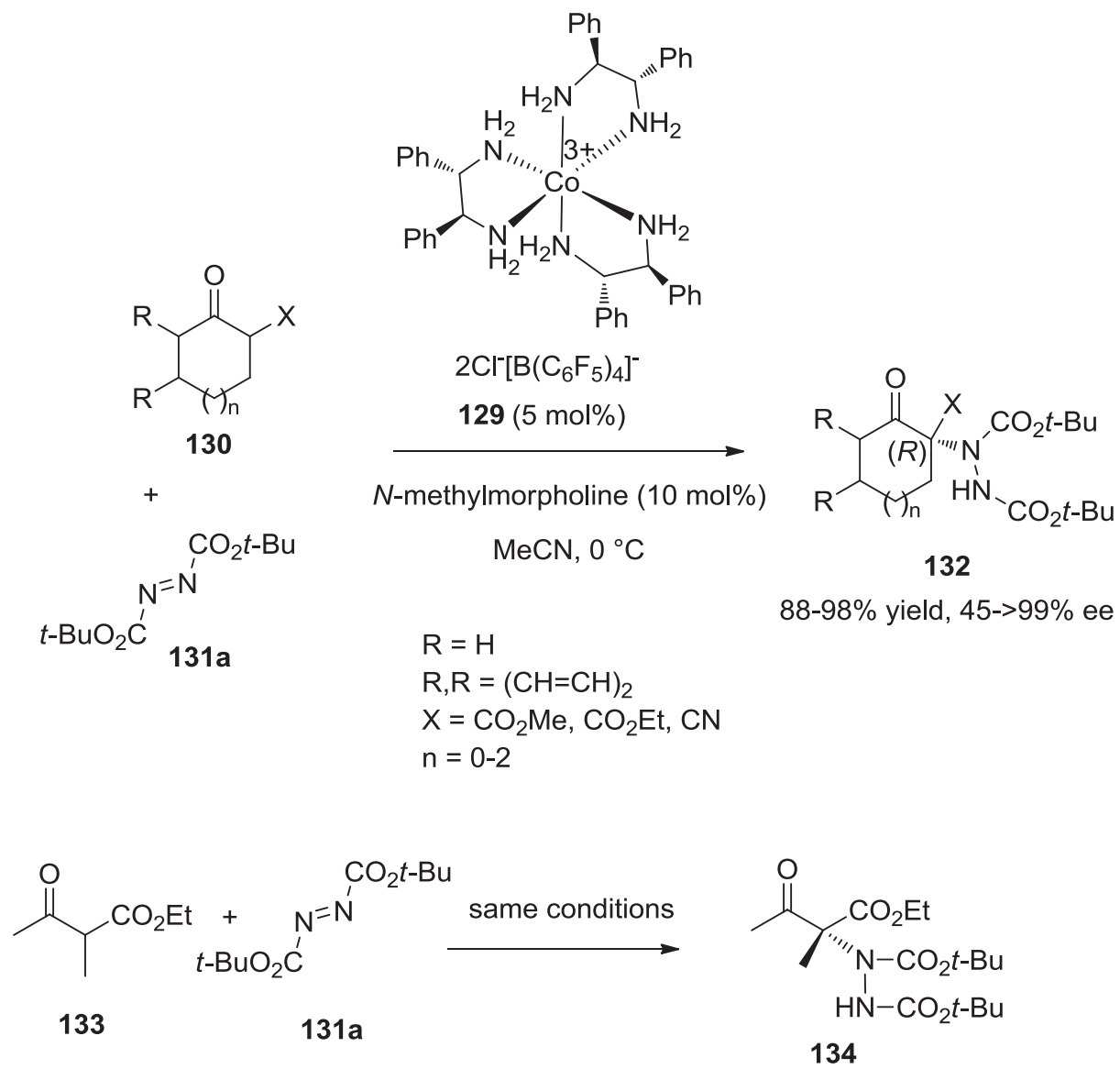

$98 \%$ yield, $>99 \%$ ee

Scheme 45. $\alpha$-Aminations of 1,3-dicarbonyl compounds and $\alpha$-cyanoketones [77]. 
reaction of $\alpha$-ketoesters 118 with vinyl boronic acids 119 was promoted by a combination of $12 \mathrm{~mol} \%$ of ligand (S,S)-BDPP and 10 mol\% of $\mathrm{CoI}_{2}$ in THF at $70^{\circ} \mathrm{C}$ in the presence of $\mathrm{K}_{2} \mathrm{CO}_{3}$ as base, it afforded the corresponding chiral tertiary allylic $\alpha$-hydroxy esters 120 in low to good yields (30-75\%) and good to high enantioselectivities (78-92\% ee), as illustrated in Scheme 41. When $\left(R, R^{\prime}, S, S^{\prime}\right)-$ DuanPhos was used as ligand instead of $(S, S)$-BDPP, the opposite enantiomers 121 were obtained under similar reaction conditions in moderate to good yields (40-75\%) and high enantioselectivities (84-95\% ee), as shown in Scheme 41. In Scheme 41: we can remove the structure of $(\mathrm{S}, \mathrm{S})$-BDPP since it is already drawn in previous scheme 40.

Moreover, $\left(R, R^{\prime}, S, S^{\prime}\right)$-DuanPhos was used in combination with $\mathrm{CoBr}_{2}$ as catalytic system to promote under the same reaction con- ditions the first enantioselective cobalt-catalyzed vinylation of isatins 122 [75]. As shown in Scheme 42, the addition of vinyl boronic acids 119 to variously substituted isatins 122 afforded the corresponding tertiary alcohols $\mathbf{1 2 3}$ in moderate to high yields (50$90 \%$ ) and high enantioselectivities (84-94\% ee). The utility of this novel methodology is related to the fact that chiral 3-alkenyl-3hydroxy oxindoles represent the core structure of a large number of biologically active entities.

The scope of the precedent methodology was extended to the first asymmetric cobalt-catalyzed vinylation of imines [75]. As illustrated in Scheme 43, when almost the same reaction conditions (10 mol\% of $\left(R, R^{\prime}, S, S^{\prime}\right)$-DuanPhos instead of $12 \mathrm{~mol} \%$ in Scheme 42) were applied to the reaction between imines, such as substituted benzoxathiazine-2,2-dioxides $\mathbf{1 2 4}$, with vinyl boronic

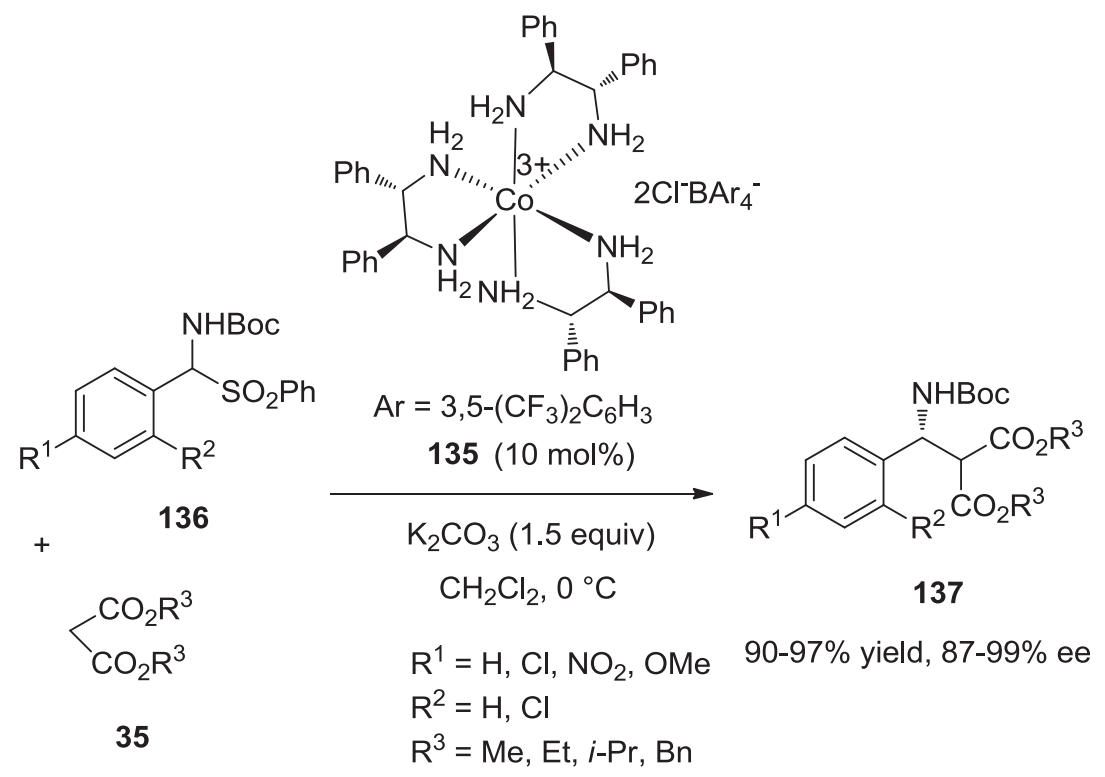

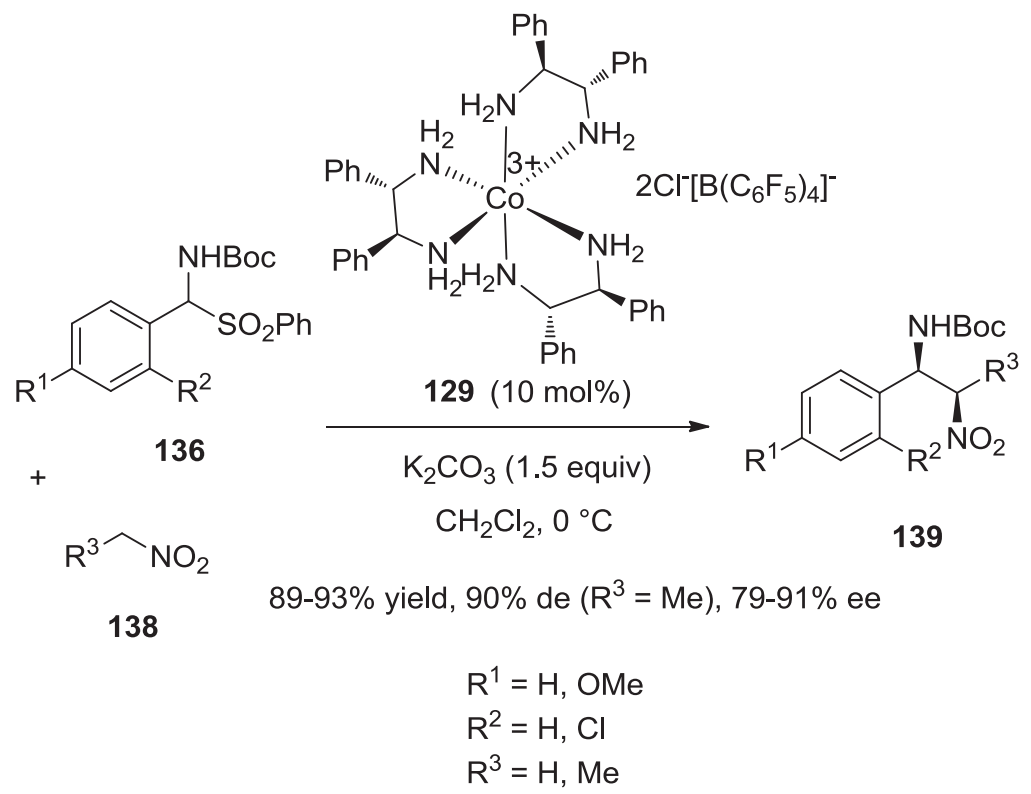

Scheme 46. Additions of malonates and nitroalkanes to imines derived from $\alpha$-amido sulfones [78]. 
acids 119, the corresponding enantiopure cyclic allylic amines 125 (98->99\% ee) were obtained in moderate to high yields (52-85\%).

In another context, Lee and Yoshikai have developed cobaltcatalyzed enantioselective C2-alkylation of Boc-protected indoles 126 with aryl alkenes 96 (Scheme 44) [76]. The catalyst was in situ generated from $20 \mathrm{~mol} \%$ of chiral phosphoramidite $\mathbf{1 2 7}$ as ligand, $10 \mathrm{~mol} \%$ of $\mathrm{Co}(\mathrm{acac})_{3}$ and $75 \mathrm{~mol} \%$ of $\mathrm{TMSCH}_{2} \mathrm{MgCl}$ in THF at room temperature, allowing the corresponding chiral C2-alkylated indoles $\mathbf{1 2 8}$ to be achieved in low to high yields (16-88\%) and moderate to good enantioselectivities (68-87\% ee).

In 2016, Gladysz and co-workers reported the use of Werner complex 129 based on chiral trication $\left[\operatorname{Co}((S, S) \text {-dpen })_{3}\right]^{3+}($ dpen $=$ 1,2-diphenylethylenediamine) to promote enantioselective $\alpha$-aminations of 1,3-dicarbonyl compounds and related substrates, such as cyanoketones, in acetonitrile at $0{ }^{\circ} \mathrm{C}$ [77]. As shown in Scheme 45, the reaction of various cyclic $\beta$-ketoesters 130 $\left(\mathrm{X}=\mathrm{CO}_{2} \mathrm{Me}, \quad \mathrm{CO}_{2} \mathrm{Et}\right)$ with di-tert-butyl azodicarboxylate 131a catalyzed by $5 \mathrm{~mol} \%$ of cobalt complex 129 in the presence of $\mathrm{N}$-methylmorpholine as base afforded the corresponding chiral tertiary amines 132 in high to quantitative yields (88-98\%) and moderate to excellent enantioselectivities (72->99\% ee). The best enantioselectivities (91->99\% ee) were achieved for five- and six-membered ketones $(n=0-1)$ while a lower enantioselectivity ( $72 \%$ ee) was obtained in the reaction of a seven-membered substrate $(n=2)$. The scope of the process was extended to acyclic $\beta$-ketoester 133 which underwent the amination to give enantiopure product 134 ( $>99 \%$ ee) in quantitative yield (98\%), as shown in Scheme 45. A $\alpha$-cyanocyclopentanone was also compatible $(\mathrm{X}=\mathrm{CN}, n=0)$, leading to the corresponding amine in $92 \%$ yield albeit with a much lower enantioselectivity of $45 \%$ ee.

Very recently, catalyst 129 and related Werner complex 135 were applied by the same authors to promote enantioselective nucleophilic additions to imines in situ generated from $\alpha$-amido sulfones 136 [78]. As shown in Scheme 46, $10 \mathrm{~mol} \%$ of cobalt catalyst 135 promoted, in dichloromethane at $0{ }^{\circ} \mathrm{C}$ in the presence of $\mathrm{K}_{2} \mathrm{CO}_{3}$ as base, the addition of various dialkyl malonates $\mathbf{3 5}$ to $\alpha$ amido sulfones 136 to give the corresponding chiral products 137 in both very high yields (90-97\%) and enantioselectivities (87-99\% ee). Furthermore, the addition of nitroalkanes $\mathbf{1 3 8}$ to the same $\alpha$ amido sulfones 136 was catalyzed under the same reaction conditions by $10 \mathrm{~mol} \%$ of Werner complex 129 to afford the corresponding chiral nitroalkanes 139 in high yields (89-93\%) and enantioselectivities (79-91\% ee), as shown in Scheme 46. When nitroethane $\left(\mathrm{R}^{3}=\mathrm{Me}\right)$ was used as nucleophile, the corresponding product was obtained as almost single diastereomer ( $90 \% \mathrm{de}$ ) in $89 \%$ yield and $83 \%$ ee.

Tietze defined a domino reaction as a process involving two or more bond-forming transformations which take place under the same reaction conditions, without adding additional reagents and catalysts, and in which the subsequent reactions result as a consequence of the functionality formed by bond formation or fragmentation in the previous step [79]. These fascinating one-pot reactions [80] have allowed the synthesis of a wide range of complex natural and biologically active products [81], avoiding costly and time-consuming protection-deprotection processes, as well as purification procedures of intermediates [82]. The forerunner in the cobalt-catalyzed domino processes was that developed by Vollhardt and co-workers with their remarkable synthesis of steroids initiated by a [2+2+2] cycloaddition [83]. Ever since, a number of enantioselective cobalt-catalyzed domino reactions have been developed. Among them, an asymmetric three-component domino hydrosilylation/hydrogenation reaction of terminal aryl alkynes 140 with $\mathrm{Ar}_{2} \mathrm{SiH}_{2}$ and $\mathrm{H}_{2}$ was developed by Lu and co-workers [84]. It was promoted by $5 \mathrm{~mol} \%$ of chiral cobalt catalyst 141 in the presence of $\mathrm{NaBHEt}_{3}$ as reductant in diethylether at $0{ }^{\circ} \mathrm{C}$, providing the corresponding chiral silanes $\mathbf{1 4 2}$ in good to excellent yields (74-97\%) and enantioselectivities (78->99\% ee), as shown in Scheme 47. Mechanistic studies demonstrated that the regiose-

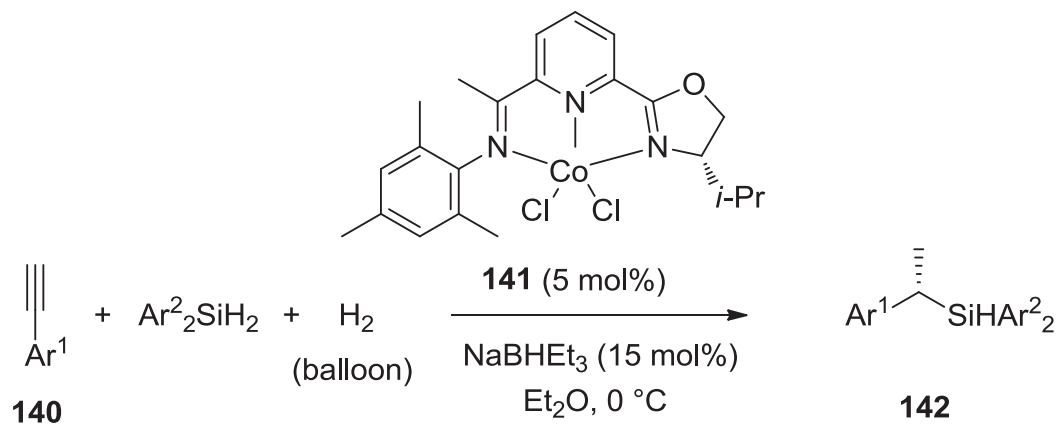

$74-97 \%$ yield, $78->99 \%$ ee

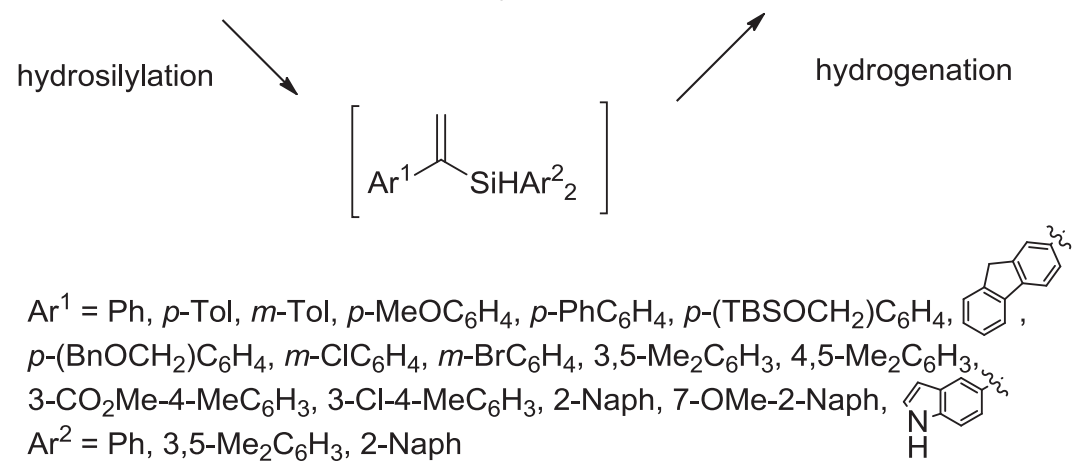

Scheme 47. Three-component domino hydrosilylation/hydrogenation reaction of terminal aryl alkynes [84]. 
lectivity of the reaction was controlled by the alkyne hydrosilylation step while the enantioselectivity was generated through the asymmetric hydrogenation of the resulting vinyl silanes.

\section{Enantioselective cobalt-catalyzed cyclization reactions}

\subsection{Cyclopropanations}

Cycloaddition reactions constitute important tools for the assembly of complex molecular structures $[6 a, 85]$. Among the metals used to catalyze cycloadditions, cobalt has been found effective to promote enantioselectively the formation of carboand heterocycles of different ring sizes. In particular, chemists have always been fascinated by the strained structure of the cyclopropane subunit [86]. The cyclopropanation of alkenes based on the transition-metal-catalyzed decomposition of diazoalkanes has been widely developed [87]. Among various metal complexes employed in these reactions are cobalt catalysts. The first enantioselective intermolecular cobalt-catalyzed cyclopropanation reaction was reported by Nakamura et al. in 1978, using a chiral cobalt(II)dioximato complex derived from camphor which allowed enantioselectivities of up to $88 \%$ ee to be achieved [88]. Ever since, various other types of chiral cobalt catalysts have been successfully applied to promote these transformations. For example, novel $C_{2^{-}}$ symmetric cobalt(II) salen complex 143 was used by White and Shaw to promote the enantioselective cyclopropanation of a range of 1,1-disubstituted alkenes $\mathbf{7 4}$ with ethyl diazoacetate (Scheme 48) [89]. The process was performed in dichloromethane at room temperature in the presence of potassium thioacetate as additive, and afforded the corresponding chiral trisubstituted cyclopropanes 144 as almost single diastereomers (90->96\% de) in uniformly high yields (89-97\%) and enantioselectivities (90$98 \%$ ee). This methodology was applied as key step in a short and efficient synthesis of the dual serotonin-epinephrine reuptake inhibitor (+)-synosutine, as illustrated in Scheme 48.<smiles>COc1cc(CN(/N=C/c2cc(OC)c(OC)cc2C(C)(C)C)C2C3CC4CC(C3)CC2C4)c(OC)c(C(C)(C)C)c1</smiles>

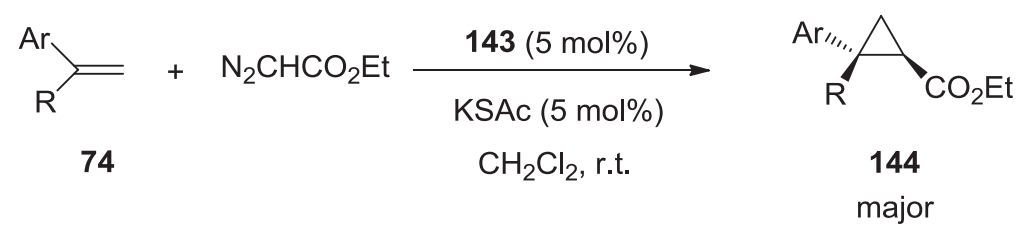

$89-97 \%$ yield, $90->96 \%$ de, $90-98 \%$ ee

$\mathrm{Ar}=\mathrm{Ph}, \mathrm{o}-\mathrm{MeOC}_{6} \mathrm{H}_{4}$, 2-furyl, o- $\left(\mathrm{MeO}_{2} \mathrm{C}\right) \mathrm{C}_{6} \mathrm{H}_{4}, 3,4-\mathrm{MeO}_{2} \mathrm{C}_{6} \mathrm{H}_{3}$, 2-thiophenyl, 1-Naph, $p$-Tol, $p$ - $\mathrm{MeOC}_{6} \mathrm{H}_{4}$, 3- $\mathrm{CO}_{2}$ Et-5-Ph-2-furyl, $p-\mathrm{F}_{3} \mathrm{CC}_{6} \mathrm{H}_{4}$ $\mathrm{R}=\mathrm{Et}, n-\mathrm{Bu}, \mathrm{Me}, \mathrm{CH}_{2} \mathrm{CO}_{2} \mathrm{Et},\left(\mathrm{CH}_{2}\right)_{2} \mathrm{CO}_{2} \mathrm{Me}, n-\mathrm{Pr}$<smiles>C=C(Oc1cccc2ccccc12)c1cccs1</smiles>

$74 a$

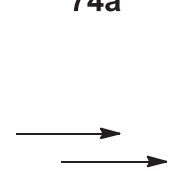

same conditions<smiles>CCOC(=O)C1C[C@@]1(Oc1cccc2ccccc12)c1cccs1</smiles>

$144 a$

$88 \%$ yield, $88 \%$ de, $94 \%$ ee<smiles>CNC[C@@H]1C[C@]1(Oc1cccc2ccccc12)c1cccs1</smiles>

(+)-synosutine

Scheme 48. Cyclopropanations of 1,1-disubstituted alkenes and synthesis of (+)-synosutine [89]. 
In 2016, the dearomatization of a series of electron-deficient nitrogen heterocycles was reported for the first time by Chen and co-workers on the basis of enantioselective cobalt-catalyzed cyclopropanations [90]. The reactions of different types of fused heteroaromatic substrates were promoted by 7.5 or $15 \mathrm{~mol} \%$ of cobalt(II) salen complex 145 in chlorobenzene at $45^{\circ} \mathrm{C}$ in the presence of $\mathrm{N}$-methylimidazole as an additive. For example, the reaction of various imidazopyrazine derivatives 146 with ethyl diazoacetate led to the corresponding tricyclic chiral products 147 exhibiting the cis-configuration as major diastereomers with high diastereoselectivity (84-90\% de). As shown in Scheme 49, these chiral polynitrogenated heterocycles were obtained in moderate to high yields (45-91\%) and enantioselectivities (60-92\% ee). The scope of the process was extended to imidazopyridazines 148 which led by reaction with ethyl diazoacetate to the corresponding cis-heterocyclic cyclopropanes $\mathbf{1 4 9}$ as major diastereomers in moderate yields (47-89\%) and diastereoselectivities (60-90\% de) along with high enantioselectivities (84-98\% ee), as summarized in
Scheme 49. Other fused heteroaromatic substrates were compatible with the reaction conditions, such as 6-chloro-[1,2,4]triazolo [4,3-b]pyridazine 150, which provided the desired product 151 in $92 \%$ yield, with both high cis-diastereoselectivity (90\% de) and enantioselectivity (92\% ee), as shown in Scheme 49.

As stable metalloradicals, cobalt(II) complexes of $D_{2}$-symmetric chiral amidoporphyrins have emerged as effective catalysts for asymmetric radical transformations through catalytic generation of metal-stabilized organic radicals as key intermediates [91]. In this context, Zhang et al. have employed chiral amidoporphyrin cobalt complex $\mathbf{1 5 2}$ to develop the first asymmetric cyclopropanation of alkenes with $\alpha$-formyldiazoacetates [92]. Indeed, complex 152 was found as an effective metalloradical catalyst that could activate $\alpha$-formyldiazoacetates $\mathbf{1 5 3}$ to react with both aromatic and aliphatic olefins 86 with varied electronic properties to give the corresponding synthetically useful 1,1-cyclopropaneformylesters $\mathbf{1 5 4}$ in moderate to quantitative yields (61-99\%) and good to excellent enantioselectivities (77-99\% ee). As illustrated in Scheme 50, these

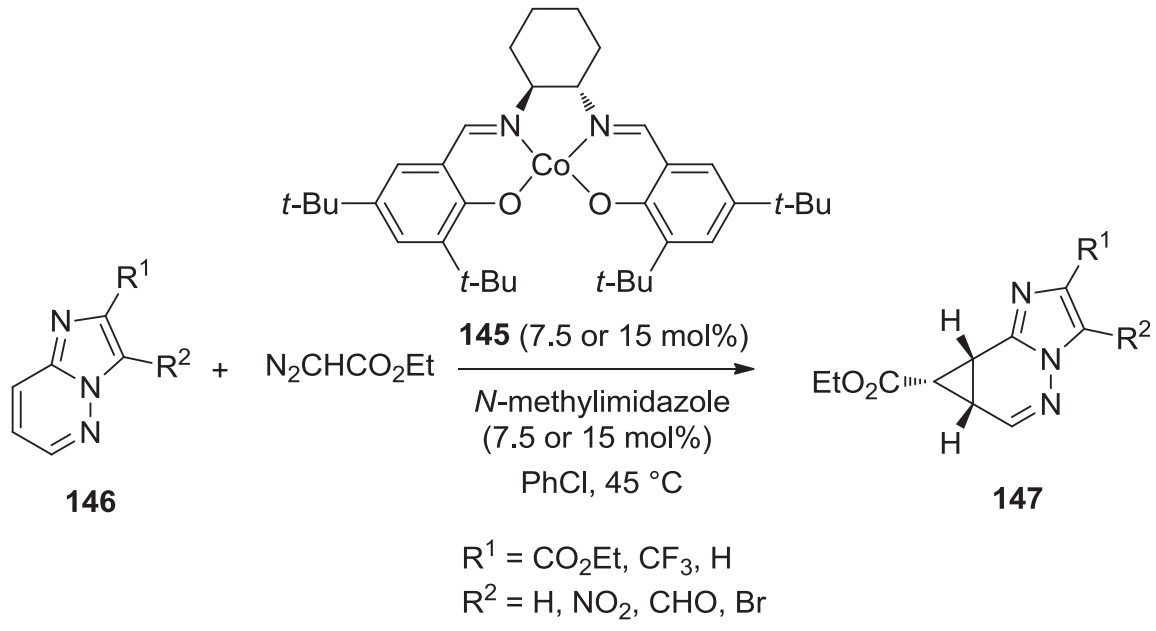

$45-91 \%$ yield, $84-90 \%$ de, $60-92 \%$ ee

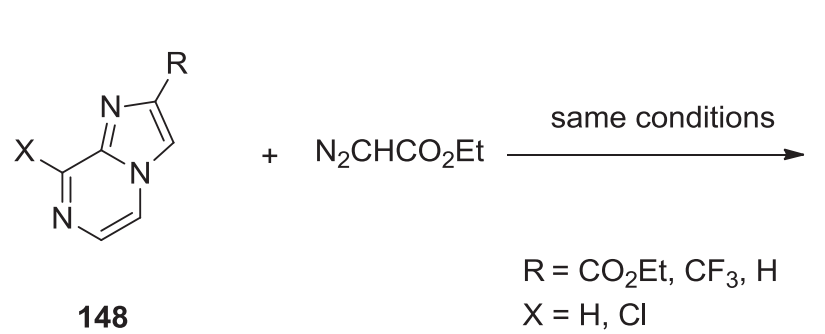<smiles>[R]C1=CN2CC2(COCC)N=C([X])C(COC)=N1</smiles>

$47-89 \%$ yield, $60-90 \%$ de, $84-98 \%$ ee<smiles>Clc1ccc2nncn2[nH+]1</smiles>

150<smiles>CCOC(=O)[C@@H]1[C@@H]2C(Cl)=Nn3cnnc3[C@H]12</smiles>

151

$92 \%$ yield, $90 \%$ de, $92 \%$ ee

Scheme 49. Cyclopropanations of imidazopyrazines, imidazopyridazines and another heteroaromatic substrate [90]. 
products were generated in toluene at $40{ }^{\circ} \mathrm{C}$ in generally high diastereoselectivities of up to $>98 \%$ de excepted 1,1,2-cyclopropane formylesternitrile $(\mathrm{R}=\mathrm{CN})$ and 1,1,2-cyclopropaneformyldiesters $\left(\mathrm{R}=\mathrm{CO}_{2} \mathrm{Me}, \mathrm{CO}_{2} \mathrm{Et}\right)$ which were obtained in much lower diastereoselectivities (2-22\% de).

Donor-substituted diazo reagents, in situ generated from sulfonyl hydrazones in the presence of a base such as $\mathrm{Cs}_{2} \mathrm{CO}_{3}$, were shown for the first time by the same authors to be suitable radical precursors for enantioselective cobalt-catalyzed cyclopropanation of alkenes [93]. As shown in Scheme 51, a related chiral amidoprophyrin cobalt complex $\mathbf{1 5 5}$ was an efficient metalloradical catalyst capable of activating $\mathrm{N}$-tosyl hydrazone $\mathbf{1 5 6}$ a for asymmetric radical cyclopropanation of a broad range of alkenes 157, affording in methanol at $40{ }^{\circ} \mathrm{C}$ the corresponding chiral cyclopropanes 158 in moderate to high yields (41-90\%), diastereoselectivities (50-92\% de) and enantioselectivities (77-99\% ee). This catalytic system was also applied to the reaction between various arylsulfonyl hydrazones 156b-g and styrene 157a, leading to the corresponding products 158a-f in good to high yields (75-91\%), uniformly excellent diastereoselectivities (90->98\% de) and moderate to excellent enantioselectivities (68-99\% ee), as shown in Scheme 51.

Chiral amidoprophyrin cobalt complex 152 was also proven by these authors to be an effective metalloradical catalyst for the asymmetric intramolecular cyclopropanation of allyl $\alpha$ diazoacetates 159 [94]. In the presence of DMAP as additive in dichloromethane at room temperature, a series of allyl $\alpha$ diazoacetates 159 were transformed into the corresponding chiral [3.1.0]bicyclic products $\mathbf{1 6 0}$ as single diastereomers ( $>98 \% \mathrm{de}$ ) in moderate to excellent yields (62-95\%) and moderate to good enantioselectivities (63-86\% ee), as shown in Scheme 52.

\subsection{Aziridinations and epoxidations}

Aziridines represent important intermediates in organic synthesis; since they act as precursors of many complex molecules due to the strain incorporated in their skeleton that enables an easy cleavage of the $\mathrm{C}-\mathrm{N}$ bond $[86 \mathrm{~d}, 95]$. The nitrogen-atom transfer to alkenes constitutes a common strategy for the generation of aziridines. In addition to catalytic systems based on copper, rhodium or ruthenium, Zhang and co-workers have demonstrated that cobalt was able to promote the asymmetric aziridination of olefins with diphenylphosphoryl azide as the nitrene source [96]. Later in 2014, chiral $D_{2}$-symmetric amidoporphyrin cobalt catalyst $\mathbf{1 6 1}$ was applied by the same authors to promote the asymmetric aziridination of styrenes with a phosphoryl azide [97]. This novel catalyst was compatible in benzene at 35 ${ }^{\circ} \mathrm{C}$ for a range of variously substituted styrenes $\mathbf{1 6 2}$ which provided by reaction with bis(2,2,2-trichloroethyl)phosphoryl azide 163 the corresponding chiral $N$-phosphorylaziridines 164 in moderate to quantitative yields (64-99\%) and low to good enantioselectivities (23-85\% ee), as shown in Scheme 53.

Later in 2017, a related chiral $D_{2}$-symmetric amidoporphyrin cobalt catalyst 165 was applied by the same authors to develop the first enantioselective radical aziridination of allyl azidoformates 166 [98]. The reaction performed in chlorobenzene at 40 or $80^{\circ} \mathrm{C}$ led to the corresponding chiral aziridine/oxazolidinonefused bicyclic products 167 as single diastereomers (99\% de) in excellent yields (>90-99\%) and moderate to excellent enantioselectivities (70->99\% ee), as shown in Scheme 54.

Chiral epoxides constitute key building blocks for the synthesis of a number of important products [99]. In particular, the asymmetric epoxidation of $\alpha, \beta$-unsaturated carbonyl compounds represents a challenging transformation in synthesis [100]. In this context, Belokon and co-workers have described the use of chiral positively charged cobalt complex $\mathbf{1 6 8}$ to catalyze the asymmetric epoxidation of chalcones with $\mathrm{H}_{2} \mathrm{O}_{2}$ under phase transfer conditions [101]. Indeed, treatment of a variety of chalcones 169 with a $30 \%$ aqueous solution of $\mathrm{H}_{2} \mathrm{O}_{2}$ in the presence of $10 \mathrm{~mol} \%$ of catalyst 168 and $t$-BuOK as base in MTBE as solvent yielded at room temperature the corresponding chiral epoxides $\mathbf{1 7 0}$ with moderate to complete conversions (50-99\%) and moderate enantioselectivities (35-55\% ee), as shown in Scheme 55.

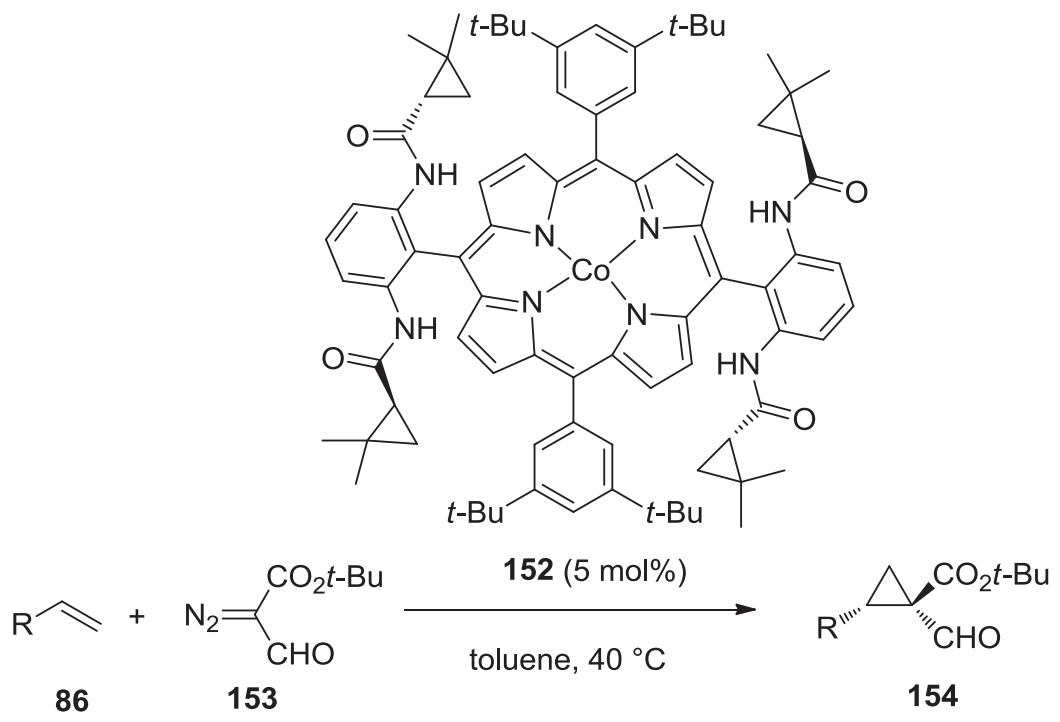

$61-99 \%$ yield, $2->98 \%$ de, $77-99 \%$ ee

$\mathrm{R}=p$-Tol, $m$-Tol, $p$ - $(t-\mathrm{Bu}) \mathrm{C}_{6} \mathrm{H}_{4}, p-\mathrm{FC}_{6} \mathrm{H}_{4}, m-\mathrm{BrC}_{6} \mathrm{H}_{4}, o-\mathrm{BrC}_{6} \mathrm{H}_{4}, m-\mathrm{O}_{2} \mathrm{NC}_{6} \mathrm{H}_{4}$, $p-\mathrm{F}_{3} \mathrm{CC}_{6} \mathrm{H}_{4}, 2-\mathrm{Naph}, \mathrm{Ph}, m-\mathrm{OHCC}_{6} \mathrm{H}_{4}, \mathrm{CN}, \mathrm{CO}_{2} \mathrm{Et}, \mathrm{CO}_{2} \mathrm{Me}, n-\mathrm{Hex}$

Scheme 50. Cyclopropanation of alkenes with $\boldsymbol{\alpha}$-formyldiazoacetates [92]. 


\subsection{1,3-Dipolar cycloadditions}

The 1,3-dipolar cycloaddition [102] of a dipolarophile with a 1,3-dipolar compound allows the synthesis of important fivemembered heterocycles [87c,103]. A variety of enantioselective versions of this reaction have successfully used different types of chiral cobalt complexes [2]. In a recent example, Feng and Liu developed highly efficient catalytic asymmetric formal [3+2] cycloadditions of 5-alkoxyoxazoles $\mathbf{1 7 1}$ with azodicarboxylates 131 performed in dichloromethane at $35^{\circ} \mathrm{C}$ in the presence of a chiral cobalt catalyst [104]. The latter was in situ generated from $10 \mathrm{~mol} \%$ of $\mathrm{Co}\left(\mathrm{BF}_{4}\right)_{2}\left(6 \mathrm{H}_{2} \mathrm{O}\right)$ and the same quantity of chiral $N_{,} N^{\prime}-$ dioxide $\mathbf{1 7 2}$ or 173. As shown in Scheme 56, the catalytic systems tolerated a range of variously substituted 5-alkoxyoxazoles, which led to the corresponding multisubstituted chiral 1,2,4-triazolines 174 in good to quantitative yields (70-99\%) and high enantioselectivities (82-98\% ee).

Soon after, the same authors investigated the 1,3-dipolar cycloaddition of nitrones with methyleneindolinones by using a related chiral $N, N^{\prime}$-dioxide ligand [105]. As illustrated in Scheme 57. the use of a combination of $10 \mathrm{~mol} \%$ of $\mathrm{Co}\left(\mathrm{BF}_{4}\right)_{2}\left(6 \mathrm{H}_{2} \mathrm{O}\right)$ and $10 \mathrm{~mol}$ $\%$ of ligand $\mathbf{1 7 5}$ as catalytic system in ethyl acetate as solvent allowed at $0{ }^{\circ} \mathrm{C}$ the $[3+2]$ cycloaddition of a wide variety of nitrones $\mathbf{1 7 6}$ with methyleneindolinones $\mathbf{1 7 7}$ to give the corresponding chiral multisubstituted spiroisoxazolidines 178 exhibiting three contiguous quaternary/tertiary stereocenters in almost all cases as single diastereomers ( $>90 \% \mathrm{de}$ ) in moderate to excellent yields (45-99\%) and uniformly excellent enantioselectivities (90-99\% ee). In only four cases of substrates $\left(\mathrm{R}^{3}=p-\mathrm{IC}_{6} \mathrm{H}_{4}\right.$ or $\mathrm{Cy}, \mathrm{R}^{4}=\mathrm{Me}$ or $p$-Tol), the diastereoselectivities of the reaction were slightly lower $(80-88 \%$ de).

\section{4. $[2+2+2]$ Cycloadditions}

The transition metal-catalyzed [2+2+2] cycloaddition of unsaturated motifs, such as alkynes and alkenes, constitutes the most atom-economical protocol for the construction of a six-membered ring system [6b,106]. Among these processes, the enantioselective $[2+2+2]$ cycloaddition is a fascinating protocol for the construction of chiral cyclic skeletons [107]. In 1990,

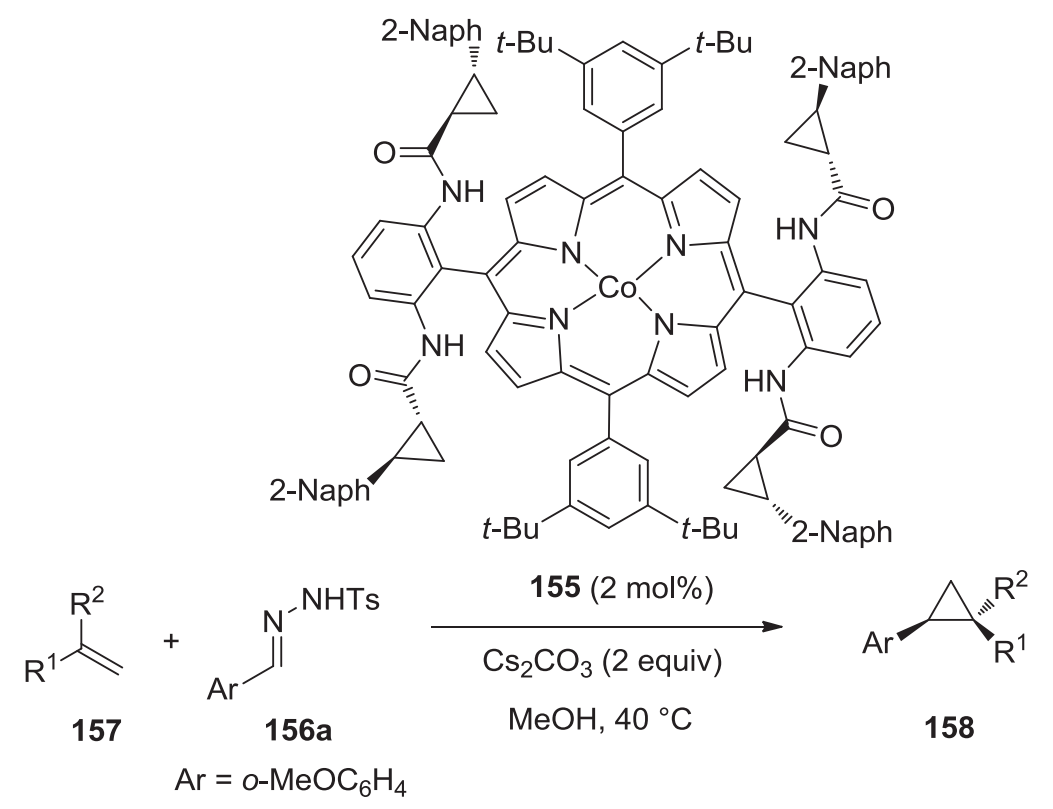

$41-90 \%$ yield, $50-92 \%$ de, $77-99 \%$ ee

$\mathrm{R}^{1}=\mathrm{H}, \mathrm{Me}, \mathrm{Br}$

$\mathrm{R}^{2}=\mathrm{Ph}, p-\mathrm{MeOC}_{6} \mathrm{H}_{4}, p-\mathrm{F}_{3} \mathrm{CC}_{6} \mathrm{H}_{4}, p-\mathrm{BrC}_{6} \mathrm{H}_{4}, m-\mathrm{BrC}_{6} \mathrm{H}_{4}, o-\mathrm{BrC}_{6} \mathrm{H}_{4}$, 2,4,6- $\mathrm{Me}_{3} \mathrm{C}_{6} \mathrm{H}_{2}, p-\mathrm{ClC}_{6} \mathrm{H}_{4}$, o-Tol, $m-\mathrm{NH}_{2} \mathrm{C}_{6} \mathrm{H}_{4}$, 2-Naph, (E)-PhCH=CH, $\mathrm{CH}_{2}=\mathrm{CMe}, \mathrm{O} i-\mathrm{Pr}, \mathrm{CONH}_{2}, \mathrm{Ac}$
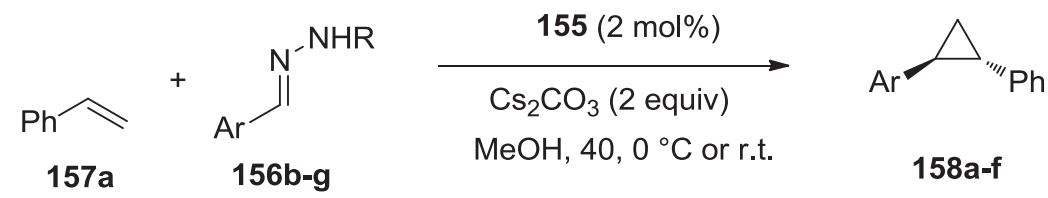

$\mathrm{MeOH}, 40,0^{\circ} \mathrm{C}$ or r.t.

$158 a-f$

$75-91 \%$ yield, $90->98 \%$ de, $68-99 \%$ ee

$\mathrm{Ar}=\mathrm{o}-\mathrm{MeOC}_{6} \mathrm{H}_{4}, \mathrm{o}-\mathrm{FC}_{6} \mathrm{H}_{4}, 2,5-\mathrm{MeO}_{2} \mathrm{C}_{6} \mathrm{H}_{3}, 2,6-\mathrm{F}_{2} \mathrm{C}_{6} \mathrm{H}_{3}, 2,4,6-\mathrm{F}_{3} \mathrm{C}_{6} \mathrm{H}_{2}, \mathrm{C}_{6} \mathrm{~F}_{5}$ $\mathrm{R}=\mathrm{Ts}$, TPS

Scheme 51. Cyclopropanations of alkenes with sulfonyl hydrazones [93]. 
Lautens and co-workers [108] and Brunner and co-workers [109] independently reported the first highly enantioselective cobaltcatalyzed $[2+2+2]$ cycloadditions performed in the presence of chiral phosphines with enantioselectivities of up to $98 \%$ ee. In 2016,
Hapke and co-workers reported the synthesis of novel indenylbased chiral cobalt complexes which were further investigated as catalysts in the asymmetric [2+2+2] cycloaddition of naphthyldiyne $\mathbf{1 7 9}$ with nitriles to give the corresponding chiral

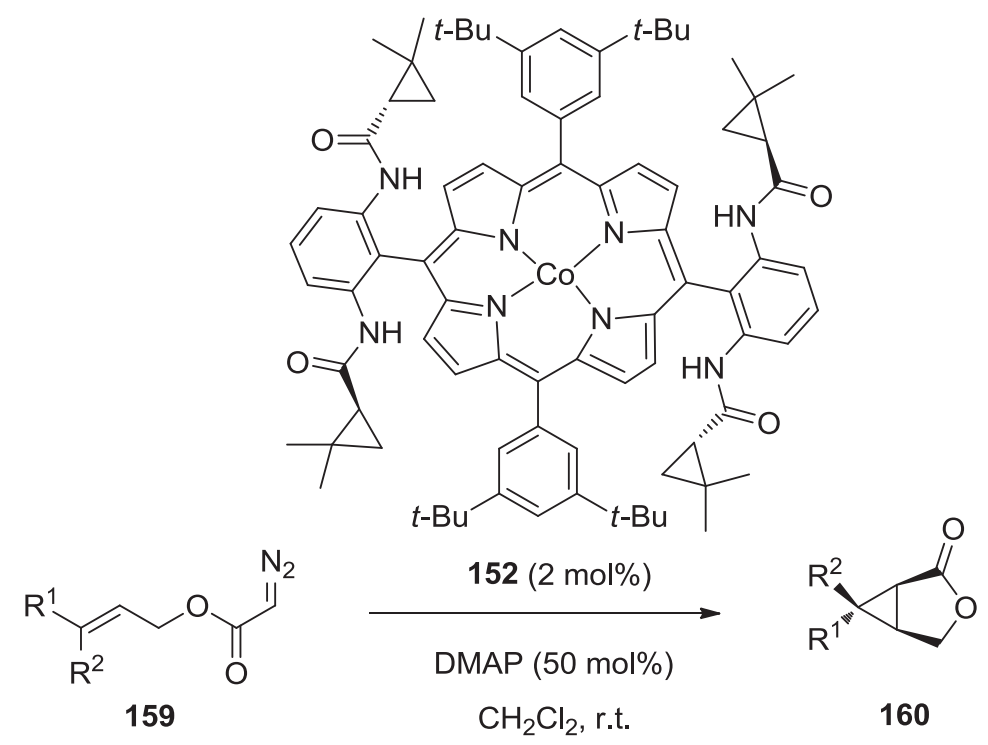

$62-95 \%$ yield, $>98 \%$ de, $63-86 \%$ ee

$\mathrm{R}^{1}=\mathrm{Ph}, p$-Tol, o-Tol, $p$-MeOC ${ }_{6} \mathrm{H}_{4}, p-\mathrm{BrC}_{6} \mathrm{H}_{4}$, 2-furyl, Me $\mathrm{R}^{2}=\mathrm{H}, \mathrm{Me}$

Scheme 52. Intramolecular cyclopropanation of allyl $\alpha$-diazoacetates [94].

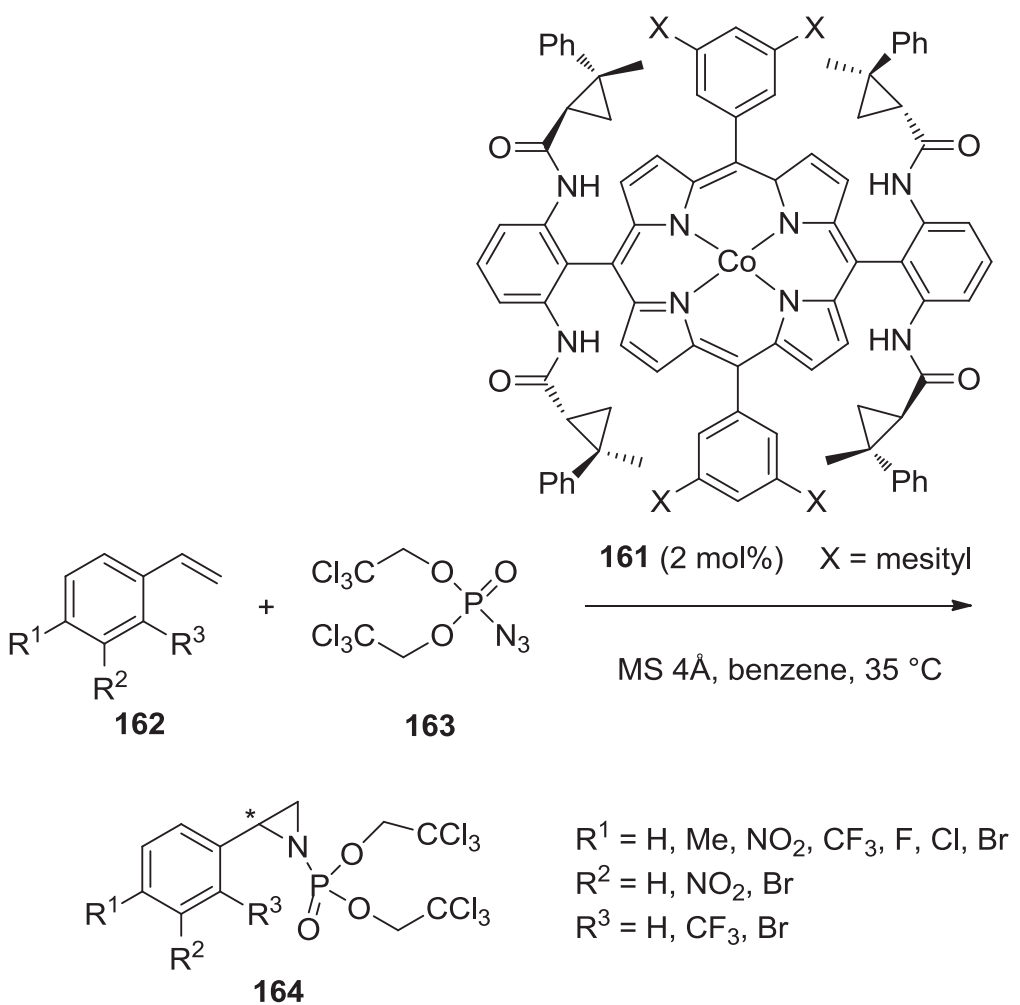

$64-99 \%$ yield, $23-85 \%$ ee

Scheme 53. Aziridination of styrenes with a phosphoryl azide [97]. 
heterobiaryl compounds $\mathbf{1 8 0}$ [110]. For example, the photochemical cycloaddition of naphthyldiyne 179 with benzonitrile 181a performed in THF at $-20{ }^{\circ} \mathrm{C}$ in the presence of only $1 \mathrm{~mol} \%$ of catalyst 182 allowed the corresponding product 180a to be obtained in both high yield (86\%) and enantioselectivity (93\% ee), as shown in Scheme 58. The authors also investigated chiral bisphosphite cobalt complex 183 in thermal comparable reactions $\left(50^{\circ} \mathrm{C}\right)$ with various nitriles 181a-d, which led to the formation of biaryl products 180a-d in the presence of 5 or $10 \mathrm{~mol} \%$ of catalyst loading (Scheme 58). In this case, the products were obtained in much lower yields (20-22\%) and moderate to good enantioselectivities
(66-80\% ee), demonstrating that the photochemical activation improved the yields compared to the thermal reaction.

Moreover, the authors described the first enantioselective cobalt-catalyzed intramolecular [2+2+2] cycloaddition of triynes 184 depicted in Scheme 59 [111]. It was promoted in THF at $25^{\circ} \mathrm{C}$ by catalyst 185 derived from $(R, R)$ - $N$-PINAP ligand, which led to variously substituted chiral tricyclic products $\mathbf{1 8 6}$ in low to excellent yields (32->95\%), low to moderate diastereoselectivities (10-46\% de) and low to good enantioselectivities (7-78\% ee). The substrate scope of the process included malonate- as well as ether-bridged triynes.

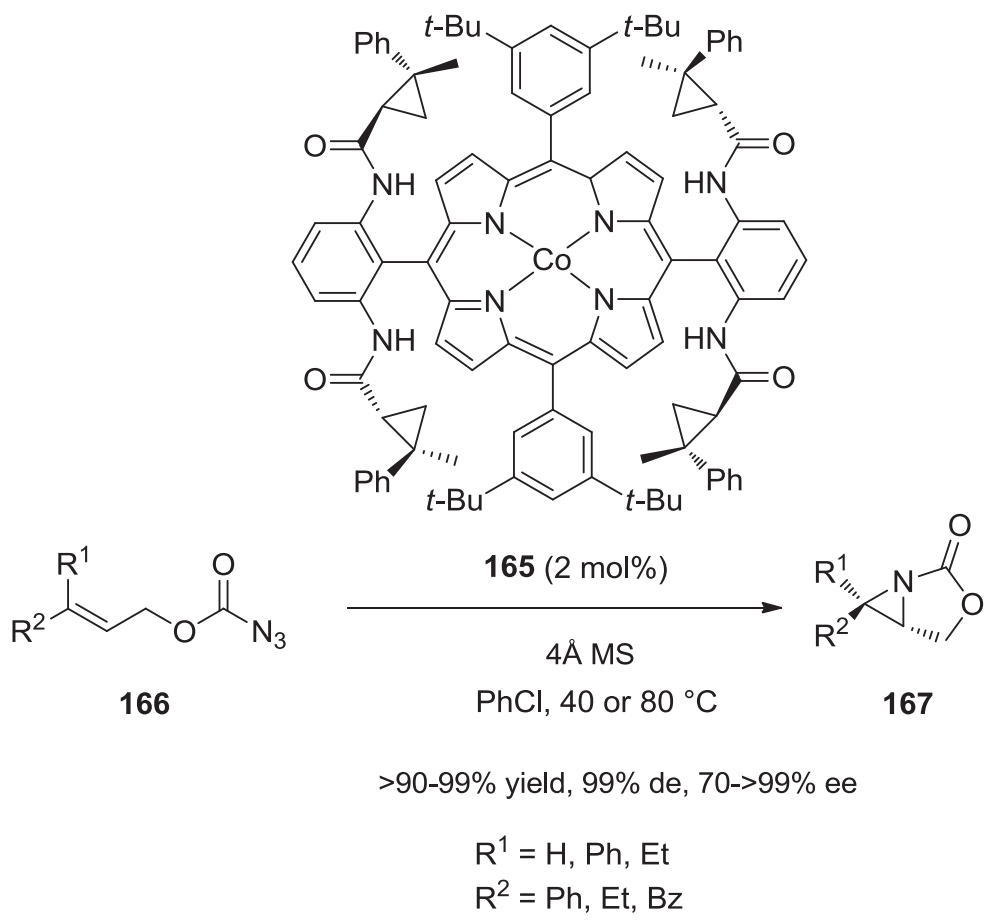

Scheme 54. Intramolecular aziridination of allyl azidoformates [98].

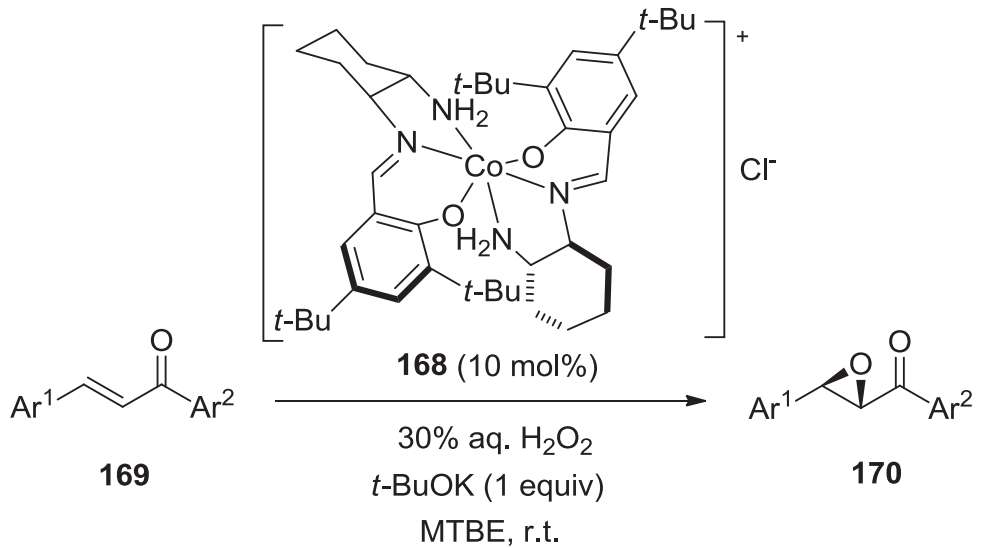

$50-99 \%$ conversion, $35-55 \%$ ee

$\mathrm{Ar}^{1}=\mathrm{Ph}, p-\mathrm{O}_{2} \mathrm{NC}_{6} \mathrm{H}_{4}, p-\mathrm{ClC}_{6} \mathrm{H}_{4}, o-\mathrm{ClC}_{6} \mathrm{H}_{4}, p-\mathrm{FC}_{6} \mathrm{H}_{4}, m-\mathrm{FC}_{6} \mathrm{H}_{4}$, $o-\mathrm{FC}_{6} \mathrm{H}_{4}, p$-Tol, $p$ - $\mathrm{MeOC}_{6} \mathrm{H}_{4}, m-\mathrm{PhOC}_{6} \mathrm{H}_{4}, 1$-Naph, 2-Naph, 9-anthracenyl $\mathrm{Ar}^{2}=\mathrm{Ph}, 2$-pyridinyl

Scheme 55. Epoxidation of chalcones [101]. 


\subsection{Hydroacylations}

The hydroacylation, consisting in the catalytic addition of an aldehyde $\mathrm{C}-\mathrm{H}$ bond across an unsaturated bond, represents an atom-efficient synthetic approach to carbonyl compounds [112]. These reactions are generally catalyzed by rhodium complexes, however, rare examples employing cobalt catalysts have been recently developed. Among them, Yang and Yoshikai have reported the enantioselective intramolecular hydroacylation of 2alkenylbenzaldehydes 187 promoted by a chiral cobalt catalyst in situ generated from $10 \mathrm{~mol} \%$ of $\mathrm{CoCl}_{2}$ and the same quantity of $(R, R)$-BDPP as ligand (Scheme 60) [113]. Performed in acetonitrile at $25{ }^{\circ} \mathrm{C}$ in the presence of $50 \mathrm{~mol} \%$ of zinc as reductant, the process led to differently substituted chiral indanones $\mathbf{1 8 8}$ in both high yields (81-95\%) and enantioselectivities (81-97\% ee).

In order to extend the scope of this catalytic system to substrates bearing trisubstituted alkenes, these authors found that the use of $\mathrm{CoBr}_{2}$ instead of $\mathrm{CoCl}_{2}$ as precatalyst and performing the reaction in DMF at $80^{\circ} \mathrm{C}$ instead of acetonitrile at $25^{\circ} \mathrm{C}$ allowed optimal results to be achieved (Scheme 61) [114]. Indeed, the enantioselective intramolecular hydroacylation of a wide range of trisubstituted alkenes $\mathbf{1 8 9}$ using a combination of only $5 \mathrm{~mol} \%$ of $\mathrm{CoBr}_{2}$ and $5 \mathrm{~mol} \%$ of $(R, R)$-BDPP in DMF at $80^{\circ} \mathrm{C}$ led to the corresponding chiral 2,3-disubstituted indanones 190 in moderate to quantitative yields (66-99\%), combined with moderate to excellent diastereoselectivities (54->90\% de) and enantioselectivities<smiles>[R]Oc1oc([R])nc1[R]</smiles>

171

$+$<smiles>[R]OC(=O)/N=N\C(=O)O[R]</smiles>

131<smiles>NC(=O)[C@@H]1CCC[N+]1([O-])CC[N@@+]1(O)CCCC1C(=O)N[Ga]</smiles>

$172\left(\mathrm{Ar}=2,6-i-\mathrm{Pr}_{2} \mathrm{C}_{6} \mathrm{H}_{3}\right)(10 \mathrm{~mol} \%)$

$$
\underset{\mathrm{CH}_{2} \mathrm{Cl}_{2}, 35^{\circ} \mathrm{C}}{\stackrel{\text { or } 173(\mathrm{Ar}=p \text {-Tol })(10 \mathrm{~mol} \%)}{\mathrm{Co}\left(\mathrm{BF}_{4}\right)_{2}\left(6 \mathrm{H}_{2} \mathrm{O}\right)(10 \mathrm{~mol} \%)}} \underset{174}{\mathrm{R}^{3} \mathrm{O}_{2} \mathrm{C}^{4} \mathrm{O}_{2} \mathrm{C}}
$$

$70-99 \%$ yield, $82-98 \%$ ee

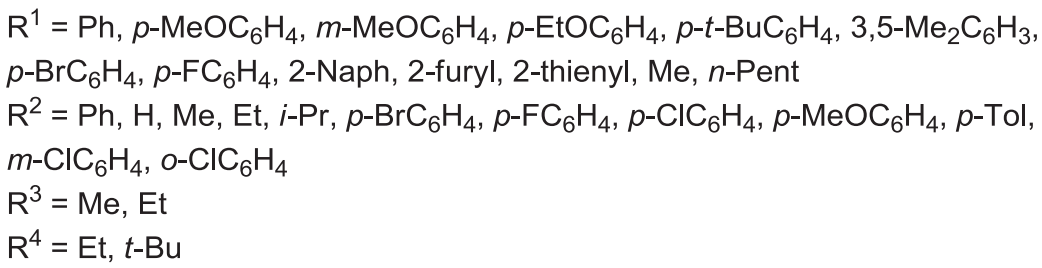

Scheme 56. 1,3-Dipolar cycloaddition of 5-alkoxyoxazoles with azodicarboxylates [104].

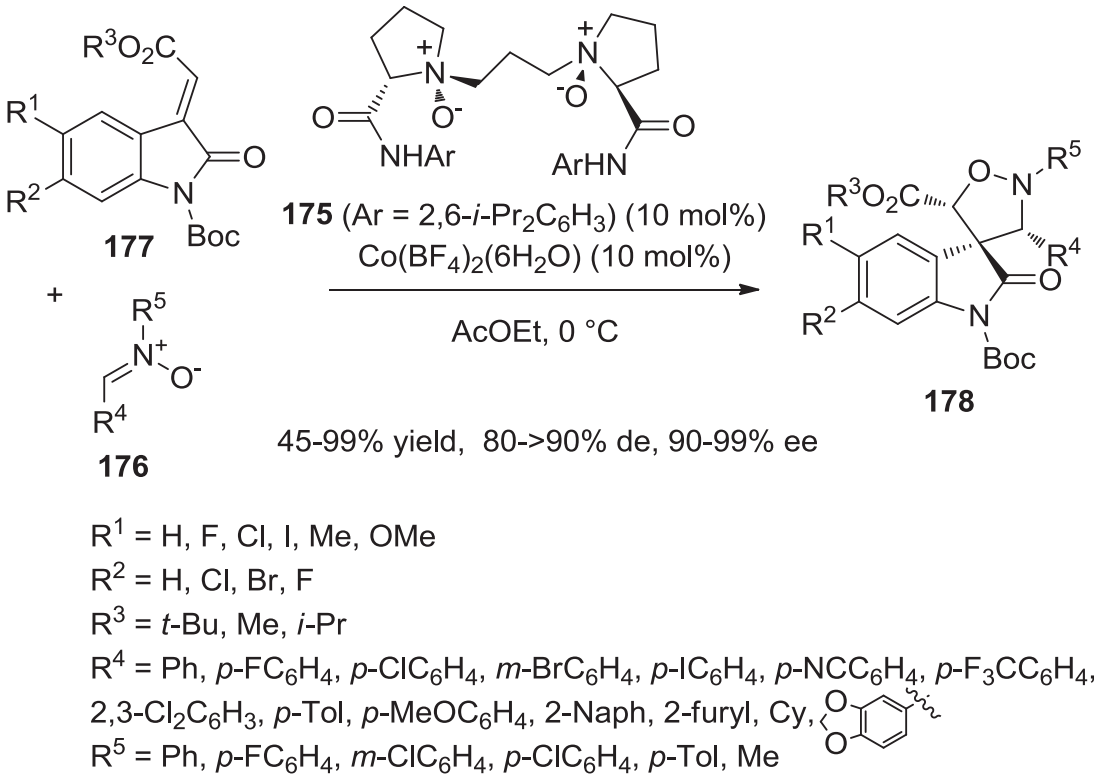

Scheme 57. 1,3-Dipolar cycloaddition of nitrones with methyleneindolinones [105]. 


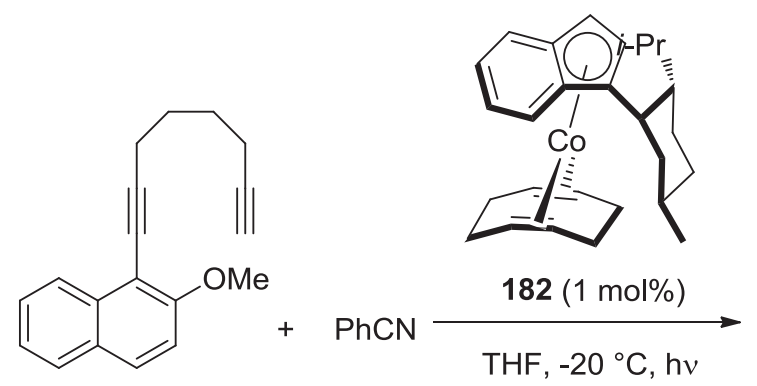

179

$181 \mathrm{a}$<smiles>COc1ccc2ccccc2c1-c1nc(-c2ccccc2)cc2c1CCCC2</smiles>

$180 a$

$86 \%$ yield, $93 \%$ ee

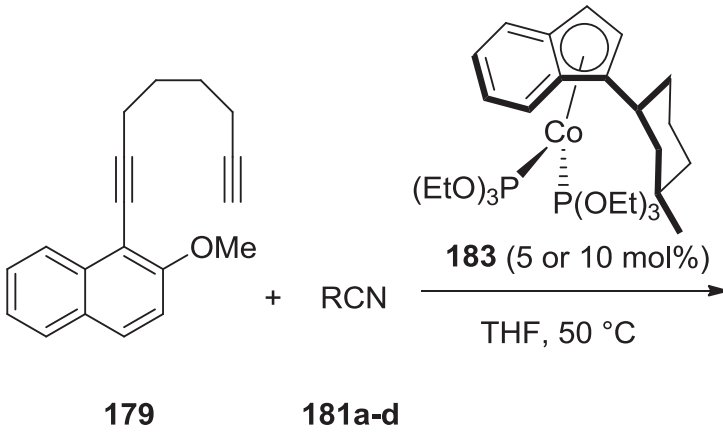<smiles>[R]c1cc2c(c(-c3c(OC)ccc4ccccc34)n1)CCCC2</smiles>

180a-d

$20-22 \%$ yield, $66-80 \%$ ee

$\mathrm{R}=\mathrm{Ph}, \mathrm{Me}, 2-\mathrm{F}-6-\mathrm{MeOC}_{6} \mathrm{H}_{3}, 3,4,5-\mathrm{MeO}_{3} \mathrm{C}_{6} \mathrm{H}_{2}$

Scheme 58. $[2+2+2]$ cycloadditions of a naphthyldiyne with nitriles [110].

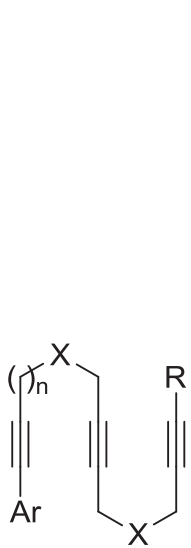

184<smiles></smiles>

$185(2.5,5$ or $10 \mathrm{~mol} \%)$

THF, $25^{\circ} \mathrm{C}$

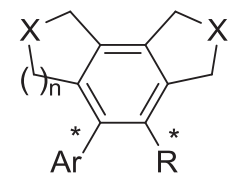

186<smiles>[R]C(=C)c1ccccc1C=O</smiles>

187<smiles>[R]C1CC(=O)c2ccccc21</smiles>

188

$$
\begin{aligned}
& 81-95 \% \text { yield, } 81-97 \% \text { ee } \\
& \mathrm{R}=\mathrm{Ph}, \mathrm{Me}, \mathrm{Et}, p-\mathrm{FC}_{6} \mathrm{H}_{4}
\end{aligned}
$$

Scheme 60. Intramolecular hydroacylation of 2-alkenylbenzaldehydes [113].

\subsection{Radical cyclizations}

Cobalt-based metalloradical catalysis has been, for the first time, successfully applied by Zhang and co-workers to develop asymmetric intramolecular $\mathrm{C}-\mathrm{H}$ alkylation of acceptor/acceptorsubstituted diazo reagents, such as $\alpha$-methoxycarbonyl- $\alpha$-diazosul fones [115]. Indeed, based on the design and synthesis of novel $D_{2}$-symmetric chiral amidoporphyrin as chiral ligand, the corresponding cobalt-based metalloradical system 191 was found capable to promote in benzene at room temperature the radical intramolecular $\mathrm{C}-\mathrm{H}$ alkylation of $\alpha$-methoxycarbonyl- $\alpha$-diazosul fones 192 having a broad range of electronic properties, which
(63-97\% ee). Interestingly, the level of enantioselectivity was independent of the stereochemistry ( $E / Z$ ratio) of the alkenyl group of the starting material. 
afforded the corresponding chiral trans-five-membered sulfolane derivatives 193 in high yields (86-99\%), diastereoselectivities ( $86-94 \%$ de), and enantioselectivities (78-94\% ee). As shown in Scheme 62, the catalytic system tolerated a remarkable degree of functional group tolerance since the substrate could exhibit allylic and allenic groups among others.
Another cobalt-porphyrin catalyst 194 was used by de Bruin and co-workers to promote the asymmetric intramolecular ringclosing $\mathrm{C}-\mathrm{H}$ bond amination of azide 195 into the corresponding chiral pyrrolidine 196 [116]. As shown in Scheme 63, performed in toluene at $100{ }^{\circ} \mathrm{C}$, the radical reaction provided this product in low yield (22\%) and modest enantioselectivity ( $46 \%$ ee).<smiles>[R]C=Cc1ccccc1C=O</smiles>

189<smiles>CC(P)C[C@@H](C)Pc1ccccc1</smiles>

$(R, R)-\operatorname{BDPP}(5 \mathrm{~mol} \%)$

$\mathrm{CoBr}_{2}(5 \mathrm{~mol} \%)$

$\mathrm{Mn}(50 \mathrm{~mol} \%)$

DMF, $80^{\circ} \mathrm{C}$<smiles>[R]C1C(=O)c2ccccc2C1[R]</smiles>

190

$66-99 \%$ yield, $54->90 \%$ de, $63-97 \%$ ee

$\mathrm{R}^{1}=n-\mathrm{Bu}, \mathrm{Ph}, \mathrm{Me}, \mathrm{Et}, p-\mathrm{MeOC}_{6} \mathrm{H}_{4}, p-\mathrm{FC}_{6} \mathrm{H}_{4}, p-\mathrm{ClC}_{6} \mathrm{H}_{4}$, $p-\mathrm{NMe}_{2} \mathrm{C}_{6} \mathrm{H}_{4}, p-\mathrm{F}_{3} \mathrm{CC}_{6} \mathrm{H}_{4}, m-\mathrm{MeOC}_{6} \mathrm{H}_{4}$ $\mathrm{R}^{2}=n-\mathrm{Bu}, \mathrm{Ph}, p-\mathrm{FC}_{6} \mathrm{H}_{4}, p-\mathrm{ClC}_{6} \mathrm{H}_{4}, p-\mathrm{F}_{3} \mathrm{CC}_{6} \mathrm{H}_{4}, p-\mathrm{MeOC}_{6} \mathrm{H}_{4}$, $m-\mathrm{FC}_{6} \mathrm{H}_{4}$, Et, Me, $\mathrm{Ph}, p-\mathrm{NMe}_{2} \mathrm{C}_{6} \mathrm{H}_{4}, m-\mathrm{MeOC}_{6} \mathrm{H}_{4}$

Scheme 61. Intramolecular hydroacylation of trisubstituted alkenes [114].

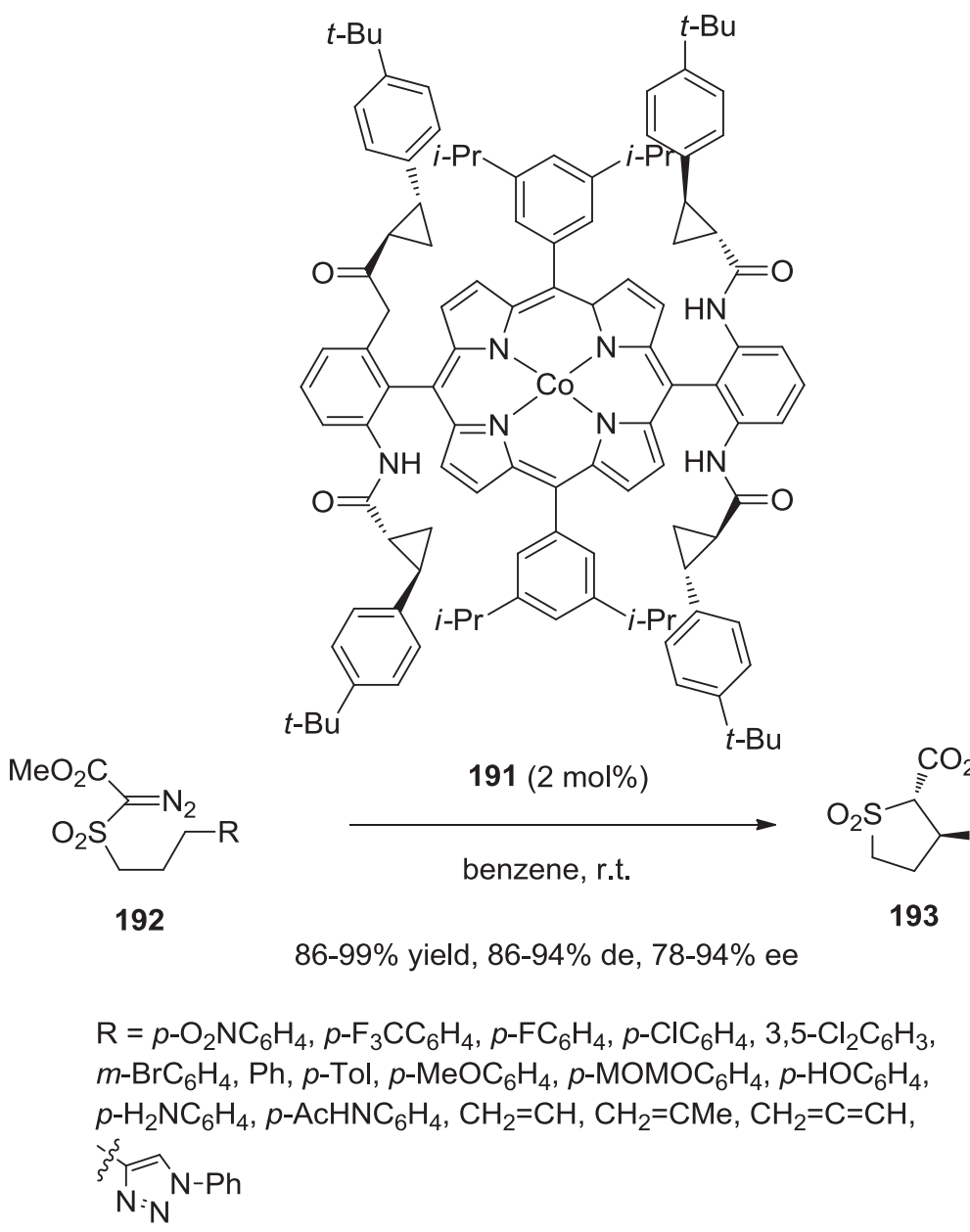

Scheme 62. Radical intramolecular C-H alkylation of $\alpha$-methoxycarbonyl- $\alpha$-diazosulfones [115]. 


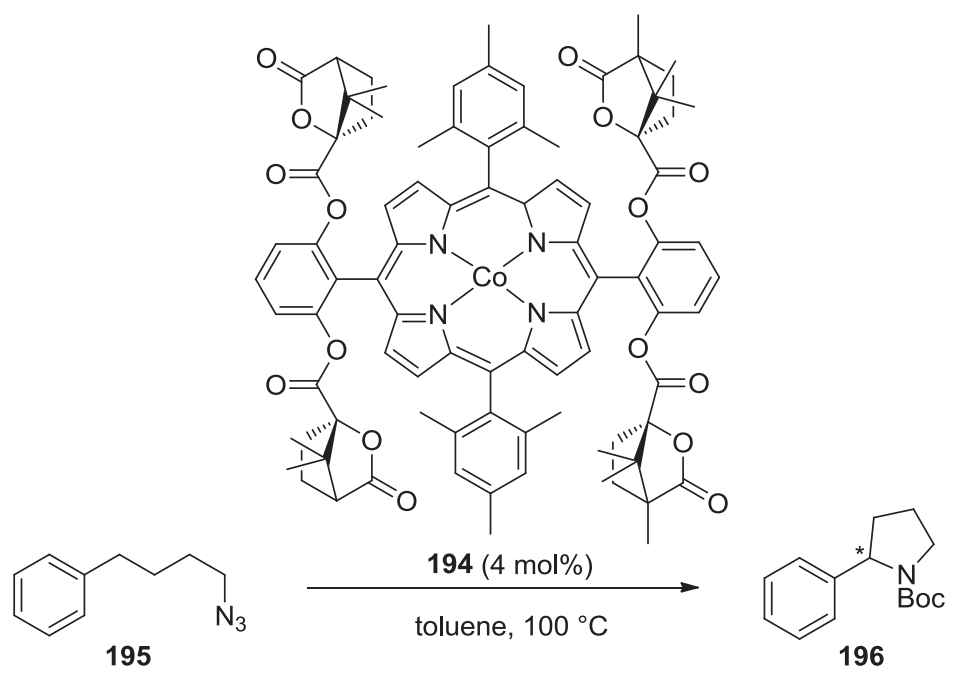

$+\mathrm{Boc}_{2} \mathrm{O}$

$22 \%$ yield, $46 \%$ ee

Scheme 63. Intramolecular ring-closing $\mathrm{C}-\mathrm{H}$ bond amination of an azide [116].

synthesis of vinyl boronate esters:

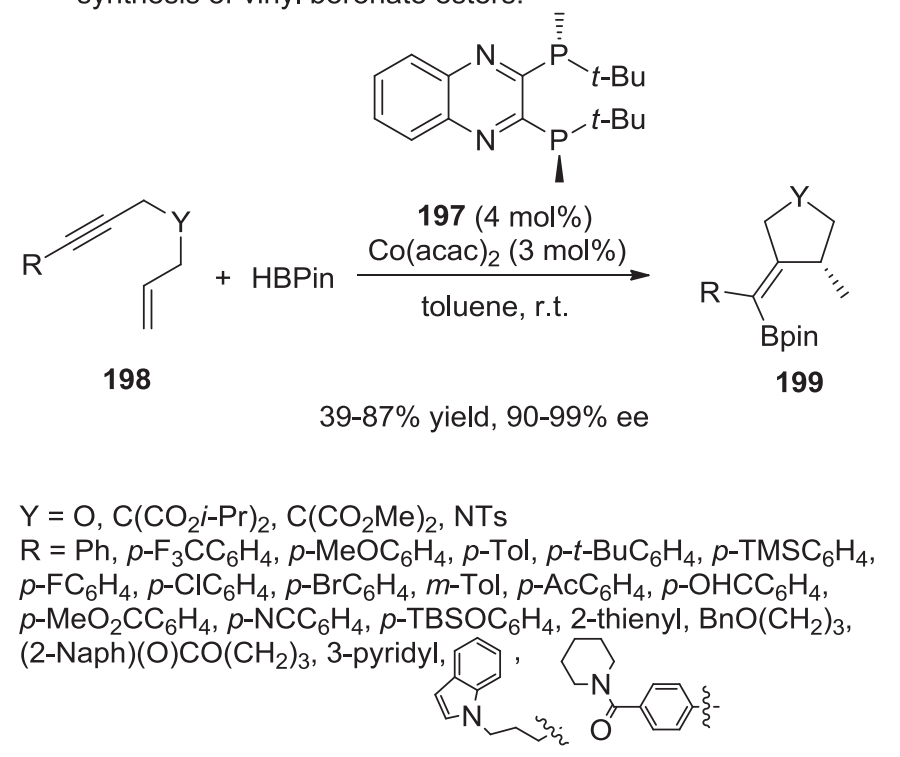

synthesis of alkyl boronate esters:

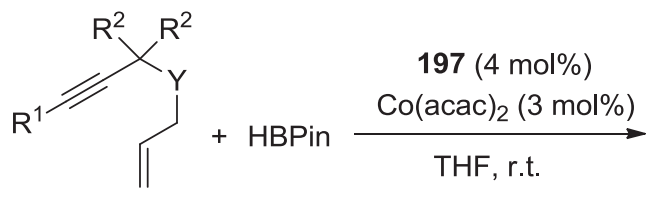

200

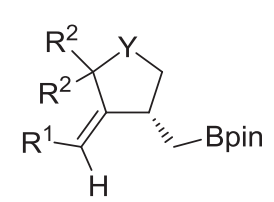

201

$50-91 \%$ yield, $86-98 \%$ ee

$\mathrm{Y}=\mathrm{O}, \mathrm{C}\left(\mathrm{CO}_{2} i-\mathrm{Pr}\right)_{2}, \mathrm{C}\left(\mathrm{CO}_{2} \mathrm{Me}\right)_{2}$, NTs

$\mathrm{R}^{1}=o-T o l, 2-\mathrm{Naph}, \mathrm{Ph}, p-\mathrm{Tol}, p-t-\mathrm{BuC}_{6} \mathrm{H}_{4}, p-\mathrm{F}_{3} \mathrm{CC}_{6} \mathrm{H}_{4}$,

$m$-Tol

$\mathrm{R}^{2}=\mathrm{H}, \mathrm{Me}, \mathrm{Ph}$

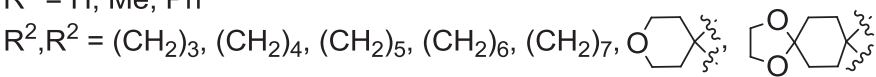

Scheme 64. Domino hydroboration/cyclization reactions of 1,6-enynes with pinacolborane [117]. 


\subsection{Miscellaneous cyclizations}

Recently, Ge and co-workers developed the first enantioselective cobalt-catalyzed domino hydroboration/cyclization reaction of 1,6-enynes with pinacolborane [117]. The cobalt catalyst was in situ generated from $\mathrm{Co}(\mathrm{acac})_{2}$ and chiral bisphosphine ligand 197 in toluene at room temperature. A variety of oxygen-, nitrogen- and carbon-tethered 1,6-enynes 198 underwent the asymmetric reaction with HBPin, yielding the corresponding vinyl-substituted boronate esters 199 containing chiral tetrahy- drofuran, pyrrolidine, and cyclopentane moieties with moderate to high yields (39-87\%) and uniformly excellent enantioselectivities (90-99\% ee). On the other hand, the authors found that enynes 200a-b containing ortho-substituted aryl groups $\left(\mathrm{R}^{1}=o\right.$-Tol, 2 Naph) reacted with HBPin in THF as solvent to provide the corresponding alkyl boronate esters 201a-b in high yields (86-88\%) and enantioselectivities (88-90\% ee), as shown in Scheme 64. Furthermore, this anti-Markovnikov hydroboration/cyclization process tolerated O-tethered 1,6-enynes bearing two substituents at the propargylic position as well as $\mathrm{N}$ - and $\mathrm{C}$-tethered 1,6-enynes<smiles>[R]c1cc2c(c([R])c1[R])N(P)C(=O)C2=O</smiles>

203<smiles>[R]C(=O)CBr</smiles>

204<smiles>NC(=O)[C@@H]1CCC[N+]1([O-])CCC[N@+]1([O-])CCC[C@H]1C(=O)N[TeH]</smiles>

$\mathrm{Ar}=2,4,6-i-\mathrm{Pr}_{3} \mathrm{C}_{6} \mathrm{H}_{2}$ $202(10 \mathrm{~mol} \%)$ $\mathrm{Co}(\mathrm{acac})_{2}(11 \mathrm{~mol} \%)$

$\left[\mathrm{K}_{3} \mathrm{PO}_{4}\right] /\left[\mathrm{K}_{2} \mathrm{HPO}_{4}\right]$

$5 \AA \mathrm{MS},-30^{\circ} \mathrm{C}$

THF/acetone (3:1)<smiles>[R]C(=O)C1OC12CN([Pb])c1c2cc([R16])c([R])c1[R]</smiles>

$18-96 \%$ yield, $98 \%$ de, $47-95 \%$ ee

$\mathrm{PG}=\mathrm{Me}, \mathrm{Et}, i-\mathrm{Pr}, \mathrm{MOM}, \mathrm{Bn}$

$\mathrm{R}^{1}=\mathrm{H}, \mathrm{OMe}, \mathrm{Me}, \mathrm{F}$

$\mathrm{R}^{2}=\mathrm{H}, \mathrm{Br}$

$\mathrm{R}^{3}=\mathrm{H}, \mathrm{F}, \mathrm{Cl}, \mathrm{Br}, \mathrm{Me}$

$\mathrm{R}^{2}, \mathrm{R}^{3}=\left(\mathrm{CH}_{2}\right)_{4},(\mathrm{CH}=\mathrm{CH})_{2}$

$\mathrm{R}^{4}=\mathrm{Ph}, p-\mathrm{MeOC}_{6} \mathrm{H}_{4}, p$-Tol, $m$-Tol, $p-\mathrm{FC}_{6} \mathrm{H}_{4}, m-\mathrm{FC}_{6} \mathrm{H}_{4}, p-\mathrm{ClC}_{6} \mathrm{H}_{4}, m-\mathrm{ClC}_{6} \mathrm{H}_{4}$,

o- $\mathrm{ClC}_{6} \mathrm{H}_{4}, p-\mathrm{BrC}_{6} \mathrm{H}_{4}, p-\mathrm{F}_{3} \mathrm{CC}_{6} \mathrm{H}_{4}$, 2-thienyl, 2-Naph, $i$-Pr, $t$-Bu, 1-adamyl

Scheme 65. Darzens reaction of isatins with phenacyl bromides [118].

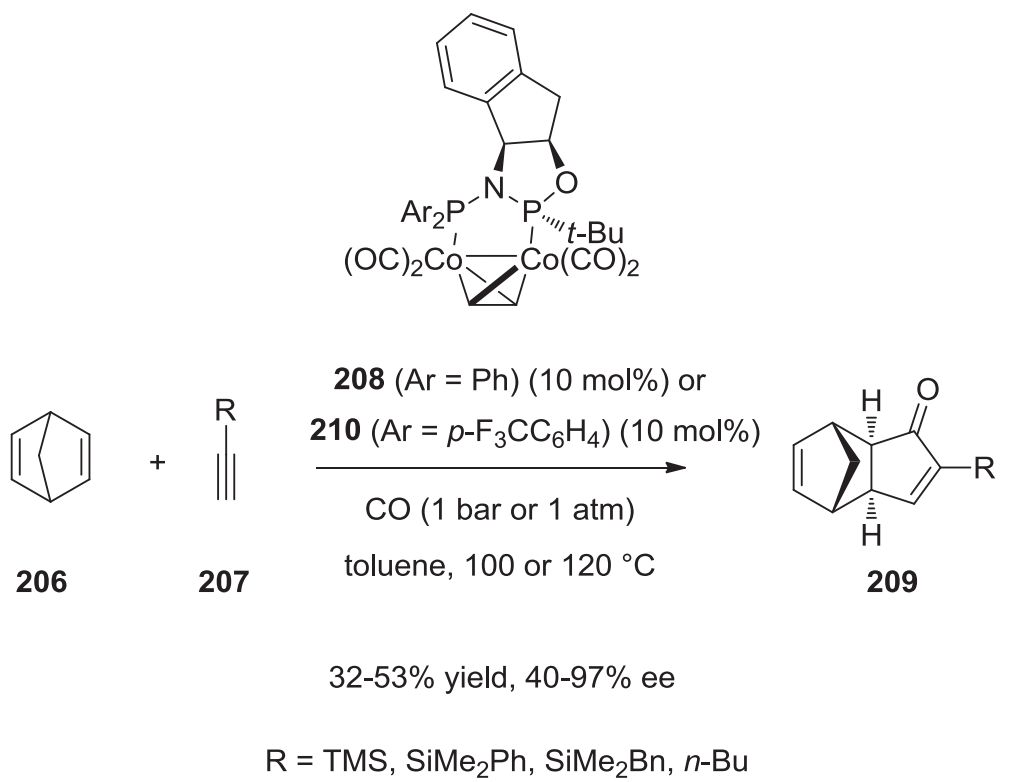

Scheme 66. Pauson-Khand reaction of norbornadiene with terminal alkynes [119]. 
which afforded the corresponding products 201 in moderate to high yields (50-91\%) and high enantioselectivities (86-98\% ee), as shown in Scheme 64.

In another context, Feng and co-workers have reported enantioselective cobalt-catalyzed Darzens reactions of $\mathrm{N}$-protected isatins with phenacyl bromides in order to synthesize potentially bioactive spiroepoxyoxindoles [118]. The optimal catalyst system for this process was constituted by a combination of $11 \mathrm{~mol} \%$ of $\mathrm{Co}(\mathrm{acac})_{2}$ and $10 \mathrm{~mol} \%$ of chiral $N, N^{\prime}$-dioxide ligand $\mathbf{2 0 2}$. The reactions were performed at $-30^{\circ} \mathrm{C}$ in a $3: 1$ mixture of THF/acetone as solvent in the presence of a mixture of $\mathrm{K}_{3} \mathrm{PO}_{4}$ and $\mathrm{K}_{2} \mathrm{HPO}_{4}$ as base. Under these conditions, the reaction of a range of $\mathrm{N}$-protected isatins 203 with phenacyl bromides 204 led to the corresponding chiral spiroepoxyoxindoles 205 as single diastereomers (98\% de) in low to excellent yields (18-96\%) and enantioselectivities (47-95\% ee), as illustrated in Scheme 65.

In 2015, Riera and co-workers reported the synthesis of chiral cobalt complexes derived from novel P-stereogenic aminodiphosphane ligands to be investigated as promoters in enantioselective Pauson-Khand reaction of norbornadiene 206 with terminal

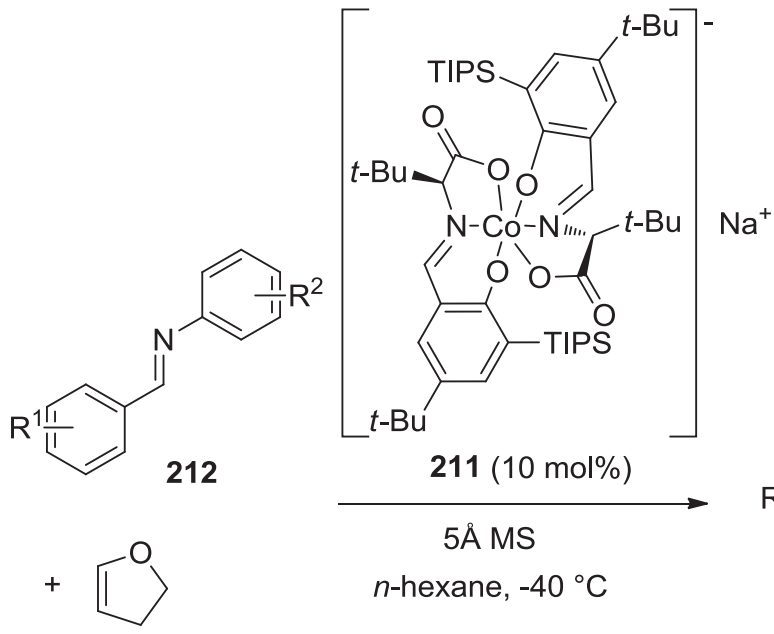

213

$40-93 \%$ yield, $88->90 \%$ de, $23-90 \%$ ee

$\mathrm{R}^{1}=\mathrm{H}, 4-\mathrm{Me}, 4-\mathrm{NO}_{2}, 4-\mathrm{CN}, 4-\mathrm{Br}, 4-\mathrm{Cl}, 2,4-\mathrm{Cl}_{2}$

$\mathrm{R}^{2}=\mathrm{H}, 4-\mathrm{Me}, 4-\mathrm{Cl}, 4-\mathrm{Br}, 4-\mathrm{CO}_{2} \mathrm{Et}$<smiles>[R]c1ccc(C=NCC)cc1</smiles>

215

same conditions<smiles>[R1]c1ccc([C@@H]2Nc3cc[R1]cc3[C@@H]3OCC[C@@H]23)cc1</smiles>

214

$$
R^{2}
$$<smiles>[R]c1ccc(C)cc1</smiles><smiles>[Y]</smiles>

$94-99 \%$ yield, $84->90 \%$ de, $82-86 \%$ ee

216<smiles>[R]c1ccc([C@H]2Nc3cc([R])ccc3[C@@H]3[C@H]2CCN3C([R])([O-])[O-])cc1</smiles>

$$
\begin{aligned}
& \mathrm{R}^{1}=\mathrm{H}, \mathrm{NO}_{2} \\
& \mathrm{R}^{2}=\mathrm{H}, \mathrm{Me}
\end{aligned}
$$<smiles>[R12]c1ccc(/N=C/c2ccccc2)cc1</smiles>

same conditions

212<smiles>[R]c1ccc(C2C[C@H](OCC)c3ccccc3N2)cc1</smiles>

$$
\mathrm{R}=\mathrm{H}, \mathrm{Me}
$$




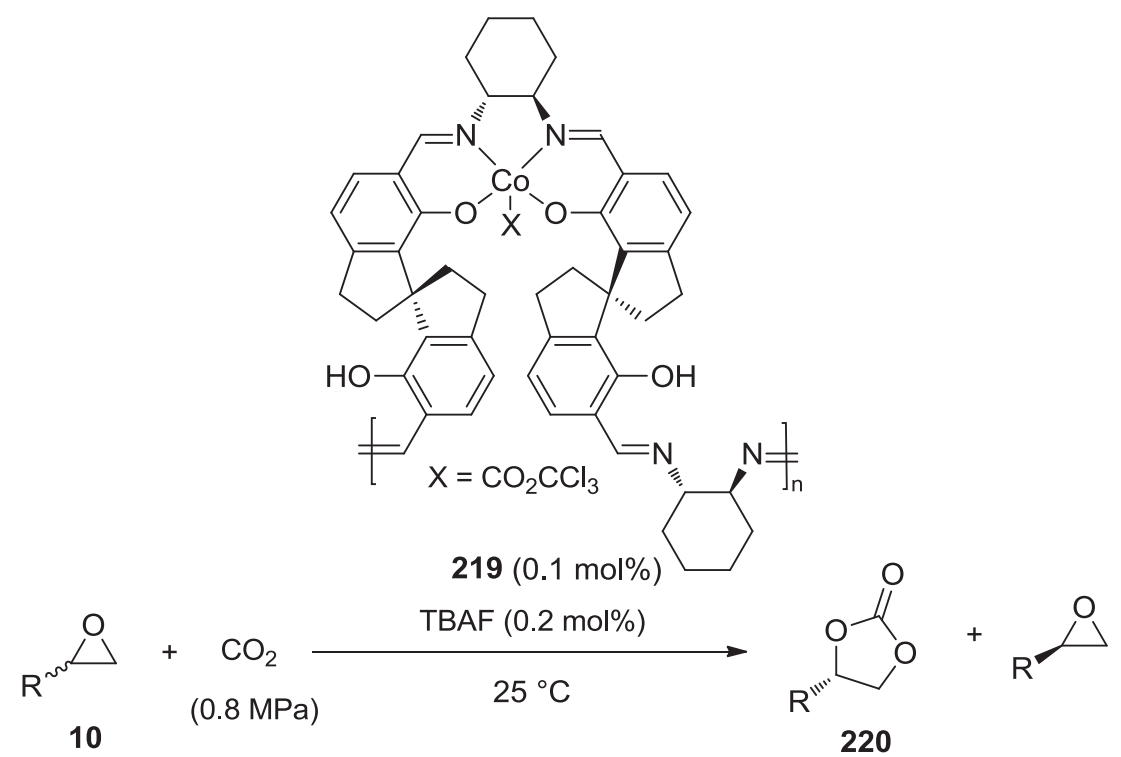

$$
\mathrm{R}=\mathrm{Me}, \mathrm{CH}_{2} \mathrm{Cl}, \mathrm{Et}
$$

Scheme 68. Cycloaddition of epoxides with $\mathrm{CO}_{2}[121]$.

alkynes 207 (Scheme 66) [119]. Among these novel catalysts, complex 208 was recognized as the first catalytic system with useful levels of enantioselection (up to $97 \%$ ee) for the reaction between norbornadiene 206 and trimethylsilylacetylene 207a $(R=T M S)$. Indeed, when this reaction was catalyzed with $10 \mathrm{~mol} \%$ of catalyst 208 in toluene at $100{ }^{\circ} \mathrm{C}$ under CO pressure ( $1 \mathrm{~atm}$ ), it afforded the corresponding product 209a in moderate yield (39\%) albeit with remarkable enantioselectivity $(97 \%$ ee $)$. Other trialkylsilylsubstituted acetylenes also provided good to high enantioselectivities (72-90\% ee) when using either catalyst $\mathbf{2 0 8}$ or related one $\mathbf{2 1 0}$ while much lower enantioselectivities ( $\leq 40 \%$ ee) were obtained in the reaction of alkyl-substituted acetylenes.

Gong and co-workers recently demonstrated that the sodium salts of anionic chiral cobalt complexes were highly promising catalysts for the asymmetric Povarov reaction of 2-azadienes with various dienophiles [120]. For example, $10 \mathrm{~mol} \%$ of catalyst $\mathbf{2 1 1}$ was found to promote the enantioselective Povarov reaction between 2-azadienes $\mathbf{2 1 2}$ and 2,3-dihydrofuran $\mathbf{2 1 3}$ in $n$-hexane at $-40{ }^{\circ} \mathrm{C}$ to give the corresponding chiral tetrahydroquinolines 214 exhibiting three contiguous stereocenters in moderate to excellent yields (40-93\%), uniformly excellent endo-diastereoselectivity (88->90\% de) and low to very high enantioselectivities (23-90\% ee), as shown in Scheme 67. The scope of this methodology was extended to $\mathrm{N}$-Cbz-2,3-dihydropyrrole 215 which reacted with 2-azadienes $\mathbf{2 1 2}$ under the same reaction conditions to provide the corresponding chiral tetrahydroquinolines $\mathbf{2 1 6}$ with high yields (94-99\%), diastereoselectivities (84->90\% de) and enantioselectivities (82-86\% ee). Moreover, other dienophiles were tolerated, such as ethyl vinyl ether 217, which led to the desired products 218 as almost single diastereomers ( $>90 \% \mathrm{de}$ ) in moderate yields (44-64\%) and high enantioselectivities (88-89\% ee).

Finally, Jing and co-workers have designed novel chiral oligomers of spiro-salen cobalt complexes which were further investigated as catalysts in the kinetic resolution of racemic epoxides $\mathbf{1 0}$ with carbon dioxide [121]. The use of optimal catalyst $\mathbf{2 1 9}$ in the presence of TBAF as additive allowed at $25^{\circ} \mathrm{C}$ the corresponding chiral cyclic carbonates $\mathbf{2 2 0}$ to be synthesized in moderate conversions (38-45\%) and enantioselectivities (54-61\% ee), as shown in Scheme 68. Notably, this stable catalyst could be recycled up to five times without loss of activity and enantioselectivity.

\section{Conclusions}

This review demonstrates that cobalt enantioselective catalysis is growing rapidly in almost all spheres of asymmetric organic transformations owing to the unique properties of cobalt catalysts of lower costs to promote novel reaction pathways to achieve both chiral acyclic and cyclic products generally under mild reaction conditions. It updates the major progress reported since the beginning of 2014 in the field of all types of enantioselective transformations promoted by chiral cobalt catalysts, illustrating the power of these green catalysts to promote a wide number of very different types of highly enantioselective cobalt-catalyzed transformations with remarkable diversification outcomes. Among them, a range of novel reactions have been recently developed, such as the first example of a transition-metal-catalyzed asymmetric Michael addition of amines to nitroalkenes with $91 \%$ ee, the first enantioselective cobalt-catalyzed Michael addition of 2-acetyl azaarenes to $\beta-\mathrm{CF}_{3}-\beta$-disubstituted nitroolefins with $98 \%$ ee, the first highly enantioselective hydrogenation of 1,1-diarylalkenes promoted by a combination of a metal and a chiral base ligand with $>99 \%$ ee, the first example of a cobalt-catalyzed enantioselective hydrogenation of ketones with molecular hydrogen with $95 \%$ ee, the first asymmetric cobalt-catalyzed hydroboration of $\alpha$-silyl alkenes with $85 \%$ ee, the first highly enantioselective cobalt-catalyzed Kumada cross-coupling reaction with $97 \%$ ee, the first enantioselective cobalt-catalyzed allylation of heterobicyclic alkenes with $>98 \%$ ee, the first cobalt-catalyzed enantioselective vinylation of activated carbonyl compounds such as $\alpha$-ketoesters with $>98 \%$ ee, the first enantioselective cobalt-catalyzed vinylation of isatins with $94 \%$ ee, the first asymmetric cobalt-catalyzed vinylations of imines with $>99 \%$ ee, the first dearomatization of a series of electron-deficient nitrogen heterocycles with $98 \%$ ee, the first asymmetric cyclopropanation of alkenes with $\alpha$-formyldiazoacetates with $99 \%$ ee, the first enantioselective cobalt-catalyzed cyclopropanation of alkenes using donor-substituted diazo reagents with $99 \%$ ee, the first 
enantioselective radical aziridination of allyl azidoformates with 99\% ee, the first enantioselective cobalt-catalyzed intramolecular $[2+2+2]$ cycloaddition of triynes with $78 \%$ ee, the first enantioselective cobalt-catalyzed domino hydroboration/cyclization reactions of 1,6-enynes with pinacolborane with $99 \%$ ee, the first highly enantioselective Pauson-Khand reaction of norbornadiene with terminal alkynes with $97 \%$ ee, and the first asymmetric radical intramolecular $\mathrm{C}-\mathrm{H}$ alkylation of acceptor/acceptor-substituted diazo reagents with $94 \%$ ee, among other transformations. The ever-growing need for environmentally friendly catalytic processes will continue to prompt organic chemists to focus on more abundant first-row transition metals such as cobalt to develop new catalytic systems to perform reactions. Consequently, a bright future is incontestable for even more sustainable novel and enantioselective cobalt-catalyzed transformations and their applications in total synthesis.

\section{References}

[1] (a) R. Noyori, Asymmetric Catalysts in Organic Synthesis, Wiley-VCH, NewYork, 1994;

(b) M. Nogradi, Stereoselective Synthesis, Wiley-VCH, Weinheim, 1995;

(c) M. Beller, C. Bolm, Transition Metals for Organic Synthesis, Vols. I and II Wiley-VCH, Weinheim, 1998;

d) E.N. Jacobsen, A. Pfaltz, H. Yamamoto, Comprehensive Asymmetric Catalysis, Springer, New York, 1999:

(e) I. Ojima, Catalytic Asymmetric Synthesis, second ed., Wiley-VCH, NewYork, 2000;

(f) G. Poli, G. Giambastiani, A. Heumann, Tetrahedron 56 (2000) 5959; (g) E. Negishi, Handbook of Organopalladium Chemistry for Organic Synthesis, John Wiley \& Sons, Hoboken NJ, 2002;

(h) A. de Meijere, P. von Zezschwitz, H. Nüske, B. Stulgies, J. Organomet. Chem. 653 (2002) 129;

(i) M. Beller, C. Bolm, Metals for Organic Synthesis, second ed., Wiley-VCH Weinheim, 2004;

(j) L.F. Tietze, I. Hiriyakkanavar, H.P. Bell, Chem. Rev. 104 (2004) 3453;

(k) D.J. Ramon, M. Yus, Chem. Rev. 106 (2006) 2126;

(1) H. Pellissier, Coord. Chem. Rev. 284 (2015) 93.

[2] H. Pellissier, H. Clavier, Chem. Rev. 114 (2014) 2775.

[3] For an early book chapter dealing with enantioselective catalysis using chiral cobalt complexes, see: A. Pfaltz Mod. Synth. Methods 5 (1989) 199.

[4] For a review on cobalt-catalyzed carbon-carbon bond formation, see: W. Hess, J. Treutwein, G. Hilt Synthesis (2008) 3537.

[5] (a) For reviews on organocobalt chemistry, see: C.J. Scheuermann, B.D. Ward New J. Chem. 32 (2008) 1850;

(b) I. Omae, Appl. Organometal. Chem. 21 (2007) 318;

(c) M.E. Welker, Curr. Org. Chem. 5 (2001) 785;

(d) J. Iqbal, M. Mukhopadhyay, A.K. Mandal, Synlett (1997) 876.

[6] (a) For reviews on asymmetric catalysis by various metals including cobalt, see: M. Lautens, W. Klute, W. Tam Chem. Rev. 96 (1996) 49;

(b) L. Canali, D.C. Sherrington, Chem. Soc. Rev. 28 (1999) 85;

(c) Y.N. Ito, T. Katsuki, Bull. Chem. Soc. Jpn. 72 (1999) 603;

(d) J.F. Larrow, E.N. Jacobsen, Top. Organomet. Chem. 6 (2004) 123;

(e) C. Baleizao, H. Garcia, Chem. Rev. 106 (2006) 3987;

(f) M. Ogasawara, S. Watanabe, Synthesis (2009) 1761

(g) E. Bergin, Annu. Rep. Prog. Chem. Sect. B: Org. Chem. 108 (2012) 353.

[7] Synthesis Special Topic, E.M. Carreira, Ed., 49 (2017) 3885.

[8] S.K. Ghosh, A. Ehnbom, K.G. Lewis, J.A. Gladysz, Coord. Chem. Rev. 350 (2017) 30.

[9] (a) H.B. Kagan, J.C. Fiaud, Top. Stereochem. 18 (1988) 249;

(b) A.H. Hoveyda, M.T. Didiuk, Curr. Org. Chem. 2 (1998) 489;

(c) G.R. Cook, Curr. Org. Chem. 4 (2000) 869;

(d) M. Keith, J.F. Larrow, E.N. Jacobsen, Adv. Synth. Catal. 343 (2001) 5;

(e) D.E.J.E. Robinson, S.D. Bull, Tetrahedron Asymmetry 14 (2003) 1407;

(f) E.R. Jarvo, S.J. Miller, in: E.N. Jacobsen, A. Pfaltz, H. Yamamoto (Eds.) Comprehensive Asymmetric Catalysis Supplement, Springer, Berlin, 2004, p. 189;

(g) E. Vedejs, M. Jure, Angew. Chem. Int. Ed. 44 (2005) 3974

[10] H. Pellissier, H. Adv, Synth. Catal. 353 (2011) 1613.

[11] C. Wang, L. Luo, H. Yamamoto, Acc. Chem. Res. 49 (2016) 193.

[12] M. Christmann, S. Brase, Asymmetric Synthesis-The Essentials, Wiley-VCH, Weinheim, 2008.

[13] M. Tokunaga, J.F. Larrow, F. Kakiuchi, E.N. Jacobsen, Science 277 (1997) 936.

[14] (a) P. Kumar, V. Naidu, P. Gupta, Tetrahedron 63 (2007) 2745;

(b) P. Kumar, P. Gupta, Synlett (2009) 1367.

[15] D.A. Devalankar, P.V. Chouthaiwale, A. Sudalai, Synlett 25 (2014) 102.

[16] R.N. Reddi, P.K. Prasad, R.G. Kalshetti, A. Sudalai, Tetrahedron Asymmetry 28 (2017) 162

[17] P.U. Karabal, D.A. Kamble, A. Sudalai, Org. Biomol. Chem. 12 (2014) 2349.
[18] L.P.C. Nielsen, C.P. Stevenson, D.G. Blackmond, E.N. Jacobsen, J. Am. Chem. Soc. 126 (2004) 1360.

[19] D.E. White, P.M. Tadross, Z. Lu, E.N. Jacobsen, Tetrahedron 70 (2014) 4165.

[20] H. Dandachi, H. Nasrallah, F. Ibrahim, X. Hong, M. Mellah, N. Jaber, E. Schulz, J. Mol. Catal. A 395 (2014) 457.

[21] H. Dandachi, E. Zaborova, E. Kolodziej, O.R.P. David, J. Hannedouche, M Mellah, N. Jaber, E. Schulz, Tetrahedron Asymmetry 27 (2016) 246.

[22] D. Patel, G.R. Kurrey, S.S. Shinde, P. Kumar, G.-J. Kim, S.S. Thakur, RSC Adv. 5 (2015) 82699.

[23] L. Li, B. Huang, Y. Li, G. Zhang, Z. Imam, A. Zheng, Y. Sun, Catal. Surv. Asia 19 (2015) 236

[24] M.M. Islam, P. Bhanja, M. Halder, S.K. Kundu, A. Bhaumik, S.M. Islam, RSC Adv. 6 (2016) 109315.

[25] Y. Liu, W.-M. Ren, C. Liu, S. Fu, M. Wang, K.-K. He, R.-R. Li, R. Zhang, X.-B. Lu, Macromolecules 47 (2014) 7775.

[26] (a) P. Perlmutter, Conjugate Addition Reactions in Organic Synthesis, Pergamon Press, Oxford, 1992;

(b) J. Christoffers, Eur. J. Org. Chem. (1998) 1259;

(c) N. Krause, Angew. Chem. Int. Ed. 37 (1998) 283;

(d) M.P. Sibi, S. Manyem, Tetrahedron 56 (2000) 8033;

e) M. Kanai, M. Shibasaki, in: I. Ojima (Ed.), Catalytic Asymmetric Synthesis, second ed., Wiley, New York, 2000, p. 569;

(f) N. Krause, A. Hoffmann-Roder, Synthesis (2001) 171;

(g) O.M. Berner, L. Tedeschi, D. Enders, Eur. J. Org. Chem. (2002) 1877;

(h) S.C. Jha, N.N. Joshi, ARKIVOC (2002) 167;

(i) J. Christoffers, A. Baro, Angew. Chem. Int. Ed. 42 (2003) 1688;

(j) T. Hayashi, Bull. Chem. Soc. Jpn. 77 (2004) 13;

(k) J. Comelles, M. Moreno-Manas, A. Vallribera, ARKIVOC ix (2005) 207;

(l) J. Christoffers, G. Koripelly, A. Rosiak, M. Rössle, Synthesis 9 (2007) 1279; (m) H. Pellissier, Adv. Synth. Catal. 357 (2015) 2745.

[27] (a) D. Almasi, D.A. Alonso, C. Najera, Tetrahedron Asymmetry 18 (2007) 299; (b) J.L. Vicario, D. Badia, L. Carrillo, Synthesis (2007) 2065:

(c) S.B. Tsogoeva, Eur. J. Org. Chem. (2007) 1701;

(d) L.F. Tietze, A. Düfert, A Catalytic Asymmetric Conjugate Reactions, WileyVCH, Weinheim, Cordova, 2010, p. 321.

[28] (a) H. Brunner, B. Hammer, Angew. Chem. Int. Ed. Engl. 23 (1984) 312;

(b) H. Brunner, J. Kraus, J. Mol. Catal. 49 (1989) 133;

(c) H. Brunner, C. Krumey, J. Mol. Catal. A 142 (1999) 7.

[29] C. Botteghi, S. Pagnelli, A. Schionato, J. Mol. Catal. 66 (1991) 7.

[30] C. Chen, S.-F. Zhu, X.-Y. Wu, Q.-L. Zhou, Tetrahedron Asymmetry 17 (2006) 2761.

[31] N. End, L. Macko, M. Zehnder, A. Pfaltz, Chem. Eur. J. 4 (1998) 818.

[32] V.I. Maleev, M. North, V.A. Larionov, I.V. Fedyanin, T.F. Savel'yeva, M.A. Moscalenko, A.F. Smolyakov, Y.N. Belokon, Adv. Synth. Catal. 356 (2014) 1803.

[33] T. Tsubo, T. Yamada, Synlett 26 (2015) 1111.

[34] Z. Zhang, X. Liu, Z. Wang, X. Zhao, L. Lin, X. Feng, Tetrahedron Lett. 55 (2014) 3797.

[35] Y. Shuto, T. Yamamura, S. Tanaka, M. Yoshimura, M. Kitamura, ChemCatChem 7 (2015) 1547.

[36] T. Kobayashi, T. Shimura, Y. Kurita, Y. Katsumata, S. Kesuka, Tetrahedron Lett. 55 (2014) 2818

[37] K.G. Lewis, S.K. Ghosh, N. Bhuvanesh, J.A. Gladysz, ACS Cent. Sci. 1 (2015) 50

[38] S.K. Ghosh, C. Ganzmann, N. Bhuvanesh, J.A. Gladysz, Angew. Chem. Int. Ed. 55 (2016) 4356.

[39] X.-Q. Hao, C. Wang, S.-L. Liu, X. Wang, L. Wang, J.-F. Gong, M.-P. Song, Org. Chem. Front. 4 (2017) 308.

[40] V.A. Pavlov, Russ. Chem. Rev. 70 (2001) 1037.

[41] (a) M.R. Friedfeld, M. Shevlin, G.W. Margulieux, L.-C. Campeau, J. Am. Chem. Soc. 138 (2016) 3314;

(b) P.J. Chirik, Acc. Chem. Res. 48 (2015) 1687.

[42] J. Chen, C. Chen, C. Ji, Z. Lu, Org. Lett. 18 (2016) 1594.

[43] M. Amezquita-Valencia, A. Cabrera, J. Organomet. Chem. 768 (2014) 145.

[44] D. Zhang, E.-Z. Zhu, Z.-W. Lin, A.-B. Wei, Y.-Y. Li, J.-X. Gao, Asian J. Org. Chem. 5 (2016) 1323.

[45] (a) K. Burgess, M.J. Ohlmeyer, Chem. Rev. 91 (1991) 1179;

(b) R. Jana, T.P. Pathak, M.S. Sigman, Chem. Rev. 111 (2011) 1417.

[46] L. Zhang, Z. Zuo, X. Wan, Z. Huang, J. Am. Chem. Soc. 136 (2014) 15501.

[47] J. Chen, T. Xi, X. Ren, B. Cheng, J. Guo, Z. Lu, Org. Chem. Front. 1 (2014) 1306.

[48] J. Guo, Z. Lu, Angew. Chem. Int. Ed. 55 (2016) 10835.

[49] H. Zhang, Z. Lu, ACS Catal. 6 (2016) 6596.

[50] (a) T. Yamada, Spec. Chem. Mag. 28 (2008) 44;

(b) R. Noyori, T. Ohkuma, Angew. Chem. Int. Ed. 40 (2001) 40;

(c) E.J. Corey, C. Helal, Angew, Chem. Int. Ed. 37 (1998) 1986.

[51] U. Leutenegger, A. Madin, A. Pfaltz, Angew. Chem. Int. Ed. Engl. 28 (1989) 60

[52] T. Nagata, K. Yorozu, T. Yamada, T. Mukaiyama, Angew. Chem. Int. Ed. Engl. 34 (1995) 2145.

[53] J. Guo, J. Chen, Z. Lu, Chem. Commun. 51 (2015) 5725.

[54] (a) O. Riant, N. Mostefaï, J. Courmarcel, Synthesis (2004) 2943:

(b) C.G. Arena, Mini-Rev. Org. Chem. 6 (2009) 159.

[55] H. Brunner, K. Amberger, J. Organomet. Chem. 417 (1991) C63.

[56] X. Chen, Z. Lu, Org. Lett. 18 (2016) 4658.

[57] B. Cheng, P. Lu, H. Zhang, X. Cheng, Z. Lu, J. Am. Chem. Soc. 139 (2017) 9439.

[58] (a) T.V. RajanBabu, Chem. Rev. 103 (2003) 2845; (b) T.V. RajanBabu, Synlett (2009) 853.

[59] D. Vogt, Angew. Chem. Int. Ed. 49 (2010) 7166. 
[60] (a) L.S. Pu, A. Yamamoto, S. Ikeda, J. Am. Chem. Soc. 90 (1968) 7170; (b) S.M. Pillai, G.L. Tembe, M. Ravindranathan, J. Mol. Catal. 84 (1993) 77; (c) G. Hilt, S. Lüers, Synthesis (2002) 609;

(d) C.-C. Wang, P.-S. Lin, C.-H. Cheng, Tetrahedron Lett. 45 (2004) 6203;

(e) M.M.P. Grutters, C. Müller, D. Vogt, J. Am. Chem. Soc. 128 (2006) 7414

[61] G. Hilt, F.-X. du Mesnil, S. Lüers, Angew. Chem. Int. Ed. 40 (2001) 387.

[62] M.M.P. Grutters, J.I. van der Vlugt, Y. Pei, A.M. Mills, M. Lutz, A.L. Spek, C. Müller, C. Moberg, D. Vogt, Adv. Synth. Catal. 351 (2009) 2199.

[63] (a) Y.N. Timsina, R.K. Sharma, T.V. RajanBabu, Chem. Sci. 6 (2015) 3994;

(b) Y.N. Timsina, S. Biswas, T.V. RajanBabu, J. Am. Chem. Soc. 136 (2014) 6215.

[64] S. Biswas, J.P. Page, K.R. Dewese, T.W. RajanBabu, J. Am. Chem. Soc. 137 (2015) 14268.

[65] S. Movahhed, J. Westphal, M. Dindaroglu, A. Falk, H.-G. Schmalz, Chem. Eur. J. 22 (2016) 7381.

[66] (a) J.M. Hammann, M.S. Hofmayer, F.H. Lutter, L. Thomas, P. Knochel, Synthesis 49 (2017) 3887;

(b) G. Cahiez, A. Moyeux, Chem. Rev. 110 (2010) 1435;

(c) C. Gosmini, J.-M. Bégouin, A. Moncomble, Chem. Commun. (2008) 3221.

[67] J. Mao, F. Liu, M. Wang, L. Wu, B. Zheng, S. Liu, J. Zhong, Q. Bian, P.J. Walsh, J. Am. Chem. Soc. 136 (2014) 17662

[68] L. Wu, J.-C. Zhong, S.-K. Liu, F.-P. Liu, Z.-D. Gao, M. Wang, Q.-H. Bian, Tetrahedron Asymmetry 27 (2016) 78.

[69] F. Liu, Q. Bian, J. Mao, Z. Gao, D. Liu, S. Liu, X. Wang, Y. Wang, M. Wang, J. Zhong, Tetrahedron Asymmetry 27 (2016) 663.

[70] H. Sasai, T. Suzuki, S. Arai, T. Arai, M. Shibasaki, J. Am. Chem. Soc. 114 (1992) 4418.

[71] S. Wu, J. Tang, J. Han, D. Mao, X. Liu, X. Gao, J. Yu, L. Wang, Tetrahedron 70 (2014) 5986.

[72] Y.-L. Wei, K.-F. Yang, F. Li, Z.-J. Zheng, Z. Xu, L.-W. Xu, RSC Adv. 4 (2014) 37859

[73] D. Taura, S. Hioki, J. Tanabe, N. Ousaka, E. Yashima, ACS Catal. 6 (2016) 4685.

[74] Y. Huang, C. Ma, Y.X. Lee, R.-Z. Huang, Y. Zhao, Angew. Chem. Int. Ed. 54 (2015) 13696.

[75] Y. Huang, R.-Z. Huang, Y. Zhao, J. Am. Chem. Soc. 138 (2016) 6571.

[76] P.-S. Lee, N. Yoshikai, Org. Lett. 17 (2015) 22.

[77] A. Kumar, S.K. Ghosh, J.A. Gladysz, Org. Lett. 18 (2016) 760.

[78] H. Joshi, S.K. Ghosh, J.A. Gladysz, Synthesis 49 (2017) 3905.

[79] (a) L.F. Tietze, U. Beifuss, Angew. Chem. Int. Ed. Engl. 32 (1993) 131; (b) L.F. Tietze, Chem. Rev. 96 (1996) 115;

(c) L.F. Tietze, G. Brasche, K. Gericke, Domino Reactions in Organic Synthesis, Wiley-VCH, Weinheim, 2006:

(d) L.F. Tietze, Domino Reactions - Concepts for Efficient Organic Synthesis, Wiley-VCH, Weinheim, 2014

[80] (a) D.J. Ramon, M. Yus, Angew. Chem. Int. Ed. 44 (2005) 1602;

(b) J. Zhu, H. Bienaymé, Multicomponent Reactions, Wiley-VCH, Weinheim, 2005;

(c) D. Enders, C. Grondal, M.R.M. Hüttl, Angew. Chem. Int. Ed. 46 (2007) 1570 ;

(d) C.J. Chapman, C.G. Frost, Synthesis (2007) 1;

(e) A.-N. Alba, X. Companyo, M. Viciano, R. Rios, Curr. Org. Chem. 13 (2009) 1432 ;

(f) J.E. Biggs-Houck, A. Younai, J.T. Shaw, Curr. Opin. Chem. Biol. 14 (2010) 371 ;

(g) M. Ruiz, P. Lopez-Alvarado, G. Giorgi, J.C. Menéndez, Chem. Soc. Rev. 40 (2011) 3445;

(h) C. De Graaff, E. Ruijter, R.V.A. Orru, Chem. Soc. Rev. 41 (2012) 3969.

[81] (a) G.H. Posner, Chem. Rev. 86 (1986) 831;

(b) T.-L. Ho, Tandem Organic Reactions, Wiley, New York, 1992;

(c) R. Bunce, Tetrahedron 51 (1995) 13103;

(d) P.J. Parsons, C.S. Penkett, A.J. Shell, Chem. Rev. 96 (1996) 195;

(e) L.F. Tietze, N. Rackelmann, Pure Appl. Chem. 76 (2004) 1967;

(f) D.M. D'Souza, T.J.J. Müller, Chem. Soc. Rev. 36 (2007) 1095;

(g) L. Albrecht, H. Jiang, K.A.A. Jørgensen, Angew. Chem. Int. Ed. 50 (2011) 8492 .

[82] (a) C. Hulme, V. Gore, Curr. Med. Chem. 10 (2003) 51;

(b) H. Pellissier, Tetrahedron 62 (2006) 1619;

(c) H. Pellissier, Tetrahedron 62 (2006) 2143;

(d) A. Padwa, S.K. Bur, Tetrahedron 63 (2007) 5341;

(e) G. Guillena, D.J. Ramon, M. Yus, Tetrahedron Asymmetry 18 (2007) 693:

(f) M. Colombo, I. Peretto, Drug Discovery Today 13 (2008) 677;

(g) B.B. Touré, D.G. Hall, Chem. Rev. 109 (2009) 4439;

(h) K.C. Nicolaou, J.S. Chen, Chem. Soc. Rev. 38 (2009) 2993;

(i) C. Grondal, M. Jeanty, D. Enders, Nat. Chem. 2 (2010) 167;

(j) H. Pellissier, Adv. Synth. Catal. 354 (2012) 237;

(k) H. Clavier, H. Pellissier, Adv. Synth. Catal. 354 (2012) 3347;

(l) H. Pellissier, Chem. Rev. 113 (2013) 442;

(m) H. Pellissier, Asymmetric Domino Reactions, Royal Society of Chemistry, Cambridge, 2013;

(n) H. Pellissier, Curr. Org. Chem. 20 (2016) 234.

[83] S.H. Lecker, N.H. Nguyen, K.P.C. Vollhardt, J. Am. Chem. Soc. 108 (1986) 856.

[84] J. Guo, X. Shen, Z. Lu, Angew. Chem. Int. Ed. 56 (2017) 615.

[85] (a) S.H. Bertz, J. Am. Chem. Soc. 103 (1981) 3599;

(b) D.P. Curran, Advances in Cycloaddition, Vols. I-III, JAI Press, Greenwich, 1994; (c) B.M. Trost, Angew. Chem. Int. Ed. Engl. 34 (1995) 259;

(d) N. Nishiwaki, Methods and Applications of Cycloaddition Reactions in Organic Syntheses, Wiley, Hoboken, 2014:

(e) H. Pellissier, Tetrahedron 71 (2015) 8855.

[86] (a) S. Patai, Z. Rappoport, The Chemistry of the Cyclopropyl Group, Wiley and Sons, New York, 1987;

(b) A. de Meijere, Small Ring Compounds in Organic Synthesis VI, Vol. 207, Springer, Berlin, 2000;

(c) M. Rubin, M. Rubina, V. Gevorgyan, Chem. Rev. 107 (2007) 3117;

(d) H. Pellissier, A. Lattanzi, R. Dalpozzo, Asymmetric Synthesis of ThreeMembered Rings, Wiley-VCH, Weinheim, 2017.

[87] (a) T. Katsuki, Res. Dev. Pure Appl. Chem. 1 (1997) 35;

(b) V.K. Singh, A. DattaGupta, G. Sekar, Synthesis (1997) 137;

(c) M.P. Doyle, D.C. Forbes, Chem. Rev. 98 (1998) 911;

(d) H. Nishiyama, Enantiomer 4 (1999) 569;

(e) M.P. Doyle, M.A. McKervey, T. Ye, Modern Catalytic Methods for Organic Synthesis with Diazo Compounds: From Cyclopropanes to Ylides, John Wiley and Sons, New York, 1998;

(f) G. Boche, J.C.W. Lohrenz, Chem. Rev. 101 (2001) 697;

(g) T. Rovis, D.A. Evans, Prog. Inorg. Chem. 50 (2001) 1;

(h) H.M.L. Davies, E. Antoulinakis, Org. React. 57 (2001) 1;

(i) H. Pellissier, Tetrahedron 54 (2008) 7041.

[88] A. Nakamura, A. Konishi, Y. Tatsuno, S. Otsuka, J. Am. Chem. Soc. 100 (1978) 3443.

[89] J.D. White, S. Shaw, Org. Lett. 16 (2014) 3880.

90] A. Joshi-pangu, R.D. Cohen, M.T. Tudge, Y. Chen, J. Org. Chem. 81 (2016) 3070.

[91] A. Studer, D.P. Curran, Angew. Chem. Int. Ed. Engl. 55 (2016) 58.

[92] X. Xu, Y. Wang, X. Cui, L. Wojtas, X.P. Zhang, Chem. Sci. 8 (2017) 4347.

[93] Y. Wang, X. Wen, X. Cui, L. Mojtas, X.P. Zhang, J. Am. Chem. Soc. 139 (2017) 1049.

94] J.V. Ruppel, X. Cui, X. Xu, X.P. Zhang, Org. Chem. Front. 1 (2014) 515.

[95] (a) A. Padwa, in: B.M. Trost, I. Fleming (Eds.), Comprehensive Organic Synthesis, Vol. 4, Pergamon, Oxford, 1991, p. 1069, Chap. 4.9;

(b) T. Tanner, Pure Appl. Chem. 65 (1993) 1319;

(c) D. Tanner, Angew. Chem. Int. Ed. Engl. 33 (1994) 599;

(d) B. Zwanenburg, P. ten Holte, in: P. Metz (Ed.), Stereoselective Heterocyclic Synthesis, III, Topics in Current Chemistry, Vol. 216, Springer, Berlin, 2001, p. 93:

(e) J.B. Sweeney, Chem. Soc. Rev. 31 (2002) 247;

(f) P. Müller, C. Fruit, Chem. Rev. 103 (2003) 2905;

(g) X.E. Hu, Tetrahedron 60 (2004) 2701;

(h) C. Mössner, C. Bolm, in: M. Beller, C. Bolm (Eds.), Transition Metals for Organic Synthesis, second ed., Wiley-VCH, Weinheim, 2004, p. 389;

(i) M. Pineschi, Eur. J. Org. Chem. (2006) 4979;

(j) A. Yudin, in: Aziridines and Epoxides in Organic Synthesis, Wiley-VCH, Weinheim, 2006;

(k) H. Pellissier, Tetrahedron 66 (2008) 1509.

[96] J.E. Jones, J.V. Ruppel, G.-Y. Gao, T.M. Moore, X.P. Zhang, J. Org. Chem. 73 (2008) 7260

97] J. Tao, L.-M. Jin, X.P. Zhang, Beilstein J. Org. Chem. 10 (2014) 1282.

[98] H. Jiang, K. Lang, H. Lu, L. Wojtas, X.P. Zhang, J. Am. Chem. Soc. 139 (2017) 9164.

[99] Q.-H. Xia, H.-Q. Ge, C.-P. Ye, Z.-M. Liu, K.-X. Su, Chem. Rev. 105 (2005) 1603.

[100] M. Frohn, Y. Shi, Synthesis (2000) 1979.

[101] V.A. Larionov, E.P. Markelova, A.F. Smolyakov, T.F. Savelyeva, V.I. Mallev, Y.N. Belokon, RSC Adv. 5 (2015) 72764.

[102] R. Huisgen, Angew. Chem. Int. Ed. Engl. 10 (1963) 565.

[103] (a) K.V. Gothelf, K.A. Jørgensen, Chem. Rev. 98 (1998) 863;

(b) A. Padwa, M.D. Weingarten, Chem. Rev. 96 (1996) 22;

(c) S. Karlsson, H.-E. Högberg, Org. Prep. Proced. Int. 33 (2001) 103;

(d) I.N.N. Namboothiri, A. Hassner, Top. Curr. Chem. 216 (2001) 1;

(e) I. Coldham, R. Hufton, Chem. Rev. 105 (2005) 2765;

(f) H. Pellissier, Tetrahedron 63 (2007) 3235

(g) S. Kanemasa, Heterocycles 82 (2010) 87.

[104] B. Wa, W. Luo, L. Lin, X. Liu, X. Feng, Chem. Commun. 53 (2017) 4077.

[105] D. Zhang, C. Yin, Y. Zhou, Y. Xu, L. Lin, X. Liu, X. Feng, Chem. Commun. 53 (2017) 7925.

[106] (a) K.P.C. Vollhardt, Angew. Chem. Int. Ed. Engl. 23 (1984) 539;

(b) N.E. Schore, in: B.M. Trost, I. Fleming (Eds.), Comprehensive Organic Synthesis, Vol. 5, Pergamon, Oxford, 1991, p. 1129;

(c) I. Ojima, M. Tzamarioudaki, Z. Li, R.J. Donovan, Chem. Rev. 96 (1996) 635;

(d) C. Aubert, O. Buisine, M. Malacria, Chem. Rev. 102 (2002) 813;

(e) J.A. Varela, C. Saa, Chem. Rev. 103 (2003) 3787:

(f) P.R. Chopade, J. Louie, Adv. Synth. Catal. 348 (2006) 2307;

(g) N. Agenet, O. Buisine, F. Slowinski, V. Gandon, C. Aubert, M. Malacria, in:

L.E. Overman (Ed.), Vol. 68, Wiley, New York, 2007, p. 1;

(h) N. Weding, M. Hapke, Chem. Soc. Rev. 40 (2011) 4525;

(i) C. Aubert, L. Fensterbank, P. Garcia, M. Malacria, A. Simmoneau, Chem. Rev. 111 (2011) 1954;

(j) Y. Shibata, K. Tanaka, Synthesis 44 (2012) 323.

[107] (a) T. Shibata, K. Tsuchikama, Org. Biomol. Chem. 5 (2008) 1317;

(b) K. Tanaka, Chem. Asian J. 4 (2009) 508.

[108] (a) M. Lautens, J.C. Lautens, A.C. Smith, J. Am. Chem. Soc. 112 (1990) 5627;

(b) M. Lautens, W. Tam, J.C. Lautens, L.G. Edwards, C.M. Crudden, A.C. Smith, J. Am. Chem. Soc. 117 (1995) 6863. 
[109] (a) H. Brunner, M. Muschiol, F. Prester, Angew. Chem. Int. Ed. Engl. 29 (1990)

(b) H. Brunner, F. Prester, J. Organomet. Chem. 414 (1991) 401.

[110] P. Jungk, T. Täufer, I. Thiel, M. Hapte, Synthesis 48 (2016) 2026.

[111] P. Jungk, F. Fischer, M. Hapke, ACS Catal. 6 (2016) 3025.

[112] (a) M.C. Willis, Chem. Rev. 110 (2010) 725

(b) J.C. Leung, M.J. Krische, Chem. Sci. 3 (2012) 2202;

(c) S.K. Murphy, V.M. Dong, Chem. Commun. 50 (2014) 13645.

[113] J. Yang, N. Yoshikai, J. Am. Chem. Soc. 136 (2014) 16748.

[114] J. Yang, A. Rérat, Y.J. Lim, C. Gosmini, N. Yoshikai, Angew. Chem. Int. Ed. 56 (2017) 2449.
[115] X. Cui, X. Xu, L.-M. Jin, L. Wojtas, X.P. Zhang, Chem. Sci. 6 (2015) 1219.

[116] P.F. Kuijpers, M.J. Tiekink, W.B. Breukelaar, D.L.J. Broere, N.P. van Leest, J.I. van der Vlugt, J.N.H. Reek, B. de Bruin, Chem. Eur. J. 23 (2017) 7945.

[117] S. Yu, C. Wu, S. Ge, J. Am. Chem. Soc. 139 (2017) 6526.

[118] Y. Kuang, Y. Lu, Y. Tang, X. Liu, L. Lin, X. Feng, Org. Lett. 16 (2014) 4244

[119] S. Orgué, T. Leon, A. Riera, X. Verdaguer, Org. Lett. 17 (2015) 250.

[120] J. Yu, H.-J. Jiang, Y. Zhou, S.-W. Luo, L.-Z. Gong, Angew. Chem. Int. Ed. 54 (2015) 11209.

[121] (a) Z. Zhu, Y. Zhang, K. Wang, X. Fu, F. Chen, H. Jing, Catal. Commun. 81 (2016) 50;

(b) S. Duan, X. Jing, D. Li, H. Jing, J. Mol. Catal. A 411 (2016) 34. 